\title{
COMPONENTES DE VARIÂNCIA E COVARIÂNCIA GENÉTICA RELACIONADOS À SELEÇÃO RECORRENTE INTRA E INTERPOPULACIONAL NO MILHO (Zea mays L.)
}

\author{
CARLOS ALBERTO ARRABAL ARIAS \\ Engenheiro Agrônomo
}

Orientador: Prof. Dr. CLÁUDIO LOPES DE SOUZA JÚNIOR

Tese apresentada à Escola Superior de Agricultura "Luiz de Queiroz", da Universidade de São Paulo, para obtenção do título de Doutor em Agronomia. Área de Concentração: Genética e Melhoramento de Plantas.

\author{
PIRACICABA \\ Estado de São Paulo \\ Julho - 1995
}


Arias, Carlos Alberto Arrabal

Componentes de variância e covariância genética relacionados à seleção recorrente intra e interpopulacional no milho (Zea mays L.). Piracicaba. 1995.

$139 \mathrm{p}$.

Tese - ESALQ

Bibliografia.

1. Genética quantitativa 2. Milho - Melhoramento 3. Milho - Seleção genética I. Escola Superior de Agricultura Luiz de Queiroz, Piracicaba. 


\section{COMPONENTES DE VARIÂNCIA E COVARIÂNCIA GENÉTICA RELACIONADOS À SELEÇÃO RECORRENTE INTRA E INTERPOPULACIONAL NO MILHO (Zea mays L.)}

\section{CARLOS ALBERTO ARRABAL ARIAS}

Aprovada em: 11.09.1995

Comissão julgadora:

Prof. Dr. Cláudio Lopes de Souza Júnior

Dr. Elto Eugênio Gomes e Gama

Dr. José Francisco Ferraz de Toledo

Prof. Dr. Luciano Lourenço Nass

Prof. Dr. Roland Vencovsky
ESALQ/USP

EMBRAPA/CNPMS

EMBRAPA/CNPSO

EMBRAPA/ESALQ

ESALQ/USP

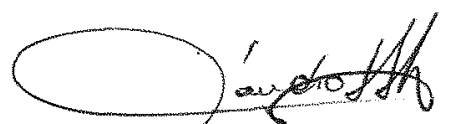

Prof. Dr. CLÁUdIO LOPES DE SOUZA JÚNIOR

Orientador 
À minha esposa Mônica

Ao meu filho Rafael Lucien Aos nossos pais e irmãos 


\section{AGRADECIMENTOS}

A todos os professores pelas informações valiosas dentro de suas disciplinas e mesmo fora delas, as quais foram fundamentais para a execução deste trabalho.

Em especial ao Professor Dr. Cláudio Lopes de Souza Jr., pela fundamental orientação durante todo o trabalho.

À ESALQ, pelo ambiente e pela oportunidade oferecida.

À CAPES, pelo apoio financeiro.

Ao amigo Cláudio Takeda, que nos acompanhou durante o desafio da coleta de dados.

Aos colegas de curso, pelo convívio e amizade.

Aos funcionários Juscelino e Alfredo, pela amizade e importante contribuição neste trabalho.

À minha esposa pelo estímulo e amor. 
Página

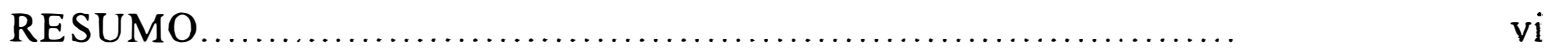

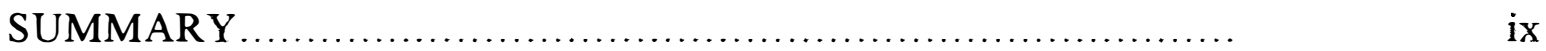

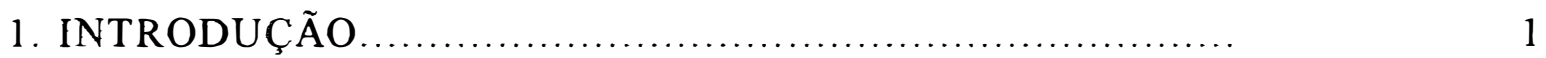

2. REVISÃO DE LITERATURA ................................ 4

2.1. Seleção recorrente intrapopulacional...................... 6

2.1.1. Seleção massal....................................... 7

2.1.2. Seleção com progênies de meios irmãos............... 9

2.1.3. Seleção com progênies de irmãos germanos........... 12

2.1.4. Seleção com progênies endogâmicas................... 14

2.2. Seleção recorrente interpopulacional....................... 17

2.2.1. Seleção com progênies de meios irmãos............... 20

2.2.2. Seleção com progênies de irmãos germanos........... 24

2.2.3. Seleção com cruzamentos testes ....................... 25

$\begin{array}{ll}\text { 2.3. Comparações entre métodos intra e interpopulacionais.... } & 27\end{array}$

2.4. Estimativas da variância genética aditiva e herdabilidade.. 32

3. MATERIAL E MÉTODOS .................................. 35

3.1. Material............................................... 35

3.2. Métodos.................................................... 36

3.2.1. Obtenção das progênies................................. 36

3.2.2. Procedimentos experimentais ........................ 37

3.2.3. Análises estatísticas................................. 38

3.2.4. Análise estatístico-genética......................... 40

3.2.4.1. Análise de variância e covariância................. 40

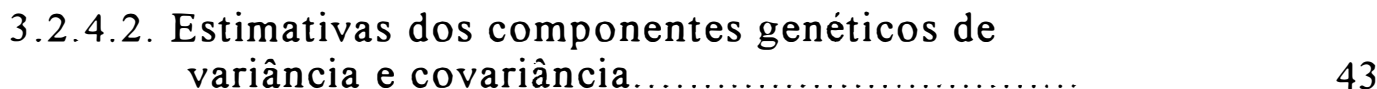

3.2.4.3. Respostas esperadas à seleção.................... 50 
4.1. Comportamento geral das populações e do seu híbrido interpopulacional.

4.2. Análises de variância.

4.3. Análise de variância e covariância das progênies intra e interpopulacionais.

4.4. Estimativas dos componentes genéticos de variância e covariância.

4.5. Variabilidade fenotípica e herdabilidade.................... 64

4.6. Respostas esperadas à seleção ................................ 65

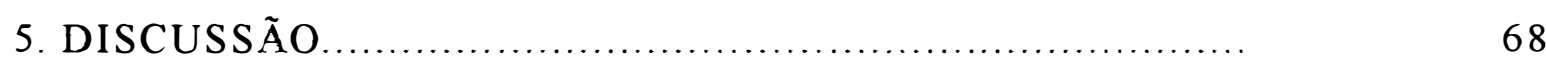

5. 1. Comportamento geral das populações e do seu híbrido interpopulacional...

5.2. Análises de variância........................................ 73

5.3. Análise de variância e covariância das progênies intra e interpopulacionais

5.4. Estimativas dos componentes genéticos de variância e covariância.

5.5. Variabilidade fenotípica e herdabilidade.................... 90

5.6. Respostas esperadas à seleção.............................. 92

6. CONCLUSÕES ................................................... 97

REFERÊNCIAS BIBLIOGRÁFICAS............................. 100

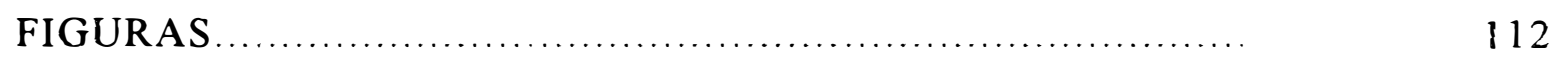

TABELAS ................................................... 116

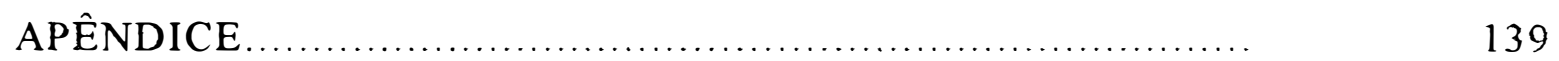




\title{
COMPONENTES DE VARIÂNCIA E COVARIÂNCIA GENÉTICA RELACIONADOS À SELEÇÃO RECORRENTE INTRA E INTERPOPULACIONAL NO MILHO (Zea mays L.)
}

\author{
Autor: CARLOS ALBERTO ARRABAL ARIAS. \\ Orientador: Prof. Dr. CLÁUDIO LOPES DE SOUZA JÚNIOR.
}

\section{RESUMO}

Com o objetivo de estimar os componentes de variância e covariância genética e comparar as respostas esperadas para os esquemas seleção recorrente recíproca (SRR), intrapopulacional (SRI), e modificada (SRM) sobre o híbrido interpopulacional, populações per se, e heterose, foram obtidas progênies de meios irmãos intra-e interpopulacionais para 100 genótipos amostrados de cada uma das populações de milho (Zea mays L.) BR-106 e BR-105. Os quatro grupos de 100 progênies, sendo dois intra- e dois interpopulacionais, foram instalados em látices $10 \times 10$ parcialmente balanceados arranjados segundo um delineamento em faixas com duas repetições, em dois anos agrícolas (1991/92 e 1992/93) e dois locais da região de Piracicaba-SP. Foram avaliados o peso das espigas despalhadas, altura de planta e espiga, relação altura de espiga sobre altura de planta, comprimento e diâmetro da espiga, número de fileiras e de grãos por fileira na espiga e prolificidade. 
As populações e o híbrido interpopulacional apresentaram produtividades elevadas e um bom potencial para a produção de híbridos de linhagens. As heteroses em relação à média dos pais e ao pai superior foram relativamente altas, mas ainda inferiores aos valores apresentados por estas populações sob outras condições. As progênies intra- e interpopulacionais foram similares na avaliação dos genótipos de BR-106, resultando em altos valores para a correlação genética entre estes tipos de progênies, enquanto para BR-105 estas correlações foram baixas.

As estimativas das variâncias aditivas obtidas para as populações per se e para o híbrido interpopulacional demonstraram o elevado potencial destas populações para o melhoramento. As magnitudes relativas das variâncias dos desvios dos efeitos aditivos intra- e interpopulacionais $\left(\sigma_{\tau 12}^{2}\right.$ para BR-106 e $\sigma_{\tau_{21}}^{2}$ para BR-105) e a covariância entre os efeitos aditivos com estes desvios [ $\operatorname{Cov}_{(\mathrm{A} 1 \pi 2)}$ para $\mathrm{BR}-106$ e $\mathrm{C}$ ov(A2721) para $\mathrm{BR}-105$ ] indicaram que estes novos componentes podem interferir de forma importante nas eficiências dos métodos de melhoramento. Todas as estimativas dos componentes genéticos da população BR-105, apresentaram erros $\wedge$

relativamente baixos, sendo que $\operatorname{Cov}_{\left(\mathrm{A} 2 \tau_{2} 1\right)}$ foi sempre negativa. Para BR-106,

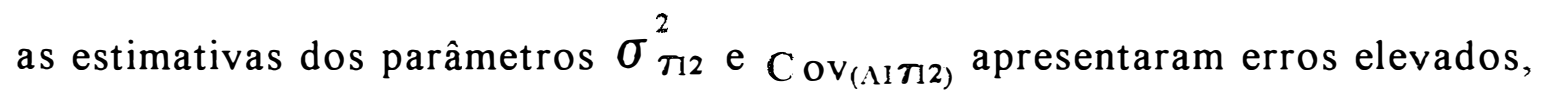
indicando que alguma mudança no delineamento pode ser necessária para estimá-los. O método denominado SRM (uma das populações serve como testadora dela própria e também da outra população) foi mais eficiente que SRR e SRI para desenvolver híbridos de linhagens. A escolha da população testadora no método SRM feita com base apenas nas médias populacionais 
pode não ser correta. Quando possivel, seria mais apropriado considerar também as variâncias genéticas aditivas intra- e interpopulacionais de cada população . 


\title{
VARIANCE AND COVARIANCE GENETIC COMPONENTS \\ RELATED TO INTRA AND INTERPOPULATION \\ RECURRENT SELECTION IN MAIZE (Zea mays L.)
}

\author{
Author: CARLOS ALBERTO ARRABAL ARIAS. \\ Adviser: Prof. Dr. CLÁUDIO LOPES DE SOUZA JÚNIOR.
}

\section{SUMMARY}

To estimate the variance and covariance genetic components and compare the expected responses for reciprocal (RRS), intrapopulation (IRS) and modified (MRS) recurrent selection on interpopulation hybrid, populations per se, and heterosis, intra- and interpopulation half-sib progenies for 100 sampled genotypes from each corn (Zea mays L.) population BR-106 and BR-105 were obtained. The four sets, two intra- and two interpopulational, of 100 progenies, were evaluated in partially balanced $10 \times 10$ lattices arranged in split-blocks with two replications in two years (1991/92 and 1992/93) and two locations in Piracicaba-SP. The traits ear weight, plant and ear height, the ratio ear height / plant height, ear length and diameter, number of rows and seeds per row on ear, and prolificacy, were recorded.

Populations and interpopulation hybrid were high yielding and showed high breeding potential for production of hybrids from inbred lines. Midparent and highest parent heterosis were relatively high, but lower than 
values reported for these populations in other environmental conditions. Intra- and interpopulation progenies were similar to evaluate genotypes from BR106 and their results showed high genetic correlation. On the other hand, for BR-105 this genetic correlation was low.

The estimates of additive variance of populations per se and for the interpopulation hybrid showed the high potential of these materials as breeding populations. The magnitude of the variance estimators for the deviations from intra- and interpopulation additive effects $\left(\sigma_{\pi 2}^{2}\right.$ for BR-106 and $\sigma_{\tau_{21}}^{2}$ for BR-105) and covariance between additive effects with these deviations [ $\left.\operatorname{Cov}_{(A 1} \pi_{2}\right)$ for $B R-106$ and $\operatorname{Cov}_{(A 2 T 21)}$ for $\left.B R-105\right]$ showed these new components can influence significantly the effectiveness of the breeding methods. Estimates of genetic components for BR-105 showed relatively

small errors, with $\hat{\operatorname{Cov}}_{\left(\mathrm{A} 2 \tau_{21}\right)}$ being negative for all traits. Estimates of $\sigma_{\pi 2}^{2}$ and $\left.\operatorname{Cov}_{(A 1} \pi_{2}\right)$ showed relatively large errors in BR-106. The MRS method (one population used as tester for itself and for the other population) was more effective than RRS and IRS to produce hybrids from inbred lines. The choice of population tester for the MRS method based on population means per se can be incorrect. The additional use, when possible, of intra- and interpopulation additive genetic variances from each population would be more appropriate. 


\section{INTRODUÇÃO}

A produção de híbridos de linhagens, tais como híbridos simples, duplos ou derivados, é o principal objetivo no melhoramento do milho. A implantação comercial destes híbridos permite um rápido aumento da produtividade, incentivando o desenvolvimento tecnológico dos produtores.

A produtividade das linhagens altera o custo de produção da semente híbrida, sendo que para a viabilização comercial do híbrido simples, que é a melhor opção para o máximo aproveitamento da heterose entre populações, são necessárias linhagens de alta produtividade. O grau de melhoramento das linhagens e de seus híbridos pode ser avaliado com base no comportamento das populações per se e dos cruzamentos interpopulacionais, respectivamente (SOUZA JR., 1993). Portanto, o melhoramento de espécies visando a produção de híbridos de linhagens precisa obter boas respostas nas populações per se e nos cruzamentos interpopulacionais para produzir híbridos superiores a partir de linhagens também superiores.

No melhoramento, estes objetivos podem ser alcançados por diferentes métodos de seleção recorrente, classificados em intrapopulacionais ou interpopulacionais. Os métodos de seleção recorrente intrapopulacionais tem como objetivo principal o melhoramento genético das populações per se, 
tendo como objetivo secundário o melhoramento dos híbridos obtidos com estas populações. Já os métodos de seleção recorrente recíproca ou interpopulacionais dão ênfase ao comportamento dos híbridos aproveitando ao máximo o fenômeno da heterose (MOLL \& STUBER, 1971). Diversos trabalhos envolvendo esquemas de seleção recorrente intra- e interpopulacionais, assim como comparações entre eles, mostraram que o método de seleção recorrente interpopulacional foi mais eficiente em melhorar o híbrido interpopulacional e uma das populações per se, ficando a outra população com ganhos não significativos ou até mesmo decréscimos significativos no rendimento; enquanto a seleção recorrente intrapopulacional melhorou as populações per se de forma eficiente, mas não melhorou o híbrido interpopulacional. Desta forma, estes métodos tem falhado em atender de forma ampla aos objetivos do melhoramento do milho, que é obter híbridos e populações melhoradas.

Para preencher todos os requisitos de um programa de híbridos de linhagens, SOUZA JR. (1993) sugeriu um método modificado de seleção recorrente, onde uma das populações, a que apresentasse o menor valor médio para o caráter, fosse utilizada como testadora de ambas as populações. A idéia surgiu a partir de simulações considerando um loco com dois alelos realizadas para os métodos modificado, intra e interpopulacional. Os resultados mostraram que a eficiência do método proposto, assim como a causa do insucesso dos métodos anteriores, podem estar relacionadas com as magnitudes relativas de novos componentes genéticos de variância e covariância sugeridos pelo autor, e que estão envolvidos nas respostas 
esperadas à seleção recorrente intra- e interpopulacional. As estimativas destes novos componentes, até agora de conhecimento apenas teórico, permitirão verificar a eficiência relativa dos processos de seleção, inclusive do novo método sugerido, assim como ajudarão no planejamento de programas de melhoramento com o objetivo de desenvolver as populações para a produção de híbridos.

Desta forma, os objetivos deste trabalho compreendem:

a. estimar os componentes genéticos de variância e covariância relacionados ao processo de seleção recorrente intra- e interpopulacional em duas populações de milho, BR-105 e BR-106;

b. estimar os progressos esperados no híbrido populacional, nas populações per se e na heterose para diversos esquemas de seleção;

c. comparar os esquemas de seleção estudados. 


\section{REVISÃ O DE LITERATURA}

A expressão seleção recorrente foi introduzida por HULL em 1945. Pode ser definida como um processo cíclico que procura aumentar a frequência dos alelos favoráveis mantendo um nível satisfatório de variabilidade genética para processos seletivos posteriores (HALLAUER et al., 1988).

Os diversos esquemas de seleção recorrente têm como objetivo aumentar continuamente a frequência dos genes favoráveis, através de ciclos sucessivos de seleção. A cada ciclo de seleção, os genótipos superiores selecionados são intercruzados a fim de promover a recombinação gênica. Conforme fora idealizada por SHULL (1909), a produção de híbridos de linhagens é uma forma de se reproduzir um genótipo superior anualmente. As linhagens para a produção desses híbridos podem ser obtidas a partir de populações melhoradas pela utilização de métodos de seleção recorrente intra- ou interpopulacionais. As linhagens produzidas podem ser total $(F=1)$ ou parcialmente endogâmicas $(\mathrm{F}<1)$, dando origem aos híbridos normais obtidos com linhagens totalmente endogâmicas, híbridos de linhagens parcialmente endogâmicas ou mesmo híbridos modificados (SOUZA JR., 1992). 
O melhoramento de espécies visando a produção de híbridos a partir de linhagens endogâmicas necessita que tanto as populações per se quanto os cruzamentos populacionais sejam melhorados de forma eficiente, pois espera-se que o grau de melhoramento das linhagens e dos híbridos obtidos a partir dessas linhagens sejam semelhantes ao das populações per se e aos cruzamentos populacionais, respectivamente (SOUZA JR., 1993).

$\mathrm{Na}$ seleção recorrente intrapopulacional, uma população é melhorada de forma independente, não sendo avaliado o seu comportamento em cruzamentos com outras populações. Após cada ciclo de seleção, amostras de plantas podem ser autofecundadas sucessivamente, produzindo novas linhagens que podem ser incluídas em programas paralelos para produção de híbridos comercias. Já no esquema de seleção recorrente recíproca ou interpopulacional, sugerido por COMSTOCK et al. (1949), os genótipos de duas populações são avaliados em cruzamentos com a população recíproca, sendo que os genótipos de cada população que apresentarem melhor capacidade de combinação com a população recíproca são recombinados entre si. Desta forma, busca-se o melhoramento das populações per se e da heterose que se manifesta nos cruzamentos, utilizando a capacidade geral e específica de combinação. Segundo HALlAUER et al. (1988), estes métodos de seleção que dão ênfase aos cruzamentos são de interesse devido à importância do fenômeno da heterose para o milho híbrido.

A seguir serão relatados alguns dos resultados obtidos pela utilização dos vários métodos de melhoramento propostos dentro destas modalidades de seleção recorrente, assim como novas propostas que surgiram nos últimos anos. 


\subsection{Seleção recorrente intrapopulacional}

Estudos de seleção recorrente conduzidos em populações têm sido mais comumente usados por causa de sua simplicidade e aplicabilidade para um grande número de características (HALLAUER et al., 1988). O método objetiva o melhoramento da população per se, para a obtenção de linhagens endogâmicas melhoradas que possam participar na produção de híbridos comerciais.

Existem vários métodos de seleção recorrente intrapopulacional, dentre eles, a seleção massal, baseada no fenótipo dos individuos, e seleção com uso de progênies, incluindo progênies de meios irmãos, irmãos completos ou de autofecundação ( 1 1 ou S2). A seleção massal, a seleção com progênies de meios irmãos e a seleção com progênies Sl têm sido os métodos mais comumente usados (HALLAUER et al., 1988).

Os diversos métodos não se diferenciam apenas quanto ao tipo de progênie utilizada na seleção, mas também quanto ao tipo de progênie utilizada na recombinação dos genótipos superiores. Desta forma, no método de seleção com progênies de meios irmãos (MI), a recombinação dos genótipos superiores pode ser feita com sementes remanescentes (MI); com progênies de autofecundação (S1), que exige plantas prolificas para obter os dois tipos de progênies; e finalmente, quando possível, clones. O mesmo vale para a seleção com progênies de irmãos germanos (IG), que pode ter como unidades de recombinação, progênies de irmãos germanos, Sl's ou clones. E finalmente os métodos de seleção com progênies endogâmicas S1 e S2, onde são recombinadas progênies S1 e S2, respectivamente. Outros métodos mistos 
são frequentemente propostos, como métodos de seleção alternando progênies S1 e de meios irmãos proposto por DHILLON \& KHEHRA (1989).

O progresso esperado $\left(G_{\mathrm{S}}\right)$ em resposta à seleção truncada, que corresponde à diferença entre os valores médios dos descendentes obtidos a partir da população selecionada e não selecionada, depende da covariância $[\operatorname{Cov}(x, y)]$ entre genitores $(x)$ e descendentes $(y)$, do diferencial de seleção estandardizado (i), e do desvio padrão fenotípico $\left(\sigma_{x}\right)$ dos genitores, como segue (SOUZA JR., 1989):

$$
\mathrm{G}_{\mathrm{S}}=\mathrm{i} \operatorname{Cov}(\mathrm{x}, \mathrm{y}) / \sigma_{\mathrm{x}}
$$

Esta relação pode ser facilmente utilizada para comparações teóricas entre os métodos relatados a seguir. Deve-se lembrar que a resposta direta à seleção intrapopulacional aparece nas populações per se e que a resposta indireta aparece nos cruzamentos populacionais.

\subsubsection{Seleção massal}

A seleção massal é frequentemente utilizada por ocasião da obtenção das progênies, sendo eficiente para caracteres de alta herdabilidade como precocidade, altura de planta e de espiga, resistência a algumas doenças e pragas, etc. Pode ser aplicada sobre um sexo ou sobre ambos, sendo que o valor da $\operatorname{Cov}(\mathrm{x}, \mathrm{y})$ é representada pela variância aditiva multiplicada pelos coeficientes 0.5 e 1 , respectivamente. O método tem sua eficiência prejudicada para caracteres de baixa herdabilidade pois a variância entre todas as plantas da população (genitores) que correspondem à unidade de 
seleção neste método, inclui efeitos genéticos (aditivos, dominantes e epistáticos) e ambientais em sua totalidade, aumentando o valor de $\sigma_{\mathrm{X}}$.

Resultados de um trabalho clássico envolvendo 15 ciclos de seleção massal sobre a população de milho Hays Golden foi relatado por GARDNER (1977, 1978). Observou-se um progresso de 3\% por ciclo na produção de grãos, um valor muito próximo do esperado $(3,08 \%$ por ciclo). A resposta à seleção massal, contudo, alcançou seu limite no $13 \underline{0}$ ciclo e começou a decrescer no 170 , demonstrando que à medida que a população se desenvolve, observa-se um decréscimo na eficiência do método.

Após três ciclos de seleção massal com controle biparental (sobre os dois sexos) para prolificidade, PATERNIANI (1980) observou progressos médios de $1,7 \%$ e $5,6 \%$ nas populações Piranão VD-2 e Piranão VF-1, respectivamente, com aumento correlacionado na produtividade de $2,3 \%$ e $6,1 \%$, respectivamente.

A seleção massal foi eficiente para diminuir $(-0,46 \mathrm{~cm}$ por ciclo) e aumentar $(0,38 \mathrm{~cm}$ por ciclo) o comprimento da espiga na população "Iowa Long-ear Synthetic". A resposta correlacionada para a produção de grãos foi negativa para os dois sentidos de seleção (SALAZAR \& HALLAUER, 1986).

Com sete ciclos de seleção massal com a variedade Lancaster, DEVEY \& RUSSELL (1983) obtiveram um decréscimo médio de -0,26 unidades de nota (escala de 0,5 a 6 ) por ciclo na incidência da podridão do colmo provocada por Diplodia maydis (Berk.) Sacc. 
Após 14 ciclos de seleção massal sobre a população BSK, MULAMBA et al. (1983) observaram um ganho de 0,59\% por ciclo na produção de grãos.

COORS \& MARDONES (1989) estimaram as respostas com 12 ciclos de seleção massal na população Golden Glow para aumentar a prolificidade nas populações per se e em cruzamentos com três linhagens endogâmicas (A632, W64A e W9). Nas avaliações realizadas em 1985 e 1986 , o número de espigas por planta aumentou nas populações per se em $2,4 \%$ e $3,3 \%$ por ciclo, obtendo ganhos correlacionados na produção de grãos por planta de $2,0 \%$ e $3,0 \%$ por ciclo, respectivamente. Também foram observados ganhos nos cruzamentos populacionais, mas foram aproximadamente metade daqueles observados nas populações per se, mostrando que a resposta indireta à seleção obteve baixa eficiência.

\subsubsection{Seleção com progênies de meios irmãos}

No método de seleção feita com progênies de meios irmãos (MI) podem-se utilizar diferentes tipos de progênies na recombinação dos genótipos selecionados, interferindo no valor esperado da $\operatorname{Cov}(x, y)$, que pode conter $25 \%$ ou $50 \%$ da variância aditiva se, na recombinação, forem utilizadas progênies de meios irmãos ou S1, respectivamente, (SOUZA JR., 1989).

PATERNIANI (1967) relatou ganhos de $13,6 \%$ por ciclo na produtividade da população Dente Paulista após três ciclos de seleção entre e dentro de progênies de meios irmãos. Para o mesmo esquema de seleção 
foram observados ganhos de 3,8\% por ciclo (PATERNIANI, 1968) após quatro ciclos de seleção sobre a população Piramex; $10,8 \%$ por ciclo para a população Tuxpeño após três ciclos (LIMA \& PATERNIANI, 1977); 1,8\% por ciclo na população IAC-1 após oito ciclos (MIRANDA et al., 1977); $2,7 \%$ para a população Composto Dentado Nordeste após três ciclos (SANTOS \& NASPOLINI Fo., 1986a); 5,1\% para a população Composto Flint Nordeste após três ciclos (SANTOS \& NASPOLINI Fo., 1986b). Pelo mesmo esquema de seleção, ganhos de $0,83 \%, 2,59 \%$ e $-0,43 \%$ por ano foram reportados (DARRAH et al., 1978) na produtividade das populações KII, Ec573, e H611, respectivamente, após seis ciclos de seleção, enquanto para a população KCA, o ganho foi de $5,2 \%$ após 10 ciclos de seleção. Seguindo ainda o mesmo esquema de seleção, SEGOVIA (1976) obteve ganho de 3,2\% por ciclo nos três ciclos iniciais e nenhum avanço nos três ciclos posteriores de seleção para o rendimento da população Centralmex.

HORNER et al. (1973) utilizaram o método de seleção recorrente com uso de progênies de meios irmãos na população Fla. 767, obtendo um ganho de $2,4 \%$ por ciclo na produção de grãos.

DUDLEY (1977) relata o trabalho mais longo de seleção para a percentagem de óleo e proteína nas sementes de milho, iniciado com a cultivar Burr's White. Após 76 gerações de seleção divergente, que foi massal nas nove gerações iniciais e com o uso de progênies de meios irmãos nas restantes, obteve ganhos de $292 \%$ com seleção para alto teor de óleo (IHO), $92 \%$ para baixo teor de óleo (ILO), $133 \%$ para alto teor de proteína (IHP) e $78 \%$ para baixo teor de proteína (ILP). DUDLEY \& LAMBERT (1992) publicaram os resultados deste experimento após 90 gerações de seleção. 
Foram completadas noventa gerações de seleção para alto e baixo teor de proteina (IHP) e (ILP), respectivamente, e alto teor de óleo (IHO); 87 gerações para baixo teor de óleo (ILO); 42 gerações para alto teor de proteina reversa (RHP), baixo teor de proteina reversa (RLP), alto teor de óleo reversa (RHO) e baixo teor de óleo reversa (RLO) e finalmente 36 gerações de "switchback" (vai-vem) para alto teor de óleo (SHO) onde é feita a seleção reversa e depois volta-se para o sentido original. Aparentemente, progressos para as linhas ILO e ILP chegaram ao fim devido à ocorrência dos limites inferiores (menos que $1 \%$ de óleo e menos que $4 \%$ de proteína, respectivamente). Desta forma, o autor acredita que pela primeira vez na história o limite da seleção tenha sido alcançado. Progressos para todas as outras linhas ainda são possiveis.

POMMER \& GERALDI (1983), avaliaram os progressos obtidos após quatro ciclos de seleção entre e dentro de progênies de meios irmãos para produção de grãos nas populações de milho IAC Maya $\mathrm{o}_{2}$ e IAC$1 \mathrm{o}_{2}$. As respostas por ciclo nestas populações foram de 4,5\% e 10,7\%, respectivamente, e de $4,8 \%$ no hibrido intervarietal obtido a partir delas (IAC Phoenix $\mathrm{O}_{2}$ ).

TANNER (1984), obteve resposta de 5,69\% por ciclo ao avaliar oito ciclos de seleção com progênies de meios irmãos para produção de grãos na população BSK, derivada da variedade "Krug Yellow Dent". 


\subsubsection{Seleção com progênies de irmãos germanos}

Neste caso, a expressão do ganho utilizando irmãos germanos (IG) para selecionar e progênies IG ou Sl's para recombinar, terá no numerador metade da variância aditiva, semelhante à seleção sobre progênies de meios irmãos (MI) com recombinação de Sl's. Mas o esquema com progênies IG terá um ganho menor, pois a variância fenotípica da unidade de seleção deve ser maior em IG do que em MI.

MOLL \& HANSON (1984) avaliaram 10 ciclos de seleção com progênies de irmãos germanos nas populações Jarvis e Indian Chief. As respostas observadas para a produção de grãos foram de 3,5\% e 1,4\% por ciclo, respectivamente. Os autores não obtiveram ganhos adicionais após o oitavo ciclo. A resposta indireta no cruzamento interpopulacional foi de $2,06 \%$ por ciclo. A heterose em relação à média das populações parentais aumentou de 13,5\% no ciclo original (Co) para 19,7\% em C10.

SINGH et al. (1986) praticaram seleção com progênies de irmãos germanos para aumentar a prolificidade na população Pastap sob densidades de plantio de 44.444 e 166.666 plantas por hectare. A resposta por ciclo, à seleção sob baixa densidade $(0,06$ espigas ou 5,5\%), foi maior que sob alta densidade (0.04 espigas ou 3,6\%). Foi obtida uma resposta correlacionada positiva para a produção de grãos na ordem de $4,5 \%$ por ciclo.

PANDEY et al. (1986) estimaram a resposta à seleção com progênies de irmãos germanos na produção de grãos de oito populações tropicais e obtiveram um aumento de $1,3 \%$ por ciclo. No entanto, a resposta observada variou de $0,2 \%$ por ciclo para Tuxpeño Caribe para 9,5\% para 
Cogollero e $9,1 \%$ para Amarillo Cristalino-1. A resposta à seleção esteve relacionada com o nível de variabilidade genética do caráter nas populações base. Por exemplo, após o quinto ciclo de seleção (C5) a produção de Amarillo Cristalino 1 foi 5,27 t/ha $(9,1 \%)$ e da Tuxpeño Caribe foi 6,21 t/ha $(0,2 \%)$.

STROMBERG \& COMPTON (1989) avaliaram o progresso obtido com dez ciclos de seleção recorrente com progênies de irmãos germanos aplicados sobre a população Nebraska Krug. Utilizou-se um índice de seleção incluindo o caráter produção de grãos. Observou-se um aumento do indice de 0,17 t/ha por ciclo $(4,4 \%$ por ciclo), que representou um aumento na produção de grãos de 0,07 t/ha por ciclo ( $1,2 \%$ por ciclo $)$.

LIVINI et al. (1992) trabalhando com a população MOD2 (variedade sintética de milho, homozigotica para o alelo $\mathrm{o}_{2}$, opaco) compararam três ciclos de seleção recorrente feitos com progênies $\mathrm{S} 1$ e progênies de irmãos germanos, analisando as performances das populações de Co a C3 per se de cada método e em cruzamentos com uma linhagem Lo8720 2. A seleção com progênies de irmãos germanos conseguiu aumentar a produção de grãos em $0,20 \mathrm{t} / \mathrm{ha} /$ ciclo $(3,7 \%$ por ciclo) nas populações per se e em $0,16 \mathrm{t} / \mathrm{ha} /$ ciclo $(1,8 \%$ por ciclo $)$ nos cruzamentos com a linhagem.

Progênies de irmãos germanos não têm sido tão extensivamente utilizadas quanto progênies de meios irmãos ou de autofecundação para a seleção (PANDEY et al., 1986). 


\subsubsection{Seleção com progênies endogâmicas}

A expressão do ganho esperado segundo o esquema de seleção com base em progênies $S 1$ com recombinação de Sl's tem em seu numerador a variância aditiva em sua totalidade, porém, também tem metade da covariância genética entre os efeitos aditivos dos alelos e os efeitos de dominância dos homozigotos $\left(D_{1}\right)$, que pode ser negativo diminuindo a eficiência do método (SOUZA JR., 1989).

Em 1953, teve início um esquema de seleção recorrente sobre a população BSK. Métodos de seleção recorrente com uso de progênies de meios irmãos [BSK(HI)] e Sl's [BSK(S)] foram aplicados, tendo a produção de grãos como objetivo principal. No esquema BSK(HI) diferentes tipos de testadores foram utilizados, em sua maioria originários de outras populações caracterizando um método interpopulacional. Já no esquema BSK(S) foram seis ciclos com progênies $\mathrm{S} 1$ e depois seguiu-se utilizando progênies S2. SMITH (1979b) e TANNER \& SMITH (1987) estudaram a resposta para estes diferentes métodos e obtiveram para BSK(S) um ganho de 2,92\% por ciclo, que foi menor em relação a método $\mathrm{BSK}(\mathrm{HI})$ que obteve um ganho médio de $4,05 \%$ por ciclo. TANNER (1984) obteve uma resposta de 5,93\% por ciclo para $\mathrm{BSK}(\mathrm{S})$. Esta resposta esteve próxima à obtida em $\mathrm{BSK}(\mathrm{HI})$ e bem superior à obtida com seleção massal BSK(M) observadas por MULAMBA et al. (1983), salientando a importância do uso de progênies para caracteres de baixa herdabilidade principalmente em virtude do maior controle ambiental baixando o valor de $\sigma_{x}$. Também estimaram o efeito da endogamia acumulada resultante da recombinação de populações pequenas durante os 
oito ciclos de seleção, sendo esperado nas populações per se um decréscimo de $2,24 \mathrm{t} / \mathrm{ha}$ em BSK(S) e $1,15 \mathrm{t} / \mathrm{ha}$ e m BSK(HI).

HORNER et al. (1973) utilizaram o método de seleção recorrente com uso de progênies S2 para produção de grãos com ganhos de $2 \%$ por ciclo na população Fla.767, resposta semelhante à obtida com progênies de meios irmãos. HORNER (1985) reexaminou estes resultados e observou que as diferenças entre os métodos para a capacidade combinatória não foi significativa, mas houve uma menor depressão por endogamia nas populações melhoradas via progênies S2.

DEVEY \& RUSSELL (1983) aplicaram sete ciclos de seleção com progênies Sl para aumentar a resistência mecânica do colmo. A resistência aumentou de $28,7 \mathrm{Kg}$ em Co para $59,6 \mathrm{Kg}$ em $\mathrm{C} 7$ que equivale a um ganho aproximado de $15,4 \%$ por ciclo. Os maiores ganhos concentraramse nos quatro primeiros ciclos de seleção, e houve uma associação positiva deste caráter com o caráter resistência à podridão do colmo, e negativa com a produção de grãos que diminuiu $40 \%$ de Co para C 7 .

LAMKEY (1992) apresentou resultados de avaliações feitas com as populações de ciclos zero a seis de BS13 desenvolvida via progênies S2 . Não houve aumento na produção da população BS13 per se. O autor também relata que houve uma resposta significativa na população per se através de seleção baseada em cruzamentos-teste feitos com o híbrido duplo Iowa 13, que será comentado posteriormente. A ineficiência do método com progênies $S 2$ em relação ao de meios irmãos, demonstra que o parâmetro $D_{1}$ 
deve ser importante para esta população, diminuindo a resposta obtida pelo primeiro esquema de seleção.

HORNER et al. (1989) estimaram os ganhos obtidos através de seleção com uso de progênies S2 em duas populações (FS8A e FS8B). Ganhos médios na capacidade de combinação das duas populações foram de $3 \%$ por ciclo. A média da população $(F=0)$ obtida após o quarto ciclo foi de $4,85 \mathrm{t} / \mathrm{ha}$. Esta mesma média foi de $6,01 \mathrm{t} / \mathrm{ha}$ quando a seleção foi baseada em cruzamentos-teste (método TC, com enfoque interpopulacional) que será comentado posteriormente. No entanto, progênies S2 apresentaram valores inferiores de depressão por endogamia no ciclo 4 [0,04 e 0,06 t/ha para cada $1 \%$ de aumento na endogamia nos métodos com progênies S2 e TC, respectivamente] e apresentaram maiores produções nas populações endogâmicas $(F=1)(1,7$ e $0,87 \mathrm{t} / \mathrm{ha}$, para $\mathrm{S} 2$ e $\mathrm{TC}$, respectivamente). O autor sugeriu que a ação gênica não aditiva (principalmente sobredominância) são importantes nas populações estudadas, já que em ausência de sobredominância espera-se que o método S2 seja mais eficiente.

O trabalho de LIVINl et al. (1992), já citado, também apresenta a resposta obtida à seleção com progênies S1 da população MOD2, analisando as performances das populações de Co a C3 per se e em cruzamentos com a linhagem Lo87202. A produção de grãos aumentou em $0,36 \mathrm{t} / \mathrm{ha} /$ ciclo $(6,6 \%$ por ciclo $)$ nas populações e em $0,47 \mathrm{t} / \mathrm{ha} /$ ciclo $(5,4 \%$ por ciclo) nos cruzamentos. 


\subsection{Seleção recorrente interpopulacional}

Os métodos de seleção recorrente interpopulacional dão ênfase às performances dos cruzamentos, tentando aproveitar ao máximo o fenômeno da heterose nos híbridos. Estes métodos surgiram a partir das hipóteses explicativas da heterose, ou seja, da sobredominância versus dominância completa ou parcial atuando nos diversos locos (HALLAUER et al., 1988). Ainda não apareceram evidências para um ou outro ponto de vista. Desta forma, COMSTOCK et al. (1949) desenvolveram o método de seleção recorrente recíproca em que a seleção é feita sobre os cruzamentos entre as duas populações formando progênies de meios irmãos tentando aproveitar os dois tipos de efeitos genéticos, não devendo ser inferior aos métodos para a capacidade específica (HULL, 1945) ou geral (JENKINS, 1940) de combinação.

Algumas alterações do método original proposto por COMSTOCK et al. (1949) foram elaboradas. HALLAUER \& EBERHART (1970) propuseram o uso de progênies de irmãos completos obtidos em plantas prolificas (RRSFS). PATERNIANI \& VENCOVSKY (1977, 1978) propuseram o uso de cruzamentos testes através de progênies de meios irmãos (RRSTS) e o uso de progênies de meios irmãos obtidos de plantas prolificas (RRSHSPP), respectivamente. SOUZA JR. (1987), propôs um método de seleção recorrente recíproca baseado em progênies de meios irmãos obtidas alternadamente de plantas So e S1 (RRSHSSoS1).

O método proposto por SOUZA JR. (1987), consiste no seguinte: No inverno do primeiro ano são plantadas duas populações A e B 
em blocos próximos (cerca de 1000 plantas por bloco). No florescimento, as espigas de plantas prolíficas são protegidas nas duas populações. As espigas inferiores são autofecundadas e as superiores são polinizadas com uma mistura de pólen da outra população. Desta forma são produzidas uma progênie Sl e uma progênie de meios irmãos interpopulacional em cada planta prolífica. As progênies S1 são armazenadas (200 a 300 pares de progênies de cada população). No verão são avaliadas as progênies de meios irmãos interpopulacionais em experimentos com repetições, sendo selecionadas 10 a $20 \%$ das progênies. No inverno do segundo ano é feita a recombinação e produção simultânea das progênies. Uma mistura de sementes Sl das progênies selecionadas das duas populações é plantada em dois blocos isolados (1000 plantas cada). No florescimento, as espigas superiores das plantas prolíficas são protegidas. As espigas inferiores são submetidas à polinização aberta com pólen de sua população para recombinação, enquanto as espigas superiores recebem uma mistura de pólen da população contrastante. Desta forma são obtidos dois tipos de progênies de meios irmãos, uma intrapopulacional que é armazenada e outra interpopulacional para as avaliações. No verão as progênies de meios irmãos interpopulacionais são avaliadas em experimentos com repetições. São selecionadas de 10 a $20 \%$ das progênies superiores. Então, repete-se o esquema do inverno do primeiro ano utilizando uma mistura de sementes das progênies de meios irmãos intrapopulacionais selecionadas. As comparações teóricas feitas pelo autor, mostraram uma maior eficiência do método proposto em relação aos métodos RRSFS (seleção recorrente recíproca com progênies de irmãos completos) e 
RRSHSPP (seleção recorrente reciproca com progênies de meios irmãos e plantas prolificas).

Deve-se lembrar que a resposta direta à seleção interpopulacional aparece nos cruzamentos entre populações e a resposta indireta nas próprias populações e que as populações resultantes nos ciclos de seleção são formadas pelo intercruzamento (recombinação) das progênies que demonstraram melhor performance nos cruzamentos com a população contrastante, servindo uma como testadora da outra.

No processo de seleção recorrente interpopulacional, os genótipos são avaliados em cruzamentos com um testador não pertencente à mesma população de origem. Os genótipos superiores devem ser recombinados, utilizando-se para isso, progênies intrapopulacionais, mantendo a identidade genética da população original. Portanto, cada genótipo obrigatoriamente deverá produzir dois tipos de progênies, uma interpopulacional e outra intrapopulacional. As progênies interpopulacionais, devem ser avaliadas em ensaios com repetições, e pode-se utilizar progênies de meios irmãos ou de irmãos germanos. Depois das avaliações e seleção dos genótipos superiores, recombinam-se as progênies intrapopulacionais, podendo-se utilizar para tanto, progênies de meios irmãos ou S1's. 


\subsubsection{Seleção com progênies de meios irmãos}

Um programa de seleção recorrente recíproca como sugerido por COMSTOCK et al. (1949) foi iniciado com as variedades sintéticas "Iowa Stiff Stalk Synthetic" (BSSS) e "Iowa Corn Borer Synthetic № 1" (BSCB1) em 1949. BSSS e BSCB 1 foram obtidas a partir do cruzamento entre 16 e 12 linhagens, respectivamente. O caráter principal considerado na seleção foi a produção de grãos. Algumas mudanças foram feitas ao longo do programa, de acordo com o desenvolvimento da própria cultura, dentre elas, o aumento das densidades de plantas, menor espaçamento entre linhas nos ensaios para avaliação de genótipos, incremento do nível de fertilizantes, plantio e colheita mecanizados, e uso de Sl's ao invés de plantas So na produção de progênies de meios irmãos. Normalmente, 100 progênies de meios irmãos foram testadas para cada população e as progênies $S 1$ das dez progênies de meios irmãos que se sobressaíram nos ensaios com repetição foram recombinadas para formar a população do ciclo seguinte. Desta forma, o tamanho efetivo populacional (Ne) foi igual a dez para as duas populações. A eficiência do programa de melhoramento vem sendo avaliado periodicamente por vários autores. As respostas diretas para a produção de grãos obtidas nos cruzamentos populacionais por ciclo seletivo foram as seguintes: $1,7 \%$ ou $0,118 \mathrm{t} / \mathrm{ha} \mathrm{em}$ cinco ciclos avaliados (PENNY \& EBERHART, 1971); 4,6\% ou 0,273 t/ha em cinco ciclos (EBERHART et al., 1973); 2,97\% ou 0,175 t/ha em sete ciclos (MARTIN \& HALLAUER, 1980); 3,1\% em 8 ciclos (SMITH, 1983), com respostas diferentes até o quarto ciclo $(0,247 \mathrm{t} / \mathrm{ha})$ e do quarto até o oitavo ciclo $(0,361 \mathrm{t} / \mathrm{ha})$, ocorridas em decorrência do uso de plantas S1 ao invés de So na produção dos cruzamentos teste e da mecanização no processo 
de colheita; $4,2 \%$ ou 0,217 t/ha em 10 ciclos (HELMS et al., 1989); e 6,6\% ou 0,28 t/ha em 11 ciclos (KEERATINIJAKAL \& LAMKEY, 1993b). Todos estes resultados obtidos comprovam a alta eficiência do método em sua resposta direta, ou seja, os cruzamentos populacionais. A resposta indireta por ciclo seletivo obtida nas populações BSCBl e BSSS per se, respectivamente, e a fonte de cada informação estão resumidos a seguir: $0,047(0,9 \%)$ e $0,024 \mathrm{t} /$ ha $(0,4 \%)$ por EBERHART et al. (1973); $-0,063$ $(-1,2 \%)$ e $0,034 \mathrm{t} / \mathrm{ha}(0,7 \%)$ por MARTIN \& HALLAUER (1980);0,034 $(0,6 \%)$ e $0,131 \mathrm{t} /$ ha $(2,2 \%)$ por SMITH $(1983) ; 3,2 \%$ ou $0,128 \mathrm{t} /$ ha para a população BSSS por HELMS et al. (1989); 0,06 (1,9\%) e 0,06 t/ha $(1,7 \%)$ por KEERATINIJAKAL \& LAMKEY (1993b).

As avaliações têm demonstrado que o método de seleção recorrente recíproca foi eficiente no desenvolvimento dos cruzamentos populacionais. As respostas nas populações per se foram, em geral, muito baixas, principalmente para a população BSCB1. Segundo SMITH (1979b, 1979a) a resposta baixa das populações per se pode estar relacionada ao efeito da endogamia provocada pelo pequeno tamanho efetivo populacional, que no esquema de seleção anterior foi de dez plantas. Com a endogamia, ocorre uma diminuição da frequência de heterozigotos nas populações. Modelos estatísticos têm sido desenvolvidos (HAMMOND \& GARDNER, 1974; SMITH, 1979b, 1979a) para permitir a partição da resposta à seleção nas populações per se naquela devida aos homozigotos e aos heterozigotos. SMITH (1983) estimou o parâmetro DQI, que mede o efeito provocado pela perda de heterozigotos na população per se, obtendo valores de $-0,022 \pm$ $0,003 \mathrm{t} / \mathrm{ha}$ para a população BSSS e de $-0,036 \pm 0,004 \mathrm{t} / \mathrm{ha}$ para a população 
BSCB1. Estes valores de DQI, representam, após oito ciclos seletivos, perdas acumuladas (2DQI $* \mathrm{n}^{2}$, onde $\mathrm{n}$ é o número de ciclos) de 2,81 e 4,61 t/ha nas populações BSSS e BSCBl, respectivamente. Desta forma, o autor sugere que a ineficiência do método em obter ganhos nas populações per se pode ser consequência da endogamia provocada pelo seu pequeno tamanho efetivo. Resultados semelhantes foram observados por KEERATINIJAKAL \& LAMKEY (1993a).

MOLL \& STUBER (1971) avaliaram seis ciclos de seleção recorrente reciproca nas populações "Jarvis Golden Prolific" e "Indian Chief". A resposta obtida para a produção de grãos foi de $3,5 \%$ por ciclo no cruzamento interpopulacional e de $2,3 \%$ e $1,2 \%$ por ciclo para Jarvis e Indian Chief, respectivamente. MOLL et al. (1978) relataram os resultados de duas avaliações independentes feitas com estas populações. A primeira incluiu seis ciclos seletivos. Obteve-se uma resposta direta de $3,1 \%$ por ciclo e indireta de $2,7 \%$ em Jarvis e $0,9 \%$ para Indian Chief para a produção de grãos. A segunda avaliação incluiu oito ciclos seletivos. A resposta direta para a produção de grãos foi de $3,2 \%$ por ciclo, e a resposta indireta foi de $2,5 \%$ para Jarvis e de $1,4 \%$ para Indian Chief. MOLL \& HANSON (1984) apresentaram as respostas após 10 ciclos de seleção recorrente recíproca nestas populações para produção de grãos e número de espigas. A resposta direta na produção de grãos com base nos cruzamentos interpopulacionais foi de $2,7 \%$ por ciclo de seleção. A resposta indireta obtida nas populações per se foram de $2,4 \%$ por ciclo para Jarvis e $-0,3 \%$ por ciclo para Indian Chief na produção de grãos. O número de espigas por planta aumentou tanto nos cruzamentos como nas populações per se. Portanto, as respostas observadas 
na população Indian Chief foram pequenas para a produção de grãos quando comparadas às respostas obtidas na outra população base e no cruzamento populacional.

PATERNIANI (1971) obteve ganhos de 13,6\%, -7,8\% e 3,7\% sobre as populações Composto Dentado, Composto Flint e sobre o híbrido interpopulacional com um ciclo de seleção recorrente recíproca para produção de grãos. Para estas mesmas populações, a resposta sobre o híbrido interpopulacional após dois ciclos de seleção foi de 3,5\% (PATERNIANI \& VENCOVSKY, 1978). PATERNIANI \& VENCOVSKY (1977) obtiveram ganhos de $3,5 \%, 7,5 \%$ e 7,5\% para as populações Piramex, Cateto e para o híbrido interpopulacional, respectivamente, também com um ciclo de seleção para a produção de grãos.

Ao avaliar três ciclos de seleção recorrente recíproca sobre as populações Teko Yellow e Natal Yellow Horsetooth, GEVERS (1975) obteve uma resposta na produção de grãos do cruzamento populacional de $6,0 \%$ por ciclo, e respostas indiretas de $6,0 \%$ e $7,9 \%$ por ciclo para as populações Teko e Natal, respectivamente. DARRAH et al. (1978) avaliaram o mesmo método com as populações KII e Ec573, e obtiveram resposta de $7 \%$ por ciclo no cruzamento entre populações e de $2,4 \%$ por ciclo na população Ec573 para a produção de grãos após três ciclos de seleção, não havendo resposta para a população KII

A seleção recorrente recíproca tem se mostrado efetiva no melhoramento dos cruzamentos interpopulacionais nos estudos feitos até o momento. Respostas indiretas nas populações per se não são tão consistentes. 
Em muitos casos, esta ausência de resposta à seleção ocorre mais severamente sobre uma das populações base, e este fato não é explicado apenas pelo efeito da endogamia provocada pelo pequeno tamanho populacional, o qual deve afetar as duas populações.

\subsubsection{Seleção com progênies de irmãos germanos}

O programa de seleção interpopulacional com progênies de irmãos germanos com as populações "Iowa Two Ear Synthetic" (BS10) e "Pioneer Two Ear Composite" (BS11) começou em 1963. A produção de progênies de irmãos germanos é feita através de cruzamentos entre plantas tomadas duas a duas ao invés de cruzamentos-teste (meios irmãos), o que significa que apenas um tipo de progênie interpopulacional será avaliada ao invés dos dois tipos obtidos na seleção recorrente recíproca. O método foi sugerido com o objetivo de aumentar a eficiência da seleção aproveitando-se efeitos genéticos não aditivos, mas até o momento, esta teoria não foi comprovada. As populações BS10 e BS11 foram escolhidas por apresentarem plantas prolíficas, o que permite obter progênies Sl's e de irmãos germanos de cada planta. As progênies Sl's das progênies de irmãos germanos interpopulacionais superiores, nos ensaios com repetição, são recombinadas para formar a população do ciclo seguinte. HALLAUER (1984) apresentou resultados de sete ciclos de seleção recorrente recíproca utilizando progênies de irmãos completos para estas populações. A resposta direta, obtida nos cruzamentos interpopulacionais, foi de $2,1 \%$ por ciclo para a produção de grãos. A resposta correlacionada nas populações BS10 e BS11 foi de $2,7 \%$ e 
2,4\% por ciclo, respectivamente. Já EYHERABIDE \& HALLAUER (1991a) avaliaram oito ciclos de seleção e obtiveram uma resposta direta de $6,5 \%$ $(0,35 \mathrm{t} / \mathrm{ha})$ por ciclo no cruzamento interpopulacional, e respostas indiretas de $3,0 \%(0,12 \mathrm{t} / \mathrm{ha})$ e $1,6 \%(0,08 \mathrm{t} / \mathrm{ha})$ para as populações BS10 e BS11, respectivamente. Os resultados indicaram que o esquema foi eficiente para desenvolver tanto o cruzamento populacional quanto as populações per se. EYHERABIDE \& HALLAUER (1991b) estimaram os efeitos da endogamia provocada nas populações per se devido ao pequeno tamanho da população utilizada nas recombinações seguindo o modelo proposto por SMITH (1979a, b, 1983). Após oito ciclos de seleção, a perda acumulada provocada pela deriva genética foi de 1,79 t/ha e 1,41 t/ha para BS10 e BS1l, respectivamente. As diferenças entre a resposta direta $(0,28 \mathrm{t} / \mathrm{ha} / \mathrm{ciclo})$ e as respostas indiretas $(0,35$ e $0,22 \mathrm{t} / \mathrm{ha} /$ ciclo, para BS10 e BS1l, respectivamente), obtidas após o ajuste para o efeito da deriva, não foram significativas $(\mathrm{P}<0,01)$.

\subsubsection{Seleção com cruzamentos-teste}

Um programa de seleção recorrente foi iniciado em 1939 com o sintético "Iowa Stiff Stalk Synthetic", e incluiu um esquema de seleção baseada em "testcrosses". Sete ciclos de seleção recorrente com progênies de meios irmãos tendo o híbrido duplo lowa 13 como testador foram completados [BSSS(HT)]. EBERHART et al. (1973) avaliaram sete ciclos de seleção, e observaram que a resposta direta avaliada nos cruzamentos com o testador foi de $0,165 \mathrm{t} / \mathrm{ha} /$ ciclo $(2,6 \%)$, e a resposta indireta na população 
BSSS per se foi de $0,074 \mathrm{t} / \mathrm{ha} /$ ciclo $(1,4 \%)$. HELMS et al. (1989) também avaliaram sete ciclos de seleção, e obtiveram uma resposta indireta superior, com valor de 0,18 t/ha $(4,6 \%)$ por ciclo na população BSSS. Resultado semelhante foi obtido por LAMKEY (1992), que obteve uma resposta na produção de 0,16 t/ha/ciclo (3,9\% por ciclo) na população per se.

HORNER et al. (1989) estimaram os ganhos obtidos com quatro ciclos de seleção com cruzamentos-teste nas populações FS8A e FS8B. Neste método, uma linhagem de FS8A serviu como testadora das progênies S2 de FS8B, e vice-versa. Ganhos médios na capacidade de combinação das duas populações foram de $4,7 \%$ por ciclo para produção de grãos.

RUSSELL et al. (1992) avaliaram um método de seleção recorrente recíproca modificado sugerido por RUSSELL \& EBERHART (1975), no qual os testadores são duas linhagens endogâmicas retiradas das populações contrastantes, normalmente linhagens elites. Trabalhando com os sintéticos BS21 e BS22, após três ciclos de seleção, foram comparados os seguintes cruzamentos: BS2l(R)xBS22(R), cruzamentos entre as populações desenvolvidas pelo esquema de seleção recorrente recíproca (SRR), onde uma população serviu como testadora da outra; BS21(A632HI)xA632, que é a população BS21 cruzada com seu testador original; BS22(H99HI)xH99, que é a população BS22 cruzada com seu testador original; BS21(R)xA632, que é o cruzamento entre BS21 (desenvolvida por SRR) e a linhagem A632; BS22(R)xH99, que é o cruzamento entre BS22 (desenvolvida por SRR) e a linhagem H99; e finalmente BS21(A632HI)xBS22(H99HI), que é o cruzamento entre as populações que tiveram as linhagens endogâmicas 
retiradas das populações contrastantes como testadoras. Pela análise dos ganhos obtidos nos cruzamentos, observou-se que o método modificado não obteve sucesso após três ciclos de seleção para produção de grãos.

\subsection{Comparações entre métodos intra e interpopulacionais}

Os resultados obtidos por MOLL \& HANSON (1984) permitiram uma boa comparação entre métodos intra e interpopulacionais após 10 ciclos de seleção. No método intrapopulacional (seleção com progênies de irmãos germanos), observaram-se respostas diretas na produção de grãos de $3,5 \%$ e $1,4 \%$ por ciclo nas populações Jarvis e Indian Chief, e resposta indireta de $2,06 \%$ no cruzamento interpopulacional. No interpopulacional, as respostas indiretas foram $2,4 \%$ e $-0,3 \%$ por ciclo para Jarvis e Indian Chief, respectivamente, e a resposta direta foi de 2,7\% por ciclo no hibrido interpopulacional.

HORNER et al. (1989) relataram as respostas obtidas por esquemas intra e interpopulacionais sobre as populações FS8A e FS8B. A seleção com progênies S2 (intrapopulacional) obteve resposta indireta sobre o híbrido interpopulacional de $4,7 \%$ por ciclo enquanto pelo método dos "testcrosses" (TC) a resposta no hibrido interpopulacional foi de 7,5\% por ciclo, apesar de que neste último os testadores não foram propriamente as populações reciprocas, mas linhagens retiradas destas populações. As 
respostas nas populações per se também indicaram uma superioridade do método TC em relação à seleção com S2 o que não era esperado em teoria.

Comparações entre métodos intra e interpopulacionais também foram realizadas por HELMS et al. (1989) para a população BSSS. A resposta à seleção recorrente recíproca (SRR) para produção de grãos foi de $3,2 \%$ por ciclo em BSSS (indireta). Pelo método dos cruzamentos-teste, a resposta em BSSS (indireta) foi de $4,6 \%$ por ciclo, enquanto pelo método intrapopulacional com progênies $\mathrm{S} 1$ a resposta (direta) foi de $8,3 \%$ por ciclo em BSSS. Portanto o método intrapopulacional mostrou-se superior aos interpopulacionais para desenvolver a população per se.

Estudos teóricos a respeito das alterações pa heterose via seleção intra e interpopulacionais realizados por SOUZA JR. \& MIRANDA Fo (1985), indicaram que a variação na heterose tende a ser negativa com métodos intrapopulacionais e positiva nos interpopulacionais, considerando modelos com dominância completa e sobredominância.

Comparações teóricas entre métodos de seleção recorrente intra-, interpopulacionais e modificado foram realizadas através de avaliações numéricas por SOUZA JR. (1993), com o objetivo de tentar atender a todos os requisitos de um programa de híbridos de linhagens. O método modificado consiste em se utilizar uma das populações como testadora de ambas as populações, sendo que a população com menor valor médio para o caráter seria utilizada como testadora. O método envolve esquemas de seleção recorrente intrapopulacional, já que uma população serve como testadora dela própria; e interpopulacional, já que a mesma população servirá como 
testadora para a outra população. Este método foi sugerido pelo autor em virtude de seus resultados em relação aos métodos intra e interpopulacionais. A idéia do método misto surgiu em consequência dos estudos feitos pelo autor a respeito das causas do insucesso dos métodos de seleção recorrente intra e interpopulacionais em atenderem de forma ampla aos objetivos do melhoramento do milho. Como já relatado em vários trabalhos, os métodos de seleção recorrente intrapopulacional obtiveram respostas superiores nas populações per se, não apresentando o mesmo resultado no híbrido populacional; enquanto a seleção recorrente recíproca ou interpopulacional tem apresentado respostas superiores no híbrido interpopulacional, positivas para uma das populações e nulas ou mesmo negativas para a outra população per se. O autor concluiu que no caso de populações base geneticamente divergentes (p-r) e dependendo do nivel de dominância do caráter, estes resultados seriam esperados, e que o método modificado foi a melhor alternativa para resolver o problema. Para chegar a essas conclusões, as variâncias genéticas aditivas interpopulacionais foram decompostas assim:

$$
\begin{aligned}
& \sigma_{\mathrm{A} 12}^{2}=\sigma_{\mathrm{A} 11}^{2}+\sigma_{\tau 12}^{2}+4 \operatorname{Cov}\left(\mathrm{A}_{1} \tau_{12}\right), \mathrm{e} \\
& \sigma_{\mathrm{A} 21}^{2}=\sigma_{\mathrm{A} 22}^{2}+\sigma_{\tau 21}^{2}+4 \operatorname{Cov}\left(\mathrm{A}_{2} \tau_{21}\right) \text {, onde: } \\
& \sigma_{\mathrm{A} 12}^{2} \text { e } \sigma_{\mathrm{A} 21}^{2} \text { são as variâncias genéticas aditivas }
\end{aligned}
$$
interpopulacionais, tendo as populações 1 e 2 como parental feminino, respectivamente; $\sigma_{\text {A11 }}^{2}$ e $\sigma_{\text {A22 }}^{2}$ são as variâncias genéticas aditivas intrapopulacionais das populações 1 e 2 , respectivamente; $\sigma_{\tau 12}^{2}$ e $\sigma_{\tau 21}^{2}$ são as variâncias genéticas dos desvios dos efeitos aditivos inter e intrapopulacionais utilizando a população 1 e 2 como parental feminino, 
respectivamente; e $\operatorname{Cov}\left(\mathrm{A}_{1} \tau_{12}\right)$ e $\operatorname{Cov}\left(\mathrm{A}_{2} \tau_{21}\right)$ são as covariâncias genéticas dos efeitos aditivos intrapopulacionais com os desvios dos efeitos aditivos inter- e intrapopulacionais, tendo as populações 1 e 2 como parental feminino, respectivamente. O procedimento usado pelo autor para decompor as variâncias genéticas interpopulacionais foram feitas de forma similar ao utilizado por COWEN (1987).

Para obter o significado genético destes parâmetros o autor utilizou o modelo de FALCONER (1960), para um loco e dois alelos, com p e $\mathbf{q}, \mathbf{r}$ e $\mathbf{s}$ sendo as frequências dos alelos favoráveis e desfavoráveis das populações 1 e 2 , respectivamente; a como metade da diferença dos valores genotípicos dos homozigotos, e d como o valor genotípico do heterozigoto, e os resultados foram os seguintes:

$$
\begin{aligned}
& \sigma_{\mathrm{A} 11}^{2}=2 \mathrm{pq}[\mathrm{a}+(\mathrm{q}-\mathrm{p}) \mathrm{d}]^{2} ; \sigma_{\mathrm{A} 22}^{2}=2 \mathrm{rs}[\mathrm{a}+(\mathrm{s}-\mathrm{r}) \mathrm{d}]^{2} ; \\
& \sigma_{\mathrm{A} 12}^{2}=2 \mathrm{pq}[\mathrm{a}+(\mathrm{s}-\mathrm{r}) \mathrm{d}]^{2} ; \sigma_{\mathrm{A} 21}^{2}=2 \mathrm{rs}[\mathrm{a}+(\mathrm{q}-\mathrm{p}) \mathrm{d}]^{2} ; \\
& \sigma_{\tau 12}^{2}=8 \mathrm{pq}(\mathrm{p}-\mathrm{r})^{2} \mathrm{~d}^{2} ; \sigma_{\tau 21}^{2}=8 \mathrm{rs}(\mathrm{p}-\mathrm{r})^{2} \mathrm{~d}^{2} ; \\
& \operatorname{Cov}\left(\mathrm{A}_{1} \tau_{12}\right)=2 \mathrm{pq}(\mathrm{p}-\mathrm{r})[\mathrm{a}+(\mathrm{q}-\mathrm{p}) \mathrm{d}] \mathrm{d} \\
& \operatorname{Cov}\left(\mathrm{A} 2 \tau_{21}\right)=2 \mathrm{rs}(\mathrm{r}-\mathrm{p})[\mathrm{a}+(\mathrm{s}-\mathrm{r}) \mathrm{d}] \mathrm{d} . \\
& \text { Nota-se que } \sigma_{\tau 12}^{2}, \sigma_{\tau 21}^{2}, \operatorname{Cov}\left(\mathrm{A}_{1} \tau_{12}\right) \text { e } \operatorname{Cov}\left(\mathrm{A}_{2} \tau_{21}\right) \text { são }
\end{aligned}
$$
relacionados à divergência genética $(p-r)$ das populações utilizadas, e ao nível de dominância (d) dos caracteres e, portanto, eles estão relacionados com a heterose. Para $\mathrm{p}>\mathrm{r}$, tem-se $\operatorname{Cov}\left(\mathrm{A}_{1} \tau_{12}\right)>0$ e $\operatorname{Cov}\left(\mathrm{A}_{2} \tau_{21}\right)<0$, e vice-versa para $\mathrm{p}<\mathrm{r}$. Assim, esta covariância será positiva para a população com maior 
frequência média de alelos favoráveis e negativa para a de menor frequência média desses alelos. Portanto, se $\mathrm{p}>\mathrm{r}$, o valor de $\sigma_{\mathrm{Al} 2}^{2}$ tende a ser maior que $\sigma_{\mathrm{A} 11}^{2}$, enquanto $\sigma_{\mathrm{A} 21}^{2}$ pode ser tanto maior quanto menor que $\sigma_{\mathrm{A} 22}^{2}$, dependendo das magnitudes de $\sigma_{\tau 21}^{2}$ e de $\operatorname{Cov}\left(\mathrm{A}_{2} \tau_{21}\right)$. Como na seleção interpopulacional a resposta esperada na população 1 per se fica em função de $\sigma_{\mathrm{A} 11}^{2}+2 \operatorname{Cov}\left(\mathrm{A}_{1} \tau_{12}\right)$, e na população 2 per se fica em função de $\sigma_{\mathrm{A} 22}^{2}+$ $2 \operatorname{Cov}\left(\mathrm{A}_{2} \tau_{21}\right)$, é possivel explicar, através desses parâmetros, porque uma das populações não tem mostrado ganhos significativos em resposta à seleção interpopulacional. O mesmo ocorre com a resposta do híbrido interpopulacional quando a seleção é intrapopulacional. Baseado nestes fatos, o autor sugeriu um método com uma abordagem interpopulacional para a população de maior média e intrapopulacional para a população de menor média, na expectativa de eliminar componentes negativos das expressões da resposta esperada para o híbrido interpopulacional e para as populações per se. As comparações teóricas mostraram que o método sugerido, denominado seleção com testecrosses (interpopulacional) e meios irmãos (intrapopulacional), foi mais eficiente que a seleção intrapopulacional com meios irmãos e tão eficiente quanto a seleção recíproca para melhorar a população 1; mais eficiente que a seleção recíproca e tão eficiente quanto a seleção intrapopulacional para melhorar a população 2 ; menos eficiente que a seleção recíproca e mais eficiente que a seleção intrapopulacional para aumentar a heterose; e mais eficiente que a seleção recíproca e a seleção intrapopulacional para o melhoramento de híbridos interpopulacionais. 


\subsection{Estimativas da variância genética aditiva e herdabilidade}

STUBER (1965) e STUBER \& COCKERHAM (1966)

definiram e caracterizaram os componentes de variância genética e a covariação entre parentes ao nível interpopulacional. Desde então, estimativas da variância genética aditiva interpopulacional indicaram que progressos significativos podem ser obtidos via seleção recorrente recíproca tanto em populações de outros países (STUBER \& COCKERHAM, 1966; OBILANA et al., 1979; MARTIN \& HALLAUER, 1980; HALLAUER, 1984), como em populações estudadas no Brasil (MIRANDA Fo. \& PATERNIANI, 1983; SOUZA JR. \& MIRAND A Fo, 1989; SOUZA JR. et al., 1993).

Em levantamento feito por RAMALHO (1977) para o caráter produção de grãos ao nível intrapopulacional, chegou-se a um valor médio para a variância aditiva de $320(\mathrm{~g} / \text { planta })^{2}$ com intervalo de variação de 41 a 758 , e uma herdabilidade média de $9,67 \%$ com intervalo de 2,09 a $28,45 \%$. GHINI \& MIRANDA Fo (1979) encontraram para altura de planta e espiga em suas revisões, valores médios da variância aditiva de 242 e 160 $(\mathrm{cm} / \text { planta })^{2}$ com intervalos de 125 a 338 e 109 a 252; e valores de herdabilidade de 58,29 e 65,98 (intervalos de variação de 44,81 a 76,80 e $51,90$ a 84,57$)$, respectivamente.

Atualmente, existe o interesse de se quantificar a magnitude das variâncias tanto ao nível intrapopulacional como também ao nível interpopulacional, e VENCOVSKY et al. (1988) apresentaram uma ampla revisão sobre o assunto. Os autores obtiveram os resultados de 58 avaliações utilizando progênies de meios irmãos intrapopulacionais no Brasil. A média 
geral para o caráter peso de espigas, considerando-se todas estas avaliações, foi de $120 \mathrm{~g} /$ planta; a estimativa média obtida para a variância aditiva intrapopulacional foi de $309(\mathrm{~g} / \mathrm{planta})^{2}$; a herdabilidade média foi de $11 \%$; a resposta média por ciclo de seleção foi de $11,7 \mathrm{~g} /$ planta $(9,75 \%)$; e o coeficiente de variação médio das avaliações foi de 16,3\%. Estimativas das variâncias aditivas ao nível interpopulacional $\left(\sigma_{\mathrm{A}_{12}}^{2}\right.$ e $\left.\sigma_{\mathrm{A}_{21}}^{2}\right)$ são definidas de acordo com a população de origem (populações parentais 1 e 2, respectivamente) e utilizada de forma similar para designar as variâncias intrapopulacionais $\left(\sigma_{\mathrm{A}_{11}}^{2}\right.$ e $\left.\sigma_{\mathrm{A}_{22}}^{2}\right)$. Algumas das estimativas intra e interpopulacionais obtidas nas populações de milho brasileiras estão resumidas na Tabela 1, e demonstram que existe variabilidade genética aditiva suficiente para a obtenção de novos progressos tanto ao nível intra como interpopulacional. Observa-se, que em todos os casos, a variância aditiva interpopulacional tendo a população 1 como parental feminino foi maior que a mesma variância obtida quando a população 2 foi o parental feminino. As diferenças entre estas variâncias $\left(\sigma_{\mathrm{A}_{12}}^{2}-\sigma_{\mathrm{A}_{21}}^{2}\right)$ foram relativamente altas em alguns casos (ESALQ PB1 x BR-105 e Piranão VD2 x Piranão VF]) e baixas em outros (ESALQ VD2 x ESALQ VF1 e BR-106 x BR-105). Comparando-se as estimativas das variâncias intra e interpopulacionais disponiveis, observase que para a população 1, a variância aditiva interpopulacional foi maior que a intrapopulacional, enquanto para a população 2 , estas estimativas apresentaram valores relativamente próximos, com vallores um pouco maiores para a variância aditiva intrapopulacional 
苂

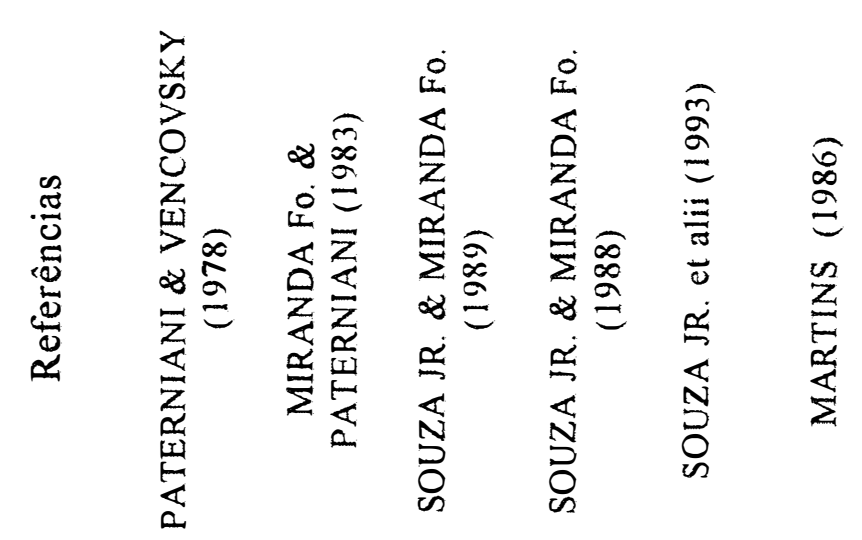

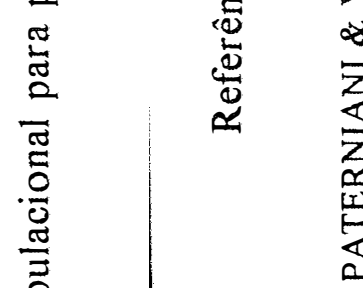

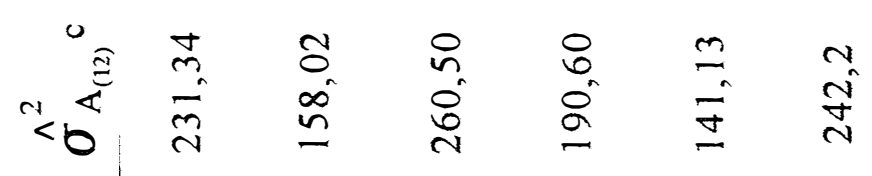

芒

$\frac{n}{2}$

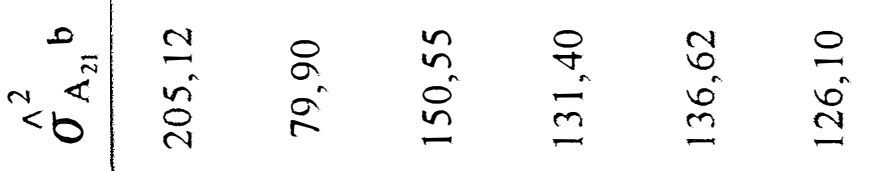

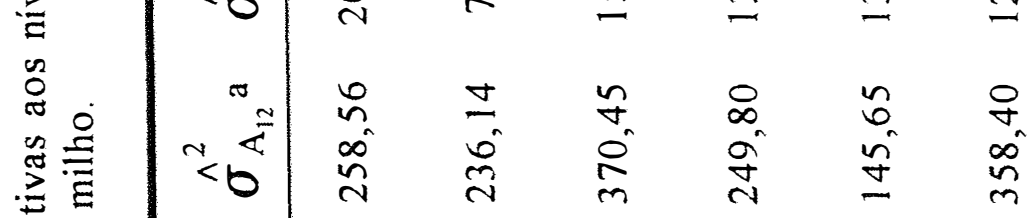

氜 。

జ

政

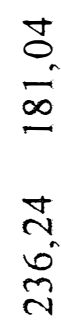

紫

芯

$0 \frac{\overline{2}}{00}$

क जo

壳告

E

네

$\frac{\pi}{\frac{\pi}{0}}$

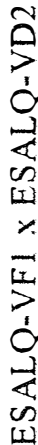

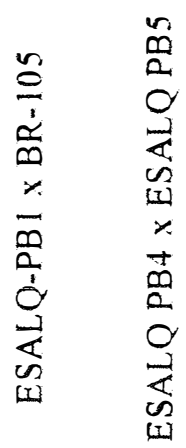

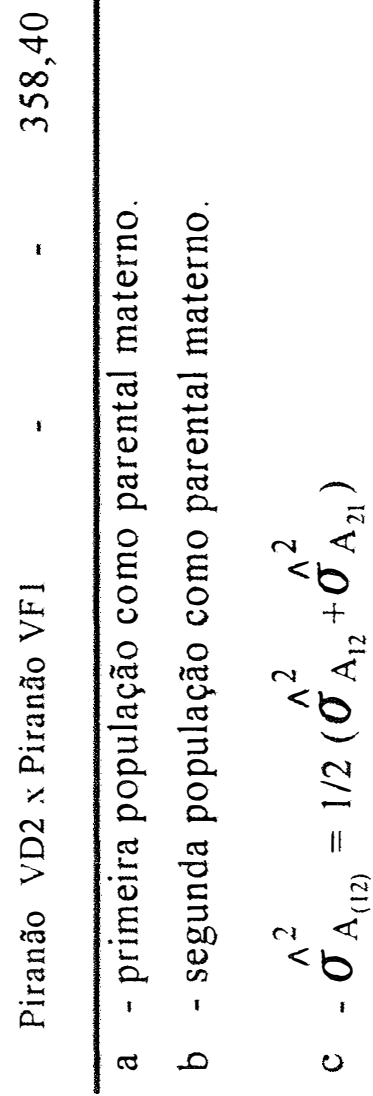




\section{MATERIAL E MÉTODOS}

\subsection{Material}

Foram utilizadas as populações de milho BR-106 e BR-105 (do Centro Nacional de Pesquisa de Milho e Sorgo - CNPMS / EMBRAPA), as quais serão denominadas de população 1 e 2 , respectivamente, e os seus cruzamentos: $1 \times 2$ (população 1 como parental feminino) e $2 \times 1$ (população 2 como parental feminino). Estas populações apresentam elevada capacidade geral de combinação (NASPOLINI Fo et al., 1981), o híbrido intervarietal é muito produtivo, apresentando heterose elevada tanto em relação à média das populações parentais quanto em relação à população superior. As populações estão descritas a seguir:

BR-106- a população BR-106 foi obtida pelo intercruzamento do composto formado de variedades tardias de porte alto (Centralmex, Compostos Dentados e Maya) com o BR-108 (Tuxpeño-1) de ciclo precoce e porte baixo. Após duas gerações de recombinação, seguiram-se três ciclos de seleção recorrente intrapopulacional para redução da altura da planta e espiga. Apresenta ciclo precoce, porte baixo, e grãos dentados de coloração amarela (SOUZA JR. et al., 1993). 
BR-105 - a população BR-105 originalmente foi denominada de Suwan-DMR, tendo sido obtida na Tailândia através de seleção entre progênies S1. Foi introduzida no Brasil em 1976, onde já foi submetida a cinco ciclos de seleção com progênies de irmãos germanos. Esta população possui porte baixo, ciclo precoce, grãos alaranjados duros, e baixa depressão por endogamia (SOUZA JR. et al., 1993).

\subsection{Métodos}

\subsubsection{Obtenção das progênies}

De cada população, 100 plantas tomadas de forma aleatória foram autofecundadas gerando progênies S1. A seguir, uma quantidade de sementes de cada progênie $S 1$, suficiente para o plantio de uma linha de quatro metros, foi utilizada para efetuar o cruzamento com a outra população em lote isolado de despendoamento, gerando as progênies de meios irmãos interpopulacionais; a mesma quantidade de sementes de cada progênie S1 foi utilizada em cruzamentos com a própria população em lote isolado de despendoamento, gerando progênies de meios irmãos intrapopulacionais. Desta forma, cada planta (100 de cada população), gerou uma progênie de meios irmãos intrapopulacional e uma progênie de meios irmãos interpopulacional, o que corresponde a dois tipos de progênies para cada genótipo de cada população. Foram obtidas, portanto, 200 progênies de cada população, totalizando 400 progênies. A utilização de progênies Sl para a 
obtenção das progênies de meios irmãos permitiu o aumento do número disponível de sementes e, portanto, uma melhor avaliação dos genótipos.

\subsubsection{Procedimentos experimentais}

Nos anos agrícolas de 1991/92 e 1992/93, e em dois locais da região de Piracicaba, denominados Areião e Caterpilar, as progênies de meios irmãos intra e interpopulacionais de cada população, foram instaladas em látices $10 \times 10$ parcialmente balanceados arranjados segundo um delineamento em faixas (STEEL \& TORRIE, 1960) com duas repetições. Este delineamento foi utilizado visando diminuir os efeitos da provável diferença de vigor existente entre as progênies interpopulacionais, que devem apresentar heterose alta, e as progênies intrapopulacionais. Desta forma, as progênies intra e interpopulacionais ficaram em faixas distintas. As subparcelas, com os tipos de progênies de cada genótipo, consistiram de uma linha de quatro metros com espaçamento de $20 \mathrm{~cm}$ entre plantas, totalizando 20 plantas. As parcelas contendo o genótipo, consistiram de duas linhas como essas, espaçadas em um metro entre si, ocupando área de $8 \mathrm{~m}^{2}$. Utilizou-se como bordadura o híbrido simples ICI8452 (Zêneca 8452), um material de boa aceitação no mercado. Este material foi semeado nas parcelas em bordadura no início e no final de cada bloco e ao redor de todo o experimento

As análises foram realizadas com médias de subparcelas para os caracteres relacionados a seguir: $\mathrm{PE}=$ peso das espigas despalhadas corrigido para o teor de umidade e para o estande inicial de 20 plantas na parcela pelo método da covariância (g/planta); AP = altura da planta medida 
nas cinco primeiras plantas competitivas dentro da parcela $(\mathrm{cm} / \mathrm{planta}) ; \mathrm{AE}=$ altura da espiga tomada como em AP ( $\mathrm{cm} /$ planta); r = AE/AP, relação entre altura da espiga sobre altura da planta; $\mathrm{CE}=$ comprimento de cinco espigas amostradas na parcela (cm/espiga); DE = diâmetro de cinco espigas amostradas na parcela (cm/espiga); $N F=$ número de fileiras de grãos por espiga contados em cinco espigas amostradas na parcela (fileiras/espiga); NGF = número de grãos por fileira na espiga contados em cinco espigas amostradas na parcela (grãos/fileira); e NE = índice de prolificidade, que é a relação entre o número de espigas total da parcela pelo estande da parcela (espigas/planta)

\subsubsection{Análises estatísticas}

Cada genótipo esteve representado na parcela enquanto o tipo de progênie (intra e interpopulacional) nas subparcelas. Foram feitas análises individuais para cada ambiente e, a seguir, as análises conjuntas envolvendo os quatro ambientes (dois anos e dois locais). Todas as análises foram realizadas com médias de parcelas. O modelo estatístico totalmente aleatório (com exceção da média) utilizado na análise conjunta, foi o seguinte:

$$
\begin{aligned}
\mathrm{y}_{\mathrm{ijkl}}= & \mu+\mathrm{a}_{\mathrm{i}}+\mathrm{r}_{\mathrm{j}(\mathrm{i})}+\mathrm{g}_{\mathrm{l}}+(\mathrm{ga})_{\mathrm{il}}+\varepsilon_{(\mathrm{a})}+\mathrm{t}_{\mathrm{k}}+(\mathrm{ta})_{\mathrm{ik}}+\varepsilon_{(\mathrm{b})}+ \\
& +(\mathrm{gt})_{\mathrm{kl}}+(\mathrm{gta})_{\mathrm{ikl}}+\varepsilon_{(\mathrm{c})}
\end{aligned}
$$


onde:

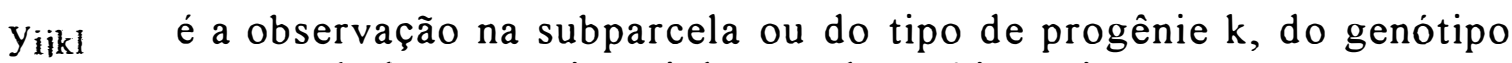
na parcela 1 na repetição $j$ dentro do ambiente $i$;

$\mu \quad$ é a média geral;

$a_{i} \quad$ é o efeito do ambiente i ( $i=1,2,3$ e 4$)$;

$r_{j(i)}$ é o efeito do bloco ou repetição $\mathrm{j}(\mathrm{j}=1,2)$, dentro do ambiente $\mathrm{i}$;

$\mathrm{g}_{1} \quad$ é o efeito do genótipo $1(1=1,2, \ldots, L)$;

$(\mathrm{ga})_{\mathrm{il}}$ é o efeito da interação entre o genótipo 1 e o ambiente i;

$\varepsilon_{(a)} \quad$ é o erro experimental ao nível de parcelas, onde $\varepsilon(a) \cap N\left(0, \sigma_{\mathrm{e}_{1}}^{2}\right)$;

$t_{k} \quad$ é o efeito do tipo de progênie $\mathrm{k}(\mathrm{k}=1,2)$;

(ta) $)_{i k}$ é o efeito da interação entre o tipo de progênie k e o ambiente i;

$\varepsilon(b) \quad$ é o erro experimental ao nível de subparcelas, onde $\varepsilon(b) \cap N\left(0, \sigma_{\mathrm{e}_{2}}^{2}\right)$;

$(\mathrm{gt})_{\mathrm{kl}}$ é o efeito da interação entre o genótipo 1 e o tipo de progênie $\mathrm{k}$;

(gta $)_{\text {ik }}$ é o efeito da interação entre o genótipo 1 com o tipo de progênie k e o 1 ambiente $\mathrm{i}$;

$\varepsilon(c) \quad$ é o erro experimental que aparece devido à não casualização das subparcelas dentro das parcelas, onde $\varepsilon(\mathrm{c}) \cap \mathrm{N}\left(0, \sigma_{\mathrm{e}_{3}}^{2}\right)$.

O esquema da análise de variância com os respectivos graus de liberdade, quadrados médios, e os testes F, segundo o modelo descrito estão representados na Tabela 2 . 


\subsubsection{Análise estatístico-genética}

As duas populações [BR-106 (1) e BR-105 (2)] geneticamente divergentes, foram utilizadas como base para estimar componentes genéticos relacionados ao processo de seleção recorrente. Os quatro tipos de progênies de meios irmãos foram reconhecidos pelos seus indices, da seguinte forma: indices 11 e 12, designando respectivamente as progênies intra e interpopulacionais da população 1; e indices 22 e 21, designando respectivamente as progênies intra e interpopulacionais da população 2 .

Com estas progênies intra e interpopulacionais foi possivel estimar os componentes de variância e covariância sugeridos por SOUZA JR. (1993), a partir dos esquemas de análise de variância e covariância descritos a seguir.

\subsubsection{Análise de variância e covariância}

Inicialmente foram feitas as análises individuais por ambiente para cada tipo de progênie e para cada população. Em seguida, para obter os quadrados médios de interesse, foram feitas as análises conjuntas considerando os dados dos quatro ambientes, para cada tipo de progênie de cada população separadamente, onde o modelo estatístico utilizado foi:

$$
\mathrm{y}_{\mathrm{ijm}}=\mu+\mathrm{a}_{\mathrm{i}}+\mathrm{r}_{\mathrm{j}(\mathrm{i})}+\mathrm{p}_{\mathrm{m}}+(\mathrm{pa})_{\mathrm{im}}+\mathrm{e}_{\mathrm{jm}(\mathrm{i})}, \quad \text { onde }
$$


Tabela 2 - Esquema da análise da variância envolvendo genótipos, ambientes e tipos de progênies obtidas de cada uma das populações em vários ambientes, seguindo uma estrutura em faixas.

\begin{tabular}{|c|c|c|c|}
\hline F.V. & GL & $\mathrm{QM}$ & F \\
\hline \multirow[b]{2}{*}{ Ambiente (A) } & \multirow[b]{2}{*}{ I-1 } & \multirow[b]{2}{*}{ Q1 } & $(\mathrm{Q} 1+\mathrm{Q} 5+\mathrm{Q} 8+\mathrm{Q} 10)$ \\
\hline & & & $(\mathrm{Q} 2+\mathrm{Q} 4+\mathrm{Q} 7+\mathrm{Q} 11)$ \\
\hline Rep/A & $\mathrm{I}(\mathrm{J}-1)$ & Q2 & $(\mathrm{Q} 2+\mathrm{Q} 11) /(\mathrm{Q} 5+\mathrm{Q} 8)$ \\
\hline Genótipo (G) & L-I & Q3 & $(\mathrm{Q} 3+\mathrm{Q} 10) /(\mathrm{Q} 4+\mathrm{Q} 9)$ \\
\hline $\mathrm{G} \times \mathrm{A}$ & $(\mathrm{I}-1)(\mathrm{L}-\mathrm{I})$ & Q4 & $(\mathrm{Q} 4+\mathrm{Q} 11) /(\mathrm{Q} 5+\mathrm{Q} 10)$ \\
\hline Resíduo (a) & $\mathrm{I}(\mathrm{J}-1)(\mathrm{L}-1)$ & Q5 & Q5/Q11 \\
\hline $\operatorname{Tipo}(\mathrm{T})^{+}$ & $\mathrm{K}-1$ & Q6 & $(\mathrm{Q} 6+\mathrm{Q} 10) /(\mathrm{Q} 7+\mathrm{Q} 9)$ \\
\hline $\mathrm{T} \times \mathrm{A}$ & $(1-1)(\mathrm{K}-1)$ & Q7 & $(\mathrm{Q} 7+\mathrm{Q} 11) /(\mathrm{Q} 8+\mathrm{Q} 10)$ \\
\hline Resíduo (b) & $\mathrm{I}(\mathrm{J}-1)(\mathrm{K}-1)$ & Q8 & Q8/Q11 \\
\hline $\mathrm{G} \times \mathrm{T}$ & $(\mathrm{K}-1)(\mathrm{L}-1)$ & Q9 & Q9/Q10 \\
\hline $\mathrm{G} \times \mathrm{T} \times \mathrm{A}$ & $(\mathrm{I}-1)(\mathrm{K}-1)(\mathrm{L}-1)$ & Q10 & Q10/Q11 \\
\hline Resíduo (c) & $\mathrm{I}(\mathrm{J}-1)(\mathrm{K}-1)(\mathrm{L}-1)$ & Q11 & $\ldots$ \\
\hline
\end{tabular}

+ Tipo de progênie obtida de cada genótipo de cada uma das populações: progênies de meios irmãos intra e interpopulacionais. 
$y_{\text {iim }}$ é a observação da progênie m no bloco j do ambiente i;

$\mu \quad$ é a média geral;

$\mathrm{a}_{\mathrm{i}} \quad$ é o efeito do ambiente i $(\mathrm{i}=1,2,3$ e 4$)$;

$r_{j}(i) \quad$ é o efeito do bloco ou repetição $j(j=1,2)$, dentro do ambiente $i$;

$\mathrm{p}_{\mathrm{m}} \quad$ é o efeito da progênie $\mathrm{m}(\mathrm{m}=1,2, \ldots, \mathrm{M})$.

$(\mathrm{pa})_{\mathrm{im}}$ é o efeito da interação entre a progênie $\mathrm{m}$ e o ambiente $\mathrm{i}$.

ejm(i) é o erro experimental associado à progênie $m$ no bloco $j$ dentro do ambiente i. Onde $e_{j m}(i) \cap N\left(0, \sigma_{e}^{2}\right)$.

O esquema da análise da variância com os graus de liberdade, e as esperanças matemáticas de interesse estão na Tabela 3. Seguindo a mesma estrutura de análise, também foram obtidos os produtos médios entre os tipos de progênies (11 com 12, e 22 com 21) para cada população. Para obtenção dos produtos médios foi seguida a metodologia sugerida por KEMPTHORNE (1966), e que também foi utilizada e detalhada por VENCOVSKY \& BARRIGA (1992), onde a análise é feita com a soma das duas variáveis definida como variável $\mathrm{z}(\mathrm{z}=\mathrm{x}+\mathrm{y})$, e então calculou-se para cada uma das fontes de covariação:

$$
\operatorname{PM}(\mathrm{x}, \mathrm{y})=1 / 2(\mathrm{QMz}-\mathrm{QMx}-\mathrm{QMy}) \text {, sendo que o esquema }
$$
da análise de covariância realizada entre tipos de progênies também se encontra na Tabela 3. Do quadro de análise de variância realizado para cada tipo de progênie de cada população, foi estimado $\sigma_{p_{x y}}^{2}$ cujos índices $\mathbf{x}$ e $\mathbf{y}$ dependem do tipo de progênie (intra ou interpopulacional) e da população ao qual se refere, onde $\sigma_{\mathrm{p}_{11}}^{2}$ e $\sigma_{\mathrm{p}_{22}}^{2}$ são as variâncias genéticas 
intrapopulacionais das progênies da população 1 e 2 , respectivamente, e $\sigma_{\mathrm{p}_{12}}^{2}$ e $\sigma_{\mathrm{p}_{21}}^{2}$ são as variâncias genéticas interpopulacionais das progênies obtidas pelo cruzamento entre populacões $1 \times 2$ e $2 \times 1$, respectivamente. De forma equivalente, os indices $\mathbf{x}$ e $\mathbf{y}$ têm a mesma função para a variância entre progênies e ambientes $\left(\sigma_{p_{x y}}^{2}\right)$ e para a variância do erro ao nível de médias de parcelas $\left(\sigma_{\mathrm{e}_{x y}}^{2}\right)$. Da mesma forma, a estimativa de $\operatorname{Cov}_{\mathrm{p}_{x} \mathrm{P}_{x y}}$ obtida da análise de covariância recebeu índices $\mathbf{x}$ e $\mathbf{y}$ de acordo com sua origem, de forma que $\operatorname{Cov}_{\mathrm{p}_{1} \mathrm{p}_{12}}$ e $\operatorname{Cov}_{\mathrm{p}_{2} \mathrm{p}_{21}}$ são as covariâncias genéticas entre progênies intra e interpopulacionais da população 1 e 2 , respectivamente. O mesmo tratamento foi dado aos parâmetros $\operatorname{Cov}_{e_{x x y}} c \operatorname{Covpa}_{\mathbf{x x y}}$, que são as covariâncias referentes ao resíduo e à interação entre progênies e ambientes, respectivamente.

\subsubsection{Estimativas dos componentes genéticos de variância e covariância}

Com estimativas dos componentes da análise de variância e covariância, também são estimáveis todas as variâncias e covariâncias de interesse, inclusive os novos componentes sugeridos por SOUZA JR. (1993). Por se tratar de progênies de meios irmãos intra e interpopulacionais obtidas a partir de plantas individuais de cada população, as estimativas dos parâmetros pertinentes são (SOUZA JR., 1993): 
Tabela 3 - Esquema das análises conjuntas de variância realizadas para cada tipo de progênie e de covariância entre tipos de progênies de cada população.

Análise de variância

\begin{tabular}{cccc}
\hline F.V. & G.L. & QM & E(QM) \\
\hline Ambiente [A] & $\mathrm{I}-1$ & $\mathrm{Q} 1$ & - \\
Rep/A & $\mathrm{I}(\mathrm{J}-1)$ & $\mathrm{Q} 2$ & - \\
Progênie [P] & $\mathrm{M}-1$ & $\mathrm{Q} 3$ & $\sigma_{\mathrm{e}_{\mathrm{xy}}^{2}}^{2}+\mathrm{J} \sigma_{\mathrm{pa}_{\mathrm{xy}}}^{2}+\mathrm{IJ} \sigma_{\mathrm{p}_{\mathrm{xy}}}^{2}$ \\
P x A & $(\mathrm{I}-1)(\mathrm{M}-1)$ & $\mathrm{Q} 4$ & $\sigma_{\mathrm{e}_{\mathrm{xy}}}^{2}+\mathrm{J} \sigma_{\mathrm{pa}}^{2}$ \\
Resíduo médio & -+ & $\mathrm{Q} 5$ & $\sigma_{\mathrm{e}_{\mathrm{xy}}}^{2}$ \\
\hline
\end{tabular}

Análise de covariância

\begin{tabular}{|c|c|c|c|}
\hline F.C. & GL & PM & $\mathrm{E}(\mathrm{PM})$ \\
\hline & & & - \\
\hline \multirow[t]{2}{*}{ Ambiente $[\mathrm{A}]$} & $\mathrm{I}-\mathrm{I}$ & $\mathrm{Pl}$ & \\
\hline & & & - \\
\hline $\operatorname{Rep} / A$ & $\mathrm{I}(\mathrm{J}-\mathrm{l})$ & P2 & \\
\hline Progênie $[\mathrm{P}]$ & M-1 & P3 & $\operatorname{Cov}_{\mathrm{exxy}_{x x}}+\mathrm{JCov}_{\mathrm{pa}} \mathrm{a}_{\mathrm{xxy}}+\mathrm{IJCov}_{\mathrm{p}_{x} \mathrm{P}_{x y}}$ \\
\hline $\mathrm{P} \times \mathrm{A}$ & $(\mathrm{I}-1)(\mathrm{M}-1)$ & P4 & $\operatorname{Cove}_{\mathrm{xxy}}+\mathrm{JCov}_{\mathrm{pa}} \mathrm{xxy}$ \\
\hline Residuo médio & -+ & P5 & $\operatorname{Cov}_{e_{x x y}}$ \\
\hline
\end{tabular}

+ $\mathrm{O}$ resíduo médio refere-se ao "pool" dos resíduos obtidos das análises individuais. 


$$
\begin{aligned}
& \hat{\sigma}_{\mathrm{A}_{11}^{2}}^{2}=4 \hat{\sigma} \stackrel{\mathrm{p}}{11}^{2} \quad \text { e } \quad \hat{\sigma}_{\mathrm{A}_{22}^{2}}^{2}=4 \hat{\sigma}_{\mathrm{p}_{22}^{2}}^{2} \\
& \hat{\sigma}_{\mathrm{A}_{12}}^{2}=4 \hat{\sigma}_{\mathrm{p}_{12}}^{2} \quad \text { e } \quad \hat{\sigma}_{\mathrm{A}_{21}}^{2}=4 \hat{\sigma}_{\mathrm{p}_{21}^{2}}^{2} \\
& \hat{\sigma}_{\tau_{12}^{2}}^{2}=4\left[\hat{\sigma}_{p_{12}^{2}}^{2}-2 \operatorname{Cov}_{(p 1 p 12)}+\hat{\sigma}_{p_{11}^{2}}^{2}\right] \\
& \hat{\sigma}_{\tau_{21}^{2}}^{2}=4\left[\hat{\sigma}_{\mathrm{p}_{21}^{2}}^{2}-2 \operatorname{Cov}_{(\mathrm{p} 2 \mathrm{p} 21)}+\hat{\sigma}_{\mathrm{p}_{22}^{2}}^{2}\right] \text {; } \\
& \operatorname{Cov}_{\left(A 1 \tau_{12}\right)}^{\wedge}=2\left[\begin{array}{cc}
\wedge & \wedge \\
\left.\operatorname{Cov}_{\left(p_{1 p 12}\right)}-\hat{\sigma}_{p_{11}}^{2}\right]
\end{array}\right. \\
& \operatorname{Cov}_{\left(\mathrm{A} 2 \tau_{21}\right)}=2\left[\begin{array}{c}
\wedge \\
\left.\operatorname{Cov}_{(\mathrm{p} 2 \mathrm{p} 21)}-\hat{\sigma}_{\mathrm{p}_{22}}^{2}\right] ;
\end{array}\right.
\end{aligned}
$$

onde:

$$
\begin{aligned}
\sigma_{\mathrm{A} 11}^{2} \mathrm{e} \sigma_{\mathrm{A} 22}^{2} & \text { são as variâncias genéticas aditivas } \\
& \text { intrapopulacionais das populações BR-106 e } \\
& \text { BR-105, respectivamente; }
\end{aligned}
$$

$$
\begin{aligned}
\sigma_{\mathrm{A} 12}^{2} \text { e } \sigma_{\mathrm{A} 21}^{2} & \text { são as variâncias genéticas aditivas } \\
& \text { interpopulacionais das populações BR-106 e } \\
& \text { BR-105, respectivamente, em cruzamentos } \\
& \text { reciprocos; }
\end{aligned}
$$$$
\sigma_{\tau 12}^{2} \text { e } \sigma_{\tau 21}^{2}
$$

são as variâncias genéticas dos desvios dos efeitos aditivos inter por intrapopulacionais das populações BR-106 e BR-105, respectivamente, em cruzamentos recíprocos. 
$\operatorname{Cov}_{\left(\mathrm{A}_{1} \tau_{12}\right)}$ e $\operatorname{Cov}_{\left(\mathrm{A} 2 \tau_{21)}\right.}$ são as covariâncias genéticas dos efeitos aditivos intrapopulacionais com os desvios dos efeitos aditivos inter por intrapopulacionais para BR-106 e BR-105, respectivamente.

As estimativas destes parâmetros e dos erros associados a eles, foram obtidos utilizando-se o processo proposto por MATHER \& JINKS (1982). Os quadrados e produtos médios foram igualados diretamente aos parâmetros como no exemplo apresentado na Tabela 4. Matricialmente, teremos:

$$
\mathbf{Y}=\mathbf{X} \boldsymbol{\theta}, \text { onde: }
$$

Y é a matriz com os quadrados e produtos médios observados.
$\mathbf{X}$ é a matriz com os coeficientes, que neste caso tem inversa única.

$\theta$ é a matriz com os parâmetros a serem estimados.

Ao sistema de equações normais foi introduzida uma matriz de pesos (V). O caso geral para a construção da matriz $\mathbf{V}$ e que foi utilizado neste trabalho pode ser observado no Apêndice 1 . 
Desta forma, a solução $\hat{\theta}$ foi obtida da seguinte forma:

$$
\hat{\theta}=\left(X^{\prime} V^{-1} \mathbf{X}\right)^{-1} X^{\prime} V^{-1} Y
$$

Os erros relacionados a cada estimativa foram obtidos a partir da diagonal da matriz $\left(\mathbf{X}^{\prime} \mathbf{V}^{-1} \mathbf{X}\right)^{-1}$. A construção da matriz $\mathbf{V}$ segundo o esquema mostrado no Apêndice 1 foi mais adequado já que um dos parâmetros a serem estimados é uma covariância de dois outros parâmetros presentes na matriz $\mathbf{Y}$ de observações. Neste caso, se for utilizada uma matriz $\mathbf{V}$ de pesos diagonal, cada valor observado presente em $\mathbf{Y}$ seria considerado independente, e os erros referentes à cada estimativa seriam calculados sem considerar qualquer correlação entre eles. A utilização da matriz $\mathbf{V}$ tal como aparece no Apêndice 1, faz com que mais informações sejam consideradas para o cálculo desses erros, melhorando a precisão de algumas estimativas. Em geral, o erros relacionados às estimativas de parâmetros quadráticos são altos, tornando dificil obter boas estimativas. Este problema é agravado quando um parâmetro é decomposto em outros derivados, como foi o caso dos parâmetros estimados neste trabalho, já que a variância aditiva interpopulacional foi decomposta em variância aditiva intrapopulacional e mais dois componentes genéticos, um de variância e outro de covariância. Desta forma, qualquer esforço no sentido de diminuir os erros relacionados às estimativas é importante, justificando o processo matricial. 
Tabela 4 - Matriz com os coeficientes que relacionam os quadrados e produtos médios (Y) aos componentes a serem estimados.

\begin{tabular}{|c|c|c|c|c|c|c|c|}
\hline \multirow[b]{2}{*}{$\mathbf{Y}$} & \multicolumn{7}{|c|}{ Índices dos componentes a } \\
\hline & & $\mathrm{e}_{\mathrm{ii}}$ & $\mathrm{e}_{\mathrm{ij}}$ & $\mathrm{e}_{\mathrm{iij}}$ & $\mathrm{A}_{\mathrm{ii}}$ & $\tau_{\mathrm{ij}}$ & $\mathrm{A}_{\mathrm{i}} \tau_{\mathrm{ij}}$ \\
\hline $\mathrm{QMp}_{\mathrm{ii}}$ & & 1 & 0 & 0 & 2 & 0 & 0 \\
\hline $\mathrm{QM}_{\mathrm{pij}}$ & & 0 & 1 & 0 & 2 & 2 & 8 \\
\hline $\mathrm{PM}_{\mathrm{Pi}} \mathrm{p}_{\mathrm{ij}}$ & & 0 & 0 & 1 & 2 & 0 & 4 \\
\hline $\mathrm{QM}_{\mathrm{e}_{\mathrm{ii}}}$ & 1 & 1 & 0 & 0 & 0 & 0 & 0 \\
\hline $\mathrm{QMe}_{\mathrm{ij}}$ & & 0 & 1 & 0 & 0 & 0 & 0 \\
\hline $\mathrm{PM}_{\mathrm{e}_{\mathrm{i}} \mathrm{e}_{\mathrm{ij}}}$ & & 0 & 0 & 1 & 0 & 0 & 0 \\
\hline
\end{tabular}

a. $e_{i i}, e_{i j} e$ e eij relativos aos erros intra, inter $e$ da covariância intra $x$ interpopulacional, e $\mathrm{A}_{\mathrm{ii}}, \quad \boldsymbol{\tau}_{\mathrm{ij}}, \mathrm{e} \quad \mathrm{A}_{\mathrm{i}} \boldsymbol{\tau}_{\mathrm{ij}}$, relativos à variância aditiva intrapopulacional, ao desvio intra $\mathrm{x}$ interpopulacional e à covariância entre eles, respectivamente. Não estão representadas as linhas e colunas correspondentes às interações dos efeitos genéticos com ambientes. 
Além dos parâmetros anteriores, também foram estimados $\operatorname{Cov}_{\left(\mathrm{AlA}_{1}\right)}$ e $\operatorname{Cov}_{\left(\mathrm{A} Z 2 A_{1}\right)}$ que correspondem às covariâncias genéticas aditivas entre tipos de progênies intra por interpopulacionais da população 1 e 2 respectivamente, que foram estimados por:

$$
\begin{aligned}
& \hat{\operatorname{Cov}}_{(\mathrm{A} 1 \mathrm{~A} 2)}=4 \operatorname{Cov}_{(\mathrm{plp} 12)} ; \\
& \hat{\operatorname{Oov}}_{(\mathrm{A} 2 \mathrm{~A} 1)}=4 \operatorname{Cov}_{(\mathrm{p} 2 \mathrm{p} 21)}
\end{aligned}
$$

Para auxiliar nas comparações entre métodos intra, interpopulacionais, e outros métodos mistos, foram estimados os seguintes parâmetros:

$$
\sigma_{\mathrm{A}_{(12)}}^{2}=\left(\sigma_{\mathrm{A}_{12}}^{2}+\sigma_{\mathrm{A}_{21}}^{2}\right) / 2 ; \text { que é a variância aditiva do híbrido }
$$
interpopulacional;

$$
\bar{\sigma}_{\mathrm{A}}^{2}=\left(\sigma_{\mathrm{A}_{11}}^{2}+\sigma_{\mathrm{A}_{22}}^{2}\right) / 2 \text {, que é a média das variâncias aditivas }
$$
intrapopulacionais ;

$$
\operatorname{CovaA}_{12)}=\left(\operatorname{Cov}_{(\mathrm{A} \mid \mathrm{A} 2)}+\operatorname{Cov}_{(\mathrm{A} 2 \mathrm{~A} 1)}\right) / 2 \text {, que é a média das }
$$
covariâncias entre progênies intra por interpopulacionais.

E a partir destes, calculou-se:

$\mathrm{R}=\sigma_{\mathrm{A}(12)}^{2} / \bar{\sigma}_{\mathrm{A}}^{2}$, que é a relação entre as médias das variâncias aditivas inter pelas intrapopulacionais; 


$$
\phi 1=\sigma_{\mathrm{A}(12)}^{2} / \operatorname{Cov}_{\mathrm{AA}(12)} \text {, que mede o potencial das populações para o }
$$

melhoramento e expressão da heterose via seleção recorrente recíproca (SOUZA JR. \& MIRANDA Fo, 1989); e

$$
\phi 2=\operatorname{Cov}_{\mathrm{AA}(12)} / \bar{\sigma}_{\mathrm{A}}^{2} \text {, que mede o potencial das populações para o }
$$
melhoramento e expressão da heterose via seleção recorrente intrapopulacional.

\subsubsection{Respostas esperadas à seleção}

Foram calculadas as estimativas dos progressos esperados para quatro modalidades de seleção: a seleção recorrente recíproca (SRR), onde uma população serve como testadora da outra; a seleção intrapopulacional (SRI), onde as progênies avaliadas são oriundas da própria população; e finalmente a seleção com testadores intra e interpopulacionais onde uma das populações serve como testadora das duas, denominada seleção recorrente modificada, sendo SRM(a) quando a testadora foi a população BR105, que apresentou a menor média, e $\operatorname{SRM(b)~quando~a~testadora~foi~a~}$ população BR-106.

As respostas à seleção foram estimadas no híbrido populacional, nas populações per se e na heterose. As expressões utilizadas para tanto estão nas Tabelas 5 e 6 . Consideraram-se progênies SI como unidade de recombinação para os diferentes esquemas, permitindo uma 
comparação entre eles. O diferencial de seleção estandardizado utilizado nos cálculos das respostas esperadas para os diferentes métodos, foi equivalente à seleção de $20 \%$ da população. As variâncias fenotípicas ao nível de médias de parcelas intra e interpopulacionais, obtidas de $\mathrm{I}=4$ ambientes (dois locais e dois anos), com $\mathrm{J}=2$ repetições por local e por ano, e com $\mathrm{K}=20$ plantas dentro das subparcelas, são genericamente representadas por:

$$
\sigma_{\overrightarrow{\mathrm{F}}}^{2}=\sigma_{\mathrm{p}}^{2}+\frac{\sigma_{\mathrm{pa}}^{2}}{\mathrm{I}}+\frac{\sigma_{\mathrm{e}}^{2}}{\mathrm{IJ}}+\frac{\sigma_{\mathrm{d}}^{2}}{\mathrm{IJK}}
$$

Com exceção de PE e NE, foram estimadas as variâncias dentro das parcelas (a partir de cinco plantas tomadas aleatoriamente), permitindo calcular os progressos esperados via seleção massal nos dois sexos através das expressões constantes na Tabela 6. Estes servirão apenas como informação adicional, já que o esquema de seleção massal não será comparado aos demais. 
Tabela 5 - Progresso genético esperado por ciclo de Seleção Recorrente Recíproca e Seleção Recorrente Intrapopulacional, utilizando progênies de meios irmãos e progênies S1 como unidade de seleção e recombinação, respectivamente, (SOUZA JR., 1993).

\section{Esquema de Seleção ${ }^{\text {a }}$}

Resposta sobre Seleção Recorrente Interpopulacional (SRR)

Híbrido Interpopulacional $\frac{i_{1}}{4 \sigma_{\bar{F}_{12}}}\left[\sigma_{\mathrm{A} 11}^{2}+\sigma_{\tau 12}^{2}+4 \operatorname{Cov(\mathrm {A}_{1}\tau _{12})}\right]+\frac{i_{2}}{4 \sigma_{\overline{\mathrm{F}}_{21}}}\left[\sigma_{\mathrm{A} 22}^{2}+\sigma_{\tau 21}^{2}+4 \operatorname{Cov(\mathrm {A}2\tau _{21})}\right]$

População 1

$$
\frac{i_{1}}{2 \sigma_{\overline{\mathrm{F}} 12}}\left[\sigma_{\mathrm{A} 11}^{2}+2 \operatorname{Cov}\left(\mathrm{A} 1 \tau_{12}\right)\right]
$$

População 2

$$
\frac{\mathrm{i}_{2}}{2 \sigma_{\overline{\mathrm{F}} 21}}\left[\sigma_{\mathrm{A} 22}^{2}+2 \operatorname{Cov}(\mathrm{A} 2 \tau 21)\right]
$$

Heterose

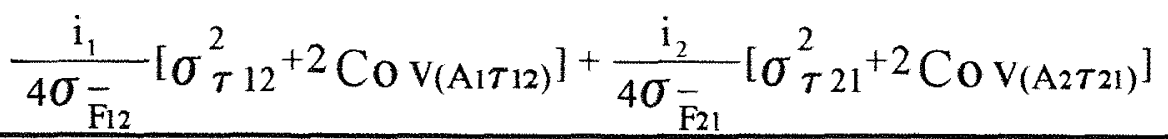

Resposta sobre

$$
\text { Seleção Recorrente Intrapopulacional (SRI) }
$$

Hibrido

Interpopulacional

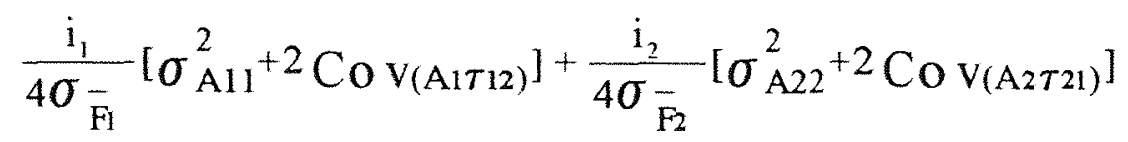

População 1

$$
\frac{i_{1}}{2 \sigma_{\bar{F} 1}}\left(\sigma_{\mathrm{A} 11}^{2}\right)
$$

População 2

$$
\frac{\mathrm{i}_{2}}{2 \sigma_{\overline{\mathrm{F}} 2}}\left(\sigma_{\mathrm{A} 22}^{2}\right)
$$

Heterose

$$
\frac{i_{1}}{2 \sigma_{-}}\left[\operatorname{Cov}\left(\mathrm{A}_{1} \tau 12\right)\right]+\frac{i_{2}}{2 \sigma_{F_{2}}}\left[\operatorname{Cov}\left(\mathrm{A}_{2} \tau 21\right)\right]
$$

a $\mathrm{i}$ e $\sigma_{F}$ referem-se ao diferencial de seleção estandardizado (os índices 1 e 2 referem-se às populações 1 e 2 , respectivamente) e ao desvio padrão fenotípico ao nível de médias de subparcelas, respectivamente. 
Tabela 6 - Progresso genético esperado por ciclo de Seleção Recorrente Modificada [SRM(a) e (b)], utilizando progênies de meios irmãos e S1's como unidades de seleção e recombinação, respectivamente e Seleção Massal sobre os dois sexos (SM).

Esquema de Seleção a

Resposta sobre Seleção Recorrente Modificada [SRM(a) $]^{\mathrm{b}}$

Híbrido Interpopulacional

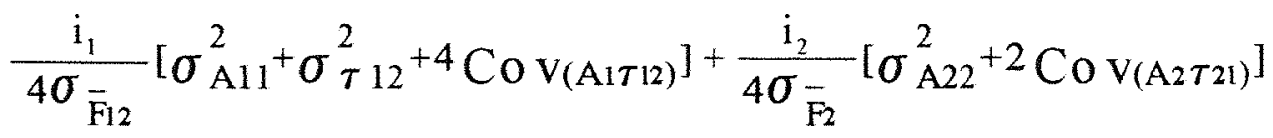

População 1 $\frac{\mathrm{i}_{1}}{2 \sigma_{\overline{\mathrm{F}} 12}}\left[\sigma_{\mathrm{A} 11}^{2}+2 \operatorname{Cov}(\mathrm{A} 1 \tau 12)\right]$

População 2

$$
\frac{\mathrm{i}_{2}}{2 \sigma_{\overline{F_{2}}}}\left(\sigma_{\mathrm{A} 22}^{2}\right)
$$

Heterose

$$
\frac{\mathrm{i}_{1}}{4 \sigma_{\overline{\mathrm{F}} 12}}\left[\sigma_{\tau 12}^{2}+2 \operatorname{Cov}\left(\mathrm{A} 1 \tau_{12}\right)\right]+\frac{\mathrm{i}_{2}}{2 \sigma_{\overline{\mathrm{F}} 2}}\left[\operatorname{Cov}\left(\mathrm{A}_{2} \tau_{21)}\right]\right.
$$

Resposta sobre

Seleção Massal (SM)

Híbrido

Interpopulacional

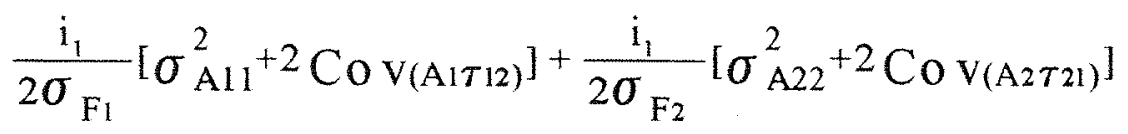

População 1

$$
\frac{\mathrm{i}_{1}}{\sigma_{\mathrm{F} 1}}\left(\sigma_{\mathrm{A} 11}^{2}\right)
$$

População 2

$$
\frac{\mathrm{i}_{1}}{\sigma_{\mathrm{F} 2}}\left(\sigma_{\mathrm{A} 22}^{2}\right)
$$

Heterose

$$
\frac{i_{1}}{\sigma_{F 1}}\left[\operatorname{Cov}\left(\mathrm{A}_{1} \tau 12\right)\right]+\frac{i_{1}}{\sigma_{F 2}}\left[\operatorname{Cov}\left(\mathrm{A}_{2} \tau 21\right)\right]
$$

a i, $\sigma_{\mathrm{F}}$ e $\sigma_{\mathrm{F}}$ referem-se ao diferencial de seleção (os índices 1 e 2 referem-se às populações 1 e 2 , respectivamente), ao desvio padrão ao nível de médias de subparcelas e ao nível de plantas, respectivamente.

b as respostas esperadas para o método SRM(b) são obtidas de forma similar a SRM(a), considerando-se a população 1 como testadora. 


\section{RESULTADOS}

\subsection{Comportamento geral das populações e do híbrido interpopulacional}

Os valores médios de todos os caracteres avaliados, incluindo as médias das duas populações base (BR-106 e BR-105), dos cruzamentos entre elas [1×2 (a) e $2 \times 1$ (b), tendo BR-106 e BR-105 como parental materno, respectivamente], a média dos híbridos interpopulacionais $[(a+b) / 2]$ e as heteroses em relação à média dos pais $(\mathrm{hmp})$ e em relação ao pai superior (hps) estão na Tabela 7. As condições ambientais dos ensaios foram consideradas normais e sem problemas que pudessem interferir de forma importante nos resultados.

Nas parcelas em bordadura o híbrido simples ICI8452 utilizado como testemunha, apresentou média para peso de espiga (PE) de $8,32 \mathrm{t} / \mathrm{ha}$; para a altura da planta e da espiga obteve-se 198,40 e 101,18 $\mathrm{cm} /$ planta, respectivamente; e para a relação entre altura da espiga pela altura da planta (r) obteve-se um valor médio de 0,51.

Para o caráter peso das espigas despalhadas (PE), os valores médios foram 148,$09 ; 136,7]$ e 151,63 (g/planta) que equivalem a uma 
produtividade de 7,$40 ; 6,84$ e 7,58 (t/ha), para as populações $\mathrm{BR}-106$, BR-105 e para a média do híbrido interpopulacional, respectivamente. Para o caráter altura da planta (AP), os valores médios foram 193,62;200,37 e 199,08 (cm/planta); para altura da espiga (AE) 100,56; 101,37 e 101,84 (cm/planta) e para $\mathbf{r}=\mathrm{AE} / \mathrm{AP} 0,52 ; 0,51$ e 0,51 para as populações BR-106, BR-105 e hibrido interpopulacional, respectivamente.

Quanto aos caracteres relacionados à espiga os valores médios foram: comprimento da espiga (CE) 15,18;15,77 e 15,55 (cm/espiga); diâmetro médio da espiga (DE) 4,73; 4,46 e 4,70 (cm/espiga); número médio de fileiras de grãos por espiga (NF) 13,65; 14,45 e 13,99 (fileiras/espiga); número médio de grãos por fileira na espiga (NGF) 34,$71 ; 33,55$ e 35,01 (grãos/fileira/espiga); e prolificidade (NE) 0,99; 0,99 e 1,00 (espigas/planta), para as populações BR-106, BR-105 e para o híbrido interpopulacional, respectivamente.

$\mathrm{O}$ valores da heterose em relação à média das populações foram de $9,23 \mathrm{~g} /$ planta $(6,48 \%) ; 2,09(1,06 \%)$ e $0,88 \mathrm{~cm} /$ planta $(0,87 \%)$ e $-0,0009(-0,18 \%)$; em relação ao pai superior foram de $3,54 \mathrm{~g} /$ planta $(2,39 \%) ;-1,29(-0,64 \%)$ e $0,47 \mathrm{~cm} /$ planta $(0,46 \%)$ e $-0,0071(-1,37 \%)$ para os caracteres PE, AP, AE e r, respectivamente. Para os caracteres da espiga, os valores de heterose em relação à média das populações e população superior foram de $0,072(0,46 \%)$ e $-0,224(-1,42 \%) \mathrm{cm} /$ espiga para CE; $0,1078(2,34 \%)$ e $-0,026(-0,55 \%) \mathrm{cm} /$ espiga para $\mathrm{DE} ;-0,067(-0,48 \%)$ e $-0,468(-3,23 \%)$ fileiras por espiga (NF); $0,885(2,59 \%)$ e $0,306(0,88 \%)$ sementes por fileira na espiga (NGF) e $0,0045(0,45 \%)$ e $0,0022(0,22 \%)$ espigas por planta para prolificidade (NE). 
A média do híbrido interpopulacional que tem BR-105 como parental materno $(2 \times 1)$ foi superior ao outro $(1 \times 2)$ principalmente para peso de espigas (PE), altura de planta (AP), comprimento da espiga (CE) e fileiras por espiga (NF), enquanto o inverso ocorreu para r. Para os demais caracteres a diferença entre os híbridos interpopulacionais foi relativamente pequena.

\subsection{Análises de variância}

Detectaram-se significâncias $(\mathrm{P}<0,05)$ para todos os caracteres com exceção de $\mathbf{r}$, NF, e NE para ambientes; todos os caracteres para genótipos; apenas em NE para a interação genótipo por ambiente (GxA); nenhum caráter para tipo; PE, CE, NF e NGF para a interação entre tipo e ambiente (TxA); nenhum caráter para a interação genótipo e tipo (GxT); e todos os caracteres com exceção de AP, $r$ e NE para a interação tripla (GxTxA), para a população BR-106 (Tabelas 8 e 9).

Para a população BR-105 (Tabelas 10 e 11), detectaram-se significâncias $(P<0,05)$ para todos os caracteres com exceção de AP, NF, e NGF para ambientes; todos os caracteres para genótipos; nenhum caráter para a interação genótipo por ambiente (GxA); PE, DE e NGF para tipo; PE e CE para a interação entre tipo por ambiente (TxA); todos os caracteres com exceção de NE para a interação genótipo por tipo (GxT); e $r$ para a interação tripla $(G \times T x A)$. 


\subsection{Análise de variância e covariância das progênies intra e interpopulacionais}

Detectaram-se significâncias $(\mathrm{P}<0,05)$ para todos os caracteres ao nível interpopulacional (12), e para PE, AP, AE, CE e NGF ao nivel intrapopulacional (11) para ambiente; todos os caracteres tanto ao nível intra como interpopulacional para progênie; $C E$, NF e NGF ao nível intrapopulacional e para todos os caracteres com exceção de AP, DE e NF ao nível interpopulacional para a interação progênie por ambiente para a população BR-106 (Tabelas 12 e 13).

Para a população BR-105 (Tabelas 14 e 15 ) houve significância $(\mathrm{P}<0,05)$ para todos os caracteres ao nivel intrapopulacional (22) com exceção de NF e NGF, e ao nível interpopulacionais (21) com exceção de AP e NF para ambiente; todos os caracteres ao nivel intra e interpopulacional para progênie; e para o caráter $\mathbf{r}$. ao nivel interpopulacional para a interação progênie por ambiente $(\mathrm{PxA})$.

Os coeficientes de variação obtidos para peso de espigas (PE) nas análises intra e interpopulacional foram respectivamente de $14,79 \%$ e $14,01 \%$ para a população BR-106 (Tabela 12), e de $14,24 \%$ e $14,10 \%$ para BR-105 (Tabela 14), que são valores razoáveis pelo tipo de experimento. Os demais caracteres também apresentaram coeficientes de variação aceitáveis, sem ocorrência de nenhum valor discrepante para um mesmo caráter (Tabelas 12 a 15). É interessante ressaltar que os caracteres CE e DE apresentaram coeficientes de variação menores em relação a NGF e NF, respectivamente, nas duas populações. 


\subsection{Estimativas dos componentes genéticos de variância e covariância.}

As estimativas das variâncias e covariâncias genéticas relacionadas ao processo de seleção recorrente intra e interpopulacionais estão nas Tabelas 16 a 22 . As variâncias genéticas entre progênies intra e interpopulacionais e das covariâncias entre elas, e também suas interações com ambientes para as duas populações estão resumidas nas Tabelas 16 e 17; as variâncias genéticas aditivas ao nível intra e interpopulacional, das covariâncias entre elas, das variâncias genéticas dos desvios dos efeitos aditivos intra por interpopulacionais e das covariâncias dos efeitos aditivos com seus desvios intra e interpopulacionais, dos caracteres estudados para as populações BR-106 e BR-105 estão nas Tabelas 18 e 19, respectivamente.

As variâncias genéticas aditivas intra e interpopulacionais estimadas para a população BR-106 (Tabela 18) foram de 376,09 e 281,39 $(\text { g/planta })^{2}$ para PE; 109,31 e 92,27 (cm/planta $)^{2}$ para AP; 74,04 e 48,83 $(\mathrm{cm} / \text { planta })^{2}$ para $\mathrm{AE} ; 7,84 \times 10^{-4}$ e $4,47 \times 10^{-4}$ para $\mathbf{r} ; 0,94$ e 1,02 $(\mathrm{cm} / \text { espiga })^{2}$ para CE; 0,06 e $0,05(\mathrm{~cm} / \text { espiga })^{2}$ para $\mathrm{DE} ; 1,41$ e 1,40 (fileiras/espiga) $^{2}$ para NF; 5,09 e 3,87 (grãos/fileira/espiga) ${ }^{2}$ para NGF; e $44 \times 10^{-4}$ e $49 \times 10^{-4}$ (espigas/planta) ${ }^{2}$ para NE, respectivamente.

Para a população BR-105 (Tabela 19), as variâncias genéticas aditivas ao nivel intra e interpopulacional, foram respectivamente: 442,31 e 522,34 (g/planta) ${ }^{2}$ para PE; 185,74 e 171,32 (cm/planta) ${ }^{2}$ para AP; 127,45 e $109,58(\mathrm{~cm} / \text { planta })^{2}$ para AE; $8,24 \times 10^{-4}$ e $8,95 \times 10^{-4}$ para $\mathbf{r} ; 1,31$ e 1,16 $(\mathrm{cm} / \text { espiga })^{2}$ para $\mathrm{CE} ; 0,08$ e $0,09(\mathrm{~cm} / \text { espiga })^{2}$ para $\mathrm{DE} ; 1,75$ e 1,77 
(fileiras/espiga) $^{2}$ para NF; 7,15 e 7,26 (sementes/fileira/espiga) ${ }^{2}$ para NGF; e $152 \times 10^{-4}$ e $56 \times 10^{-4}$ (espigas/planta) $)^{2}$ para NE.

Para a população BR-106, pode-se verificar que as estimativas das variâncias aditivas intrapopulacionais foram 33,7\%, 18,5\%, 51,6\%, $75,4 \%, 23,0 \%, 0,8 \%$, e $31,7 \%$ superiores às interpopulacionais para $\mathrm{PE}, \mathrm{AP}$, $\mathrm{AE}, \mathbf{r}, \mathrm{DE}, \mathrm{NF}$ e NGF, respectivamente, e $7,7 \%$ e $11,4 \%$ inferiores às interpopulacionais para CE e NE, respectivamente. Para a população BR-105, foram $8,4 \%, 16,3 \%, 12,3 \%$ e $173,9 \%$ superiores às interpopulacionais para $\mathrm{AP}, \mathrm{AE}, \mathrm{CE}$ e $\mathrm{NE}$; e $15,3 \%, 7,9 \%, 10,2 \%, 1,4 \%$ e $1,5 \%$ inferiores às interpopulacionais para PE, $\mathbf{r}, \mathrm{DE}, \mathrm{NF}$ e NGF, respectivamente.

As variâncias dos desvios dos efeitos aditivos intra e interpopulacionais $\left(\begin{array}{ll}\hat{\sigma}_{\tau_{12}}^{2}\end{array}\right)$ obtidos para a população BR-106 (Tabela 18) apresentaram erros muito altos quando comparados aos demais, com exceção do caráter CE e principalmente para NGF que tiveram valores negativos não esperados teoricamente indicando algum problema no método de estimação ou na própria amostragem. Para a população BR-105 (Tabela 19), os erros relacionados a essas estimativas para todos os caracteres foram pequenos em relação aos demais, com exceção de NE. Os valores obtidos para $\hat{\sigma}_{\tau_{21}}^{2}$ foram 433,67 (g/planta $)^{2}$ para PE; 164,24 e $110,37(\mathrm{~cm} / \text { planta })^{2}$ para AP e AE; $7,66 \times 10^{-4}$ para $\mathbf{r} ; 0,77$ e $0,06(\mathrm{~cm} / \text { espiga })^{2}$ para $\mathrm{CE}$ e $\mathrm{DE} ; 1,21$

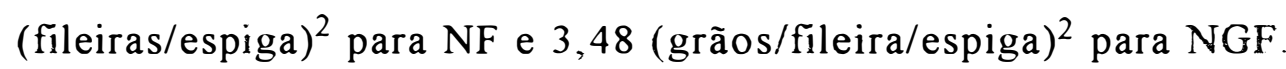

As covariâncias entre os efeitos aditivos e de seus desvios intra e interpopulacionais $\hat{C o v}_{(A 1} \mathcal{T}_{12}$, também apresentaram erros com 
magnitudes elevadas para todos os caracteres da população BR-106 e para NGF da população BR-105. Para esta última, os valores foram todos negativos, de $-88,41(\mathrm{~g} / \text { planta })^{2}$ para $\mathrm{PE} ;-44,67$ e $-32,06(\mathrm{~cm} / \text { planta })^{2}$ para $\mathrm{AP}$ e $\mathrm{AE} ;-1,74 \times 10^{-4}$ para $\mathbf{r} ;-0,23$ e $-0,01(\mathrm{~cm} / \text { espiga })^{2}$ para $\mathrm{CE}$ e $\mathrm{DE} ;-0,30$ (fileiras/espiga) $^{2}$ para NF e -0,004 (espigas/planta) ${ }^{2}$ para NE.

Comparando-se as magnitudes das estimativas da variância aditiva intrapopulacional $\left(\hat{\sigma}_{\mathrm{A}_{11}^{2}}^{2}\right)$ em relação à variância do desvio intra e interpopulacional $\left(\hat{\sigma}_{\tau_{12}}^{2}\right)$ e destes com a covariância entre eles $\left(\hat{\operatorname{Cov}}_{(\mathrm{A} 1 \tau 12)}\right)$, obtidas para a população BR-106, verifica-se que para todos os caracteres, $\hat{\sigma}_{A_{11}}^{2}$ foi superior. Os valores de $\hat{\sigma}_{\tau_{12}^{2}}^{2}$ foram superiores à covariância para todos os caracteres com exceção de $\mathrm{AE}$, e apresentou valores relativamente elevados em NGF e NE, médio para $\mathrm{PE}, \mathrm{AP}, \mathbf{r}, \mathrm{CE}$ e $\mathrm{DE}$, e baixos para $\mathrm{AE}$ e NF. As estimativas da covariância, em geral, foram baixas para todos os caracteres, com magnitude média equivalente a aproximadamente $8 \%$ do valor da variância aditiva intrapopulacional, com mínimo de $1,5 \%$ para $\mathrm{NF}$ e máximo de $11 \%$ para NE (Figura 1 ).

Para a população BR-105, a variância aditiva intrapopulacional foi superior em relação a os outros parâmetros para todos os caracteres. Entretanto, a variância do desvio intra e interpopulacional apresentou magnitudes altas para $\mathrm{PE}, \mathrm{AP}, \mathrm{AE}, \mathbf{r}$, e $\mathrm{DE}$ (média de $89 \%$ da variância aditiva intrapopulacional, da qual se aproxima muito em alguns casos), e magnitudes um pouco menores para CE, NF, NGF e NE (média de $52 \%$ da variância aditiva intrapopulacional). A magnitude da covariância foi, 
em média, aproximadamente $20 \%$ do valor da variância aditiva intrapopulacional, com minimo de $12 \%$ para NGF e máximo de $25 \%$ para AE (Figura 2).

As relações $(R)$ entre as médias das variâncias genéticas aditivas interpopulacionais $\left(\hat{\sigma}_{\mathrm{A}_{(12)}^{2}}^{2}\right)$ presentes na Tabela 20 pelas intrapopulacionais $\left[\left(\hat{\sigma}_{\mathrm{A}_{11}}^{2}+\hat{\sigma}_{\mathrm{A}_{22}}^{2}\right) / 2\right]$ calculadas a partir das Tabelas 18 e 19 foram estimadas e obteve-se: $0,98(\mathrm{PE}) ; 0,89(\mathrm{AP}) ; 0,79(\mathrm{AE}) ; 0,83$ (r);0,97 $(\mathrm{CE}) ; 0,98(\mathrm{DE}) ; 1,00(\mathrm{NF}) ; 0,91(\mathrm{NGF})$ e $0,53(\mathrm{NE})$.

As estimativas de $\hat{\phi}_{1}$ e $\hat{\phi}_{2}$ tomados como medidas do potencial genético das populações para o melhoramento e expressão da heterose pelo esquema de seleção recorrente reciproca (SRR) e seleção recorrente intrapopulacional, respectivamente, foram de 1,44 e 0,68 (PE); 1,40 e 0,64 (AP); 1,26 e 0,62 (AE); 1,15 e 0,72 (r); 1,11 e 0,88 (CE); 1,32 e 0,75 (DE); 1,26 e 0,80 (NF); 0,96 e 0,94 (NGF) e 0,92 e 0,58 (NE), respectivamente (Tabela 20 ).

A relação entre a estimativa da variância aditiva intrapopulacional $\left(\hat{\sigma}_{\mathrm{A}_{11}}^{2}\right)$ pelas estimativas $\hat{\sigma}_{\tau_{12}^{2}}$ e $\hat{\operatorname{Cov}}_{\left(\mathrm{A} 1 \tau_{12}\right)}$ obtidas para PE para a população BR-106 foram 5,40 e -9,15; respectivamente. Estas mesmas proporções foram de 5,89 e $-12,28$ para AP; $-50,02$ e $-12,49$ para $A E ;-5,64$ e $-16,00$ para r. Para os caracteres da espiga foram de $-3,26$ e 10,26 para CE e $-1,60$ e 10,40 para NGF; 10,00 e -13,86 para DE e 19,74 e -68,35 para NF; e 1,81 e $-9,46$ para $\mathrm{NE}$, respectivamente (Tabela 18). 
Para a população BR-105 essas relações foram de 1,02 e $-5,00$ para $\mathrm{PE} ; 1,13$ e $-4,16$ para AP; 1,15 e $-3,98$ para $\mathrm{AE} ; 1,08$ e $-4,74$ para $\mathbf{r}$. Para os caracteres da espiga foram de 1,70 e -5,74 para CE e 2,06 e -8,49 para NGF; 1,27 e -5,91 para DE e 1,45 e -5,92 para NF; e 3,07 e -4,16 para NE, respectivamente (Tabela 19).

A relação $\hat{\sigma}_{\tau_{12}^{2}}^{2} / \hat{\operatorname{Cov}}_{\left(\mathrm{A} 1 \tau_{12}\right)}$ para a população $\mathrm{BR}-106$ apresentou valores de $-1,69$ para $\mathrm{PE} ;-2,09$ para AP; 0,25 para AE; 2,84 para r. Para os caracteres da espiga, estes valores foram de $-3,14$ para CE e -6,51 para NGF; $-1,39$ para DE e $-3,46$ para NF; e $-5,22$ para NE. Para a população BR-105, esta relação apresentou valores de $-4,91$ para $\mathrm{PE} ;-3,68$ para AP; $-3,44$ para $\mathrm{AE} ;-4,40$ para r. Para os caracteres da espiga, estes valores foram de $-3,37$ para CE e $-4,13$ para NGF; -4,66 para DE e -4,09 para NF; e -1,36 para NE. A relação $\hat{\operatorname{Cov}}_{\left(\mathrm{A} 1 \tau_{2}\right)} / \mathrm{C} \hat{\mathrm{Ov}}_{\left(\mathrm{A} 2 \tau_{21}\right)}$ apresentou valores de 0,46 para $\mathrm{PE}$; 0,20 para AP; 0,18 para $\mathrm{AE} ; 0,28$ para $\mathbf{r}$. Para os caracteres da espiga, obteve-se $-0,40$ para CE e $-0,58$ para NGF; 0,33 para DE e 0,07 para NF; e 0,13 para NE (Tabelas 18 e 19 ).

As estimativas das variâncias da interação dos efeitos genéticos aditivos com ambientes ao nível intra $\left(\hat{\sigma}_{\mathrm{aA}_{11}}^{2}\right)$ e interpopulacional $\left(\hat{\sigma}_{\mathrm{aA}_{12}^{2}}\right)$ da população $\mathrm{BR}-106$, apresentaram valores relativamente baixos associados a erros elevados. Algumas exceções foram os caracteres CE e NF ao nível intrapopulacional, com valores de 0,69 (cm/espiga $)^{2}$ e 0,35

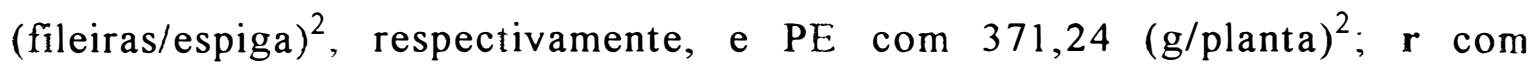


$4,13 \times 10^{-4} ;$ CE com $0,49 \quad(\mathrm{~cm} / \text { espiga })^{2}$ e $\mathrm{NGF}$ com 4,34 (sementes/fileira/espiga) $^{2}$ ao nível interpopulacional (Tabela 21 ).

Variâncias da interação dos desvios dos efeitos aditivos intra por interpopulacionais com ambientes $\left(\hat{\sigma}_{\mathrm{a}}^{2} \tau_{\mathrm{1} 2}\right)$ que apresentaram valores elevados em relação ao erro associado foram observados em AE com 68,33 $(\mathrm{cm} / \text { planta })^{2} ; \mathrm{CE}$ com $1,70(\mathrm{~cm} / \text { espiga })^{2} ; \mathrm{NF} \operatorname{com} 0,67$ (fileiras/espiga) $^{2} \mathrm{e}$ NGF com 7,22 (sementes/fileira/espiga) ${ }^{2}$. As estimativas da covariância da interação dos efeitos aditivos com seus desvios intra e interpopulacionais com ambientes $\left[\hat{\mathrm{O} v}_{(\mathrm{aA} 1 \mathrm{~T} 2)}\right]$ também apresentaram erros elevados, como as anteriores. Algumas estimativas para este parâmetro com erros menores foram

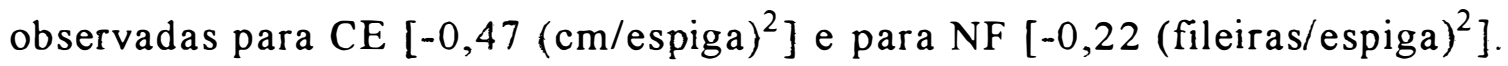

Para a população BR-105 (Tabela 22), todas as estimativas foram pequenas em relação ao seu erro associado, com exceção da estimativa da interação entre os desvios dos efeitos aditivos intra por interpopulacionais com ambiente $\left(\hat{\sigma}_{\mathrm{a}}^{2} \tau_{21}\right)$ para o caráter $\mathbf{r}$. 


\subsection{Variabilidade fenotípica e herdabilidade.}

As estimativas das variâncias fenotipicas ao nível de médias de progênies e de plantas, das herdabilidades, e das variâncias do erro experimental ao nivel intra e interpopulacional estão nas Tabelas 23 a 26 . Não foram tomados dados de plantas amostradas dentro da parcela para os caracteres PE e NE, portanto, a variância fenotípica dentro de parcelas não foi estimada para estes caracteres.

A herdabilidade no sentido restrito calculada ao nível de plantas da população BR-106 foi de 35,10\% para AP; 37,88\% para AE; $25,98 \%$ para $\mathbf{r}$. Para os caracteres da espiga foi de $35,44 \%$ para CE e $22,63 \%$ para NGF; $48,79 \%$ para DE e 47 , e $18 \%$ para NF. Para a população BR-105 foi de 53,61\% (AP); 59,73\% (AE); $26,54 \%$ (r); 43,28\% (CE) e 33,02\% (NGF); 62,09\% (DE) e $51,44 \%(\mathrm{NF})$.

A herdabilidade no sentido restrito calculada ao nível de parcelas de progênies intra e interpopulacionais da população BR-106 foram, respectivamente, 56,96 e 47,53\% para $\mathrm{PE} ; 63,54$ e 55,23\% para AP; 66,98 e $57,75 \%$ para $\mathrm{AE} ; 61,06$ e $51,14 \%$ para $\mathbf{r}$. Para os caracteres da espiga foram de 63,14 e $64,22 \%$ para CE e 56,82 e $45,41 \%$ para NGF; 75,72 e $69,84 \%$ para DE e 78,72 e $79,21 \%$ para NF; e 30,59 e $30,56 \%$ para NE. Para a população BR-105 foram de 69,65 e 65,70\% (PE); 77,78 e 80,95\% (AP); 81,24 e $78,04 \%(\mathrm{AE}) ; 67,16$ e $67,11 \%$ (r); 74,48 e $70,72 \%$ (CE) e 72,09 e $66,57 \%$ (NGF); 80,98 e $82,98 \%$ (DE) e 82,65 e $85,31 \%$ (NF); e 57,29 e $35,65 \%(\mathrm{NE})$, respectivamente. 


\subsection{Respostas esperadas à seleção.}

As respostas esperadas à seleção no híbrido populacional, nas populações per se e na heterose foram calculadas para os esquemas de seleção recorrente recíproca (SRR), seleção recorrente intrapopulacional (SRI), seleção recorrente modificada 1 e 2 (SRM(a) e SRM(b), tendo as população BR-105 e BR-106 como testadoras das duas populações, respectivamente), seleção massal (SM), e estão nas Tabelas 27 e 28 . Os valores foram relativamente altos, em consequência das avaliações terem sido feitas em dois anos, aumentando o valor da herdabilidade, e por ser o resultado de uma seleção truncada.

As respostas esperadas por ciclo de seleção recorrente recíproca com recombinação de progênies S1 para o caráter peso de espigas (Figura 3 e Tabela 27), foram de 21,05 (13,9\%); 16,91 (11,4\%); 13,18 (9,6\%) e $6,01 \mathrm{~g} /$ planta $(65,2 \%)$; no híbrido interpopulacional, nas populações BR-106 e BR-105 e na heterose, respectivamente. No esquema de seleção intrapopulacional estas respostas esperadas foram de 15,38 (10,1\%), 20,49 $(13,8 \%), 24,57(18,0 \%)$ e $-7,15 \mathrm{~g} /$ planta $(-77,4 \%)$, respectivamente. Para SRM(a) obteve-se $15,47(10,2 \%) ; 16,91 \quad(11,4 \%) ; 24,57(18,0 \%)$ e $-5,26$ g/planta (-57,0\%); e para SRM(b) $20,97(13,8 \%) ; 20,49(13,8 \%) ; 13,18$ $(9,6 \%)$ e $4,14 \mathrm{~g} /$ planta $(44,9 \%)$; para o híbrido, população BR-106, BR-105 e heterose, respectivamente.

As respostas (\%) por ciclo para o esquema SRR para AP, AE e $\mathbf{r}$ foram de 6,$6 ; 10,0$ e 5,4\% no híbrido interpopulacional; 5,$1 ; 9,4$ e $6,3 \%$ na população BR-106;4,6; 7,4 e 3,6\% para a população BR-105; e 172,2; 
196,9 e $257 \%$ na heterose, respectivamente. No esquema SRI estas respostas esperadas foram de 4,6;7,5 e 4,5\% no híbrido interpopulacional; 6,0;9,8 e $5,9 \%$ na população $\mathrm{BR}-106 ; 8,4 ; 14,0$ e $6,5 \%$ para a população $\mathrm{BR}-105$; e $-239,1 ;-501,9$ e $-983,9 \%$ na heterose, respectivamente. Para SRM(a) obteve-se de 4,7; 7,1 e 3,9\% no híbrido interpopulacional; 5,$1 ; 9,4$ e 6,3\% na população BR-106; 8,$4 ; 14,0$ e $6,5 \%$ para a população BR-105; e -191,8; $-527,6$ e $-1391,6 \%$ na heterose, respectivamente. Para SRM(b) foram de 6,6; 10,4 e $6,0 \%$ no híbrido interpopulacional; 6,$0 ; 9,8$ e 5,9\% na população BR-106; 4,6; 7,4 e 3,6\% para a população BR-105; e 127,2; 222,6 e 673,6\% na heterose, respectivamente.

As respostas por ciclo para o esquema SRR para CE e NGF foram de 7,7 e $7,0 \%$ no híbrido interpopulacional (H.I.); 8,2 e $8,4 \%$ na população BR-106; 5,9 e 6,9\% em BR-105 e 154,3 e -16,9\% na heterose, respectivamente. Pelo método SRI, obteve-se 7,0 e $7,5 \%$ para H.I.; 7,1 e $6,9 \%$ para BR-106; 8,8 e 9,5\% para BR-105 e $-187,3$ e $-16,4 \%$ na heterose para CE e NGF, respectivamente. Pelo método SRM(a), obteve-se 6,5 e 6,1\% para H.I.; 8,2 e $8,4 \%$ para BR-106; 8,8 e 9,5\% para BR-105 e $-412,1$ e $-102,0 \%$ na heterose, respectivamente; e por SRM(b), as respostas foram de 8,2 e $8,4 \%$ para H.I.; 7,1 e $6,9 \%$ para BR-106; 5,9 e $6,9 \%$ para BR-105 e 380,1 e $68,8 \%$ para a heterose, respectivamente.

As respostas para DE e NF por SRR foram 6,8 e $11,4 \%$ para H.I.; 5,8 e $10,6 \%$ para BR-106; 5,1 e $7,8 \%$ para BR-105 e 64,4 e $468,1 \%$ na heterose, respectivamente. Para SRI, obteve-se 5,2 e 9,1\% para H.I.; 6,4 e $10,8 \%$ para BR-106; 8,0 e $11,6 \%$ para BR-105 e -75,5 e $-455,0 \%$ na heterose; para SRM(a) obteve-se 5,3 e 9,2\% no H.I.; 5,8 e 10,6\% em BR-106; 8,0 e 
$11,6 \%$ em BR-105 e $-62,2$ e $-399,2 \%$ na heterose; para SRM(b) foram 6,8 e $11,3 \%$ em H.I.; 6,4 e $10,8 \%$ em BR-106; 5,1 e 7,8\% em BR-105 e 51,1 e $413,4 \%$ na heterose, respectivamente.

Para o caráter NE, as respostas via SRR foram de 5,8\% para H.I.; 3,8\% para BR-106; $8,9 \%$ para BR-105 e $-109,9 \%$ para a heterose; para SRI, foram de 5,4\% para H.I.; 5,2\% para BR-106; $13,1 \%$ para BR-105 e $-817,2 \%$ na heterose; para $\operatorname{SRM}(a)$ foram de $6,1 \%$ para H.I.; $3,8 \%$ para BR-106; 13,1\% para BR-105 e -515,9\% na heterose; e para SRM(b) foram de $5,1 \%$ para H.I.; $5,2 \%$ para BR-106; $8,9 \%$ para $\mathrm{BR}-105$ e $-413,04 \%$ na heterose. 


\section{DISCUSSÃO}

\subsection{Comportamento geral das populações $e$ do híbrido interpopulacional.}

Os experimentos foram realizados dentro de condições normais de ambiente, sem a ocorrência de maiores problemas. Este fato se refletiu nos coeficientes de variação das análises que apresentaram valores considerados normais de acordo com o tipo de experimento, em relação a outros trabalhos (Tabelas 8 a 15 ).

As médias das populações BR-106, BR-105 e do híbrido interpopulacional para $\operatorname{PE}(7,40 ; 6,84$ e 7,58 t/ha, respectivamente), foram 11,18 e $9 \%$ menores que a média do híbrido simples $\operatorname{ICI} 8452(8,32 \mathrm{t} / \mathrm{ha})$ utilizado como testemunha. As médias do híbrido interpopulacional para AP e $\operatorname{AE}(199,08$ e 101,84$)$ foram superiores e a relação $\mathbf{r}(0,51)$ foi igual à da testemunha. Como a média do híbrido interpopulacional representa a média de todos os possiveis híbridos simples obtidos destas duas populações, espera-se que estes híbridos simples sejam em média menos produtivos, com maiores alturas de planta e de espiga, e com a mesma relação altura de espiga sobre altura de planta quando comparados à testemunha, sob as condições em que foram avaliados. Como se trata da média de todos os possiveis híbridos 
simples retirados dessas populações, é provável que alguns deles ultrapassem a produtividade apresentada pela testemunha, já que em média o híbrido interpopulacional foi apenas $9 \%$ menos produtivo.

SOUZA JR. et al. (1993) trabalhando com estas mesmas populações no ano agrícola de 1985/86 em três locais (Sete Lagoas, MG, Londrina, PR e Goiânia, GO), obtiveram médias para peso de espigas de 143,$26 ; 139,97 ; 168,84$ gramas por planta para as populações BR-106, BR105, e para o híbrido interpopulacional, respectivamente. Estes valores equivalem à 7,$16 ; 7,00$ e 8,44 t/ha, respectivamente. Embora sejam locais diferentes, a comparação ajudará a conhecer melhor estas populações. A população BR-106 foi 3,37\% superior para PE enquanto a população BR-105 e o híbrido interpopulacional foram 2,33 e 10,19\% menos produtivos que em SOUZA JR. et al. (1993), respectivamente. Portanto, o híbrido interpopulacional destas populações na região de Piracicaba produziu em média $10,19 \%$ menos que naqueles locais. É interessante observar que as diferenças entre as médias populacionais e entre os cruzamentos populacionais recíprocos em SOUZA JR. et al. (1993) foram pequenas $(3,29 \mathrm{e}$ $0,74 \mathrm{~g} /$ planta, para BR-106 e BR-105, respectivamente), enquanto aqui estas diferenças foram bem maiores (11,38 e 5,32 g/planta, para BR-106 e BR-105, respectivamente), sendo que o cruzamento com BR-105 como parental materno foi mais produtivo em Piracicaba enquanto que naquela oportunidade o outro cruzamento foi ligeiramente superior.

Para os caracteres altura da planta e da espiga, SOUZA JR. et al. (1993) obtiveram valores de 192,71 e 114,86 para BR-105; 204,46 e 114,46 para BR-106 e 204,79 e 124,56 (cm/planta) para o híbrido 
interpopulacional, respectivamente. Com exceção da altura da planta na população BR-105, todas as outras médias foram superiores às obtidas neste trabalho. A heterose em relação à média das populações parentais e à ppopulação superior foram de 19,23 e 17,86\% para peso da espiga; 3,12 e $0,16 \%$ para altura da planta e de 5,15 e $2,06 \%$ para altura da espiga; que são valores bem superiores aos obtidos aqui (Tabela 7). Heteroses elevadas como estas, são interessantes para $\mathrm{PE}$, pois garantem a produção de híbridos cada vez mais produtivos e heteróticos em relação às populações base; para AP e $\mathrm{AE}$, não há o interesse em heteroses elevadas e positivas, pois o objetivo do melhoramento é manter ou até diminuir as alturas de planta e espiga para diminuir problemas com acamamento e permitir maiores densidades de plantio.

As comparações mostraram que as condições experimentais permitiram a expressão de maiores diferenças entre as populações per se e também entre os cruzamentos populacionais recíprocos. Entretanto, a expressão da heterose ficou reduzida em relação ao trabalho citado. Apesar de menores, os valores obtidos para as heteroses de PE foram considerados de magnitude intermediária. Os valores de heterose em relação à população parental superior (hps) foi calculado para cada caráter separadamente, de forma que para AP, AE e $\mathbf{r}$, o híbrido interpopulacional apresentou em média menor estatura e maior altura de espiga que BR-105, e menor relação $\mathbf{r}$ que BR-106. As heteroses positivas para os caracteres altura de planta e espiga não são interessantes agronomicamente. Os valores positivos obtidos para AP em relação à média das populações e para AE nos dois casos, mesmo sendo relativamente pequenos, representam uma tendência de que os híbridos em 
média apresentaram alturas um pouco superiores às das populações base, quando o ideal é o decréscimo ou pelo menos a manutenção destas medidas. O valor negativo da heterose em relação ao parental superior obtido para AP por exemplo, indica que o híbrido interpopulacional apresentou uma altura inferior ao do parental mais alto (BR-105, no caso), evitando assim problemas com acamamento (Tabela 7 ).

Quanto aos caracteres da espiga, as heteroses para CE e NGF foram bem diferentes $(0,46$ e $2,59 \%$ em relação à média das populações parentais e $-1,42$ e 0,88\% em relação à população superior, respectivamente), o mesmo ocorrendo para $\operatorname{DE}$ e $\operatorname{NF}(2,34$ e $-0,48 \%$ em relação à média das populações parentais e $-0,55$ e $-3,23 \%$ em relação à população superior, respectivamente), mas este fato não impede que $\mathrm{CE}$ e $\mathrm{DE}$ não possam ser utilizados como indicadores do nivel de heterose apresentados por NGF e NF, respectivamente, desde que se conheça o viés. Com exceção de NGF, os demais componentes da produção apresentaram heteroses negativas em relação às populações superiores, o que não é interessante comercialmente. Valores positivos para a heterose são muito interessantes, como os obtidos para a prolificidade $(0,45$ e $0,22 \%)$ que embora pequenos, mostram que o hibrido interpopulacional produziu mais espigas por planta que o parental superior. Também observou-se valores relativamente altos de heterose para NGF em relação à média dos parentais e ao parental superior $(2,59$ e $0,88 \%$, respectivamente), provavelmente porque este caráter é alvo de seleção no momento do descarte dos materiais que por qualquer razão apresentem número insuficiente de sementes para a produção das progênies (Tabela 7). 
Sob o ponto de vista comercial, a heterose medida em relação à população parental superior é a que tem real importância, já que só materiais superiores aos já existentes, seja por apresentar maior nível produtivo, ou mesmo, igual nível produtivo aliado a outras características de interesse como resistência a doenças e pragas, resistência ao acamamento, ou mesmo características específicas de óleo ou proteína nos grãos, podem ter alguma chance de sucesso no mercado. Em função das frequências gênicas e dos efeitos genotípicos, a heterose em relação à população parental superior (hps) é (SOUZA JR. et al., 1993):

$$
\mathrm{hps}=\sum_{\mathrm{i}}\left(\mathrm{r}_{\mathrm{i}}-\mathrm{p}_{\mathrm{i}}\right) \alpha_{\mathrm{i}}
$$

Onde $r_{i}$ e $p_{i}$ são as frequências dos alelos favoráveis na população inferior e superior, respectivamente, e $\alpha_{\mathrm{i}}$ é o efeito médio de uma substituição gênica da população considerada superior. Portanto, nos locos onde as frequências dos alelos favoráveis são altas na população inferior e baixas na superior, haverá uma contribuição positiva para a hps. Ou seja, a população inferior só vai complementar bem a superior quando possuir altas frequências dos alelos favoráveis que estiverem em baixas frequências na população considerada superior. 


\subsection{Análises de variância}

A significância $(P<0,05)$ de ambientes (anos e locais) para a maioria dos caracteres (exceção de $\mathbf{r}$, NF e NE para BR-106 e de AP, NF e NGF para BR-105), mostram que o material genético foi avaliado sob condições ambientais distintas. Isto já era esperado, já que os dois locais apresentam características bem diferentes quanto ao tipo de solo e fertilidade (Tabelas 8 a 11 ).

O efeito de genótipo mede as diferenças entre plantas amostradas das populações, cada uma avaliada através de progênies intra e interpopulacionais. A significância $(\mathrm{P}<0,05)$ observada para todos os caracteres das duas populações, indica que existe variabilidade genética aditiva para todos os casos, uma vez que se tratam de progênies de meios irmãos e a variância genética entre elas é de $1 / 4$ da variância genética aditiva (Tabelas 8 a 11). Neste caso, a variância aditiva refere-se tanto ao tipo intra com o interpopulacional reunidos, pois os dois tipos de progênies representaram cada genótipo.

A interação entre genótipos e ambientes $(G \times$ A) mede se o comportamento médio dos genótipos avaliados uns em relação aos outros, foi constante nos quatro ambientes, ou se houve respostas diferentes de alguns genótipos em relação aos outros quanto às variações do ambiente. Não foi detectada significância $(P<0,05)$ da interação $G \times A$ para todos os caracteres das duas populações (exceção de NE para BR-106), desta forma, em média, os genótipos que foram superiores ou inferiores em um determinado ambiente, 
mantiveram este padrão nos demais ambientes para as populações BR-106 (Tabelas 8 e 9) e BR-105 (Tabelas 10 e 11 ).

Os tipos de progênies correspondem às progênies intra e interpopulacionais obtidas de cada planta avaliada, que são diferentes quanto ao tipo de testador, sendo que no tipo intrapopulacional o testador é a própria população, e no outro, o testador é a população contrastante. Desta forma, o efeito mede na realidade a divergência genética entre populações, pois não havendo divergência não haverá diferenças entre o testador intra e o interpopulacional. Não foi detectada significância $(\mathrm{P}<0,05)$ para tipos de progênies em todos os caracteres da população BR-106 (Tabelas 8 e 9), o mesmo não ocorrendo para PE, DE e NGF em BR-105 (Tabelas 10 e 11). Portanto, para a população BR-106 que foi a mais produtiva, a não significância deste efeito indica que o nivel de divergência genética oferecida por BR-105 não foi suficientemente grande para ser detectado pelo teste. Já para a população BR-105, a significância deste efeito mostra que o tipo de testador foi importante e que BR-106 apresentou divergência genética suficiente para complementar de forma favorável a população BR-105. A população BR-106 contribuiu como testadora de BR-105 para PE, DE e NGF, o mesmo não ocorrendo para os demais caracteres neste cruzamento e para todos os caracteres no cruzamento recíproco.

A interação entre tipos e ambientes ( $\mathrm{T} \times \mathrm{A}$ ) mede se o efeito de testador foi homogêneo para todos os ambientes experimentados. Os resultados mostraram que o efeito de testador variou nos ambientes para PE, CE, NF e NGF na população BR-106 (Tabelas 8 e 9), e para PE e CE em BR-105 (Tabelas 10 e 11). 
Dos dois últimos parágrafos, observa-se que o efeito do testador para PE e CE variou entre ambientes, mas em média foi importante apenas para BR-105, enquanto para NGF este efeito foi uniforme nos ambientes em BR-105, onde alcançou significância na média dos ambientes.

A interação entre genótipos e tipos de progênies $(G \times T)$ mede se a avaliação dos genótipos é influenciada pelo tipo de progênie. Não foi detectada significância $(\mathrm{P}<0,05)$ para nenhum dos caracteres avaliados da população BR-106 (Tabelas 8 e 9). Para a população BR-105, este efeito foi altamente significativo $(\mathrm{P}<0,01)$ para todos os caracteres com exceção de prolificidade (NE). Isto indica que, para a população $\mathrm{BR}-106$, o resultado da avaliação das plantas (genótipos) não mudou de acordo com o tipo de progênie avaliada. O mesmo não ocorreu com a população BR-105, onde o tipo de progênie faz com que genótipos diferentes sejam selecionados. Também vale lembrar que as progênies avaliadas com material de origem diferente normalmente apresentam um nível de vigor superior àquele avaliado com material de mesma origem, e que portanto, esta diferença de vigor não afetou a avaliação dos genótipos em BR-106 e afetou em BR-105.

Este resultado difere de outros na literatura (SOUZA JR., 1983; MIRANDA Fo \& PATERNIANI, 1983), onde detectaram-se efeitos significativos para tipos de progênies e não significativos para a interação genótipos $\mathrm{x}$ tipos para as duas populações estudadas, indicando que existiu divergência genética entre aquelas populações e que cada uma complementou bem a outra fazendo com que seus híbridos ( $1 \times 2$ e $2 \times 1)$ fossem diferentes dos tipos intrapopulacionais, e também que o comportamento dos genótipos 
não fossem dependentes do tipo de progênie avaliada para as duas populações.

$\mathrm{O}$ efeito de interação genótipos $\mathrm{x}$ tipos de progênies sendo não significativos como ocorreu para BR-106 indica que a correlação genética entre tipos de progênies deve ser elevada, enquanto a significância deste efeito para BR-105 é um indicativo de que a mesma correlação seja baixa. Como esperado, obteve-se valores de correlação genética entre tipos de 0,90 (PE); 0,91 (AP); 1,03 (AE); 1,16 (r); 1,14 (CE); 0,95 (DE); 0,97 (NF); 1,37 (NGF); e 0,74 (NE) para a população BR-106; e de 0,55 (PE); 0,54 (AP); $0,54(\mathrm{AE}) ; 0,55(\mathbf{r}) ; 0,69(\mathrm{CE}) ; 0,63(\mathrm{DE}) ; 0,65(\mathrm{NF}) ; 0,76(\mathrm{NGF}) ;$ e 0,86 (NE) para a população BR-105.

Valores de correlação acima do valor teórico máximo de 1,0 estão associados a erros de estimação. Entretanto, observa-se claramente que os valores de correlação foram superiores para a população BR-106, com exceção de NE. As diferenças entre as correlações das duas populações estudadas para os caracteres comuns foram maiores que os calculados em SOUZA JR. (1983) [ 0,96 (PE); 1,07 (AP); e 0,95 (AE); para a população ESALQ-PB 1; e 0,79 (PE); 0,89 (AP); e 1,04 (AE) para a população BR-105] e em MOLL \& STUBER (1971)[0,63 para a população Jarvis e 0,72 em Indian Chief para PE]. Os valores de correlação encontrados ratificam o fato de que a avaliação de genótipos na população BR-106 feita com progênies de meios irmãos intra ou interpopulacionais afetou menos o "rank" de genótipos em relação à $\mathrm{BR}-105$. 
5.3. Análises de variância e covariância das progênies intra e interpopulacionais.

Nas análises de variância feitas individualmente para cada tipo de progênie reunindo dados dos quatro ambientes, detectaram-se significância $(\mathrm{P}<0,05)$ de ambientes para todos os caracteres ao nivel interpopulacional e para todos com exceção de $\mathbf{r}, \mathrm{DE}, \mathrm{NF}$ e $\mathrm{NE}$ ao nível intrapopulacional da população BR-106; todos com exceção de NF e NGF ao nível intrapopulacional e de AP e NF ao nível interpopulacional da população BR-105. Tal como no experimento em faixas, este resultado também era esperado aqui (Tabelas 12 a 15 ).

A alta significância $(\mathrm{P}<0,01)$ observada entre progênies de meios irmãos intra e interpopulacionais para todos os caracteres, indicam a existência de variabilidade genética aditiva tanto ao nivel intra como interpopulacional, já que a variância genética entre estas progênies equivale a 1/4 da variância aditiva intra e interpopulacional, respectivamente (Tabelas 12 a 15).

O efeito de interação entre progênies e ambientes mede se as progênies mantiveram o mesmo comportamento relativo nos quatro ambientes. Nos casos onde este efeito foi significativo (CE, NF e NGF ao nível intrapopulacional e para todos os caracteres menos $\mathrm{AP}, \mathrm{DE}$ e $\mathrm{NF}$ ao nivel interpopulacional da população BR-106 e apenas para $\mathbf{r}$ ao nivel interpopulacional da população BR-105) a classificação relativa das progênies variou de um ambiente para outro. Ficou claro que as progênies tanto ao nivel intra como interpopulacional da população BR-105 foram muito mais estáveis às variações do ambiente em relação à BR-106. Por sua vez, as progênies 
intrapopulacionais foram estáveis para um maior número de caracteres (inclusive $\mathrm{PE}$ ) quando comparadas às interpopulacionais da população BR-106 (Tabelas 12 a 15).

Os coeficientes de variação das análises estão com valores considerados normais em relação a outros trabalhos, e indicam que a execução das avaliações transcorreram dentro de condições normais para este tipo de experimento (Tabelas 12 a 15).

\subsection{Estimativas dos componentes genéticos de variância e covariância.}

As estimativas dos componentes genéticos aditivos intrapopulacionais foram maiores para a população BR-105 do que para BR-106 para todos os caracteres avaliados. As magnitudes dessas estimativas foram bem diferentes para cada uma das populações per se. As duas populações, inclusive BR-106 que é agronomicamente mais desenvolvida, ainda apresentaram bastante variabilidade para progressos posteriores (Tabelas 18 e 19).

Revisões feitas sobre estimativas da variância aditiva intrapopulacional sugerem valores médios de $\hat{\sigma}_{\mathrm{A}}^{2}=309,0$ (g/planta) ${ }^{2}$ (VENCOVSKY et al., 1988) para PE; $\hat{\sigma}_{\mathrm{A}}^{2}=242,0$ para AP e $\hat{\sigma}_{\mathrm{A}}^{2}=160,0$ $(\mathrm{cm} / \text { planta })^{2}$ para AE (GHINI \& MIRANDA Fo , 1979). As estimativas obtidas para BR-106 e BR-105 foram maiores que a média para PE (376,09 e 
442,31; respectivamente) e menores para AP $(109,31$ e 185,74; respectivamente) e $\mathrm{AE}\left[74,04\right.$ e $127,45(\mathrm{~cm} / \text { planta })^{2}$; respectivamente], o que indica que em média, estas populações tem ainda grande potencial de melhoramento para rendimento de grãos e que estão relativamente homogêneas para AP e AE em relação ao universo de populações amostradas nas revisões citadas.

Comparando-se as estimativas das variâncias aditivas interpopulacionais (281,39 e 522,34 para BR-106 e BR-105, respectivamente) com outras estimativas relatadas na literatura para PE (Tabela 1), observa-se que estes valores foram relativamente altos. Um fato que chama a atenção é que na literatura observa-se a relação $\hat{\sigma}_{\mathrm{A}_{12}}^{2}>\hat{\sigma}_{\mathrm{A}_{21}}^{2}$, o que ficou invertido neste trabalho. A população base designada como população 1 normalmente é a mais produtiva e que possui a maior variância aditiva intrapopulacional em relação à população designada como população 2 . Neste trabalho, em termos de PE, a população BR-106 foi a mais produtiva, mas apresentou variância aditiva intra e interpopulacional menor que BR-105. Designando-se BR-106 como sendo a população 1 baseado apenas em sua média, ocorreu uma inversão da relação escrita acima, ficando: $\hat{\sigma}_{\mathrm{A}_{12}}^{2}<\hat{\sigma}_{\mathrm{A}_{21}}^{2}$. Este resultado é importante pois indica que a classificação correta das populações deve ser feita com base nas variâncias. Apesar disso, a notação foi mantida de acordo com a utilizada para estas mesmas populações por SOUZA JR. et al. (1993).

As estimativas das variâncias aditivas interpopulacionais obtidas para a população BR-106 foram inferiores às intrapopulacionais para a maioria dos caracteres (exceção de CE e NE). Para a população BR-105, 
ocorreu o inverso para os caracteres $\mathrm{PE}, \mathbf{r}, \mathrm{DE}, \mathrm{NF}$ e $\mathrm{NGF}$, onde a variância aditiva interpopulacional liberada foi maior. A variância aditiva interpopulacional da população BR-106 pode ser escrita assim (SOUZA JR., $1993)$ :

$$
\begin{aligned}
& { }^{2}{ }_{A_{12}}=\sigma_{A_{11}}^{2}+\sigma_{\pi_{12}}^{2}+4 \operatorname{Cov}\left(A_{1} \pi_{2}\right) \\
& \text { Desta forma, se } \sigma_{\pi_{2}}^{2}+4 \operatorname{Cov}\left(A_{1} \tau_{12}\right) \neq 0 \text {, então } \sigma_{A_{12}}^{2} \neq \sigma_{A_{11}}^{2}
\end{aligned}
$$

Portanto, a variância inter será diferente da intrapopulacional quando a variância dos desvios dos efeitos aditivos intra por interpopulacionais for diferente do valor da covariância do efeito aditivo com este desvio multiplicado por quatro em módulo, ou seja, quando $\sigma_{\tau_{12}} \neq\left|4 \operatorname{Cov}\left(\Lambda_{1} \tau_{12}\right)\right|$. Se a covariância for positiva, a relação será $\sigma_{A_{12}}^{2}>\sigma_{A_{11}}^{2}$; e se for negativa, a relação dependerá da magnitude da covariância, sendo que quando 2 222 $\sigma_{n 2}>\left|4 \operatorname{Cov}\left(A_{1} \pi_{2}\right)\right|$ então $\sigma_{A_{12}}>\sigma_{A_{11}}$, e quando $\sigma_{n 2}<\left|4 \operatorname{Cov}\left(A_{1} \tau_{12}\right)\right|$ então 22 $\sigma_{A_{12}}<\sigma_{A_{11}}$. As mesmas relações também valem para a população BR-105. Mas como já foi demonstrado, quando as populações são divergentes esperase que estas covariâncias obtidas para as duas populações tenham sinais opostos. Se a magnitude dessas covariâncias ultrapassarem $25 \%$ do valor de 2 $\sigma_{\tau}$, então serão observadas as relações:

$$
\begin{aligned}
& \sigma_{\mathrm{A}_{12}}^{2}>\sigma_{\mathrm{A}_{11}}^{2} \text { e } \sigma_{\mathrm{A}_{21}}^{2}<\sigma_{\mathrm{A}_{22}}^{2} \text { ou } \\
& 22 \quad 2 \quad 2 \\
& \sigma_{A_{12}}<\sigma_{A_{11}} \text { e } \sigma_{A_{21}}>\sigma_{A_{22}} \text {, dependendo de qual covariância }
\end{aligned}
$$
apresente o sinal negativo. Caso a magnitude da covariância com sinal negativo não alcance $25 \%$ do valor de $\sigma_{\tau}^{2}$, então sempre a variância interpopulacional será superior 
Considerando-se o caráter PE como exemplo, ao utilizarmos BR-105 como testadora, a estimativa da variância aditiva interpopulacional $\left(\hat{\sigma}_{\mathrm{A}_{12}}^{2}=281,39\right)$ foi $25,18 \%$ inferior à intrapopulacional $\left(\hat{\sigma}_{\mathrm{A}_{11}^{2}}^{2}=376,09\right)$; e quando a testadora foi BR-106, esta estimativa $\left(\hat{\sigma}_{\mathrm{A}_{21}^{2}}^{2}=522,34\right)$ foi $18,09 \%$ superior à intrapopulacional $\left(\hat{\sigma}_{\mathrm{A}_{22}}^{2}=442,31\right)$. Estes resultados indicam que Cova $\pi_{2}$ deve ter sinal negativo e magnitude superior a $1 / 4 \sigma_{\tau_{12}}^{2}$. Com isso, a população BR-105 não foi uma boa testadora dos genótipos de BR-106 nas condições estudadas, pois a discriminação entre genótipos ficou mais dificultada. Já a população BR-106 serviu muito bem como testadora de BR-105 pois liberou maior variabilidade genética (Tabelas 18 e 19).

Para os caracteres AP $\mathrm{e} A \mathrm{AE}$ as variâncias aditivas intrapopulacionais foram superiores às interpopulacionais das duas populações. Para a relação entre elas (r), as relações entre variâncias aditivas intra e interpopulacionais se comportaram como em $\mathrm{PE}\left(\sigma_{\mathrm{A}_{12}}^{2}<\sigma_{\mathrm{A}_{11}}^{2}\right.$ e $\sigma_{\mathrm{A}_{21}}^{2}$ $\left.>\sigma_{\mathrm{A} 22}^{2}\right)($ Tabelas 18 e 19$)$.

Para os caracteres relacionados à espiga, CE e NGF apresentaram comportamentos bem diferentes, sendo que CE e também NE apresentou as seguintes relações: $\sigma_{\mathrm{A}_{12}}^{2}>\sigma_{\mathrm{A}_{11}}^{2}$ e $\sigma_{\mathrm{A}_{21}}^{2}<\sigma_{\mathrm{A}_{22}}^{2}$; enquanto DE, NF e NGF foram similares entre sí e com PE e $\mathbf{r}$, apresentando as seguintes relações: $\sigma_{\mathrm{A}_{12}}^{2}<\sigma_{\mathrm{A}_{11}}^{2}$ e $\sigma_{\mathrm{A}_{21}}^{2}>\sigma_{\mathrm{A}_{22}}^{2}$ (Tabelas 18 e 19).

Estimativas da variância aditiva ao nivel interpopulacional foram obtidas por SOUZA JR. et al. (1993) para o caráter peso de espigas 
obtendo valor de $\hat{\sigma}_{\mathrm{A}_{12}}^{2}=145,65$ para a população BR-106 (BR-105 como testadora) e $\hat{\sigma}_{\mathrm{A}_{21}}^{2}=136,62$ para $\mathrm{BR}-105$ (BR-106 como testadora); que são valores 48,24 e $73,84 \%$ inferiores aos encontrados aqui, respectivamente. Como já foi citado anteriormente, BR-106 apresentou uma variância aditiva interpopulacional superior à $\mathrm{BR}-105$, inversamente ao resultado obtido aqui, demonstrando como o comportamento dessas populações variaram sob condições diferentes.

As estimativas das variâncias genéticas aditivas interpopulacionais $\left(\hat{\sigma}_{\mathrm{A}_{(12)}^{2}}\right.$, da Tabela 20$)$ podem ser comparadas aos valores obtidos por outros autores (Tabela 1) que variaram de 141,13 (g/planta) ${ }^{2}$ obtido para as populações BR-106 e BR-105 por SOUZA JR. et al. (1993) a $260,50$ (g/planta $)^{2}$ obtido para as populações ESALQ-PB] e BR-105 por SOUZA JR. \& MIRANDA Fo (1989) para o caráter peso das espigas, com média entre eles de 203,97 (g/planta $)^{2}$. Esta média equivale a aproximadamente $51 \%$ do valor obtido neste trabalho $(401,87)$. Para os caracteres altura da planta e espiga, SOUZA JR. (1983) obteve 255,27 e $88,06$ (g/planta $)^{2}$; que são 93,69 e $11,17 \%$ superiores às estimativas deste trabalho, respectivamente.

Os valores de $\phi_{1}$ tomado como uma medida do potencial genético das populações para o melhoramento e expressão da heterose via seleção recorrente interpopulacional (SOUZA JR. \& MIRANDA Foo, 1989), foram relativamente altos para $\mathrm{PE}, \mathrm{AP}, \mathrm{AE}, \mathrm{r}, \mathrm{CE}, \mathrm{DE}$ e NF (superiores a 1,0), e mais baixos para NGF e NE, indicando que estas populações apresentaram maior potencial para alguns caracteres como peso de espigas do 
que para outros como NGF e NE, sendo que em todos estes com exceção de AP, AE e r, existe o interesse de aumento da heterose (Tabela 20).

Os valores de $\phi_{2}$ tomado como uma medida do potencial genético das populações para o melhoramento e expressão da heterose via seleção recorrente intrapopulacional, foram menores que $\phi_{1}$ para todos os caracteres, comprovando que a heterose é mais eficientemente melhorada através da seleção interpopulacional, em virtude do aproveitamento do 2

componente $\sigma \tau$ (Tabela 5 ) na expectativa da resposta à seleção. Valores mais altos para $\phi_{2}$ foram obtidos para CE e $\operatorname{NGF}(0,88$ e 0,94 ; respectivamente), um pouco menores para $\mathrm{PE}, \mathrm{AP}, \mathrm{AE}, \mathbf{r}, \mathrm{DE}, \mathrm{NF}, \mathrm{NE}(0,68 ; 0,64 ; 0,62 ; 0,72$; 0,$75 ; 0,80$ e 0,58 ; respectivamente), evidenciando que as respostas na heterose via seleção intrapopulacional devem ser menores (Tabela 20).

Os valores de $\mathrm{R}$ (relação entre a variância aditiva média interpopulacional pela intrapopulacional) estiveram bem próximos ou até iguais a 1,0 para $\mathrm{PE}, \mathrm{CE}, \mathrm{DE}$ e NF, demonstrando que foram semelhantes na média. Para AP, AE, r, NGF e NE, estas relações $(0,89 ; 0,79 ; 0,83 ; 0,91$ e 0,53 ; respectivamente) foram relativamente menores, indicando que em média a variância aditiva interpopulacional foi menor que a intrapopulacional (Tabela 20).

As estimativas das variâncias dos desvios dos efeitos aditivos intra e interpopulacionais $\left(\hat{\sigma}_{\tau_{12}^{2}}^{2}\right.$ e $\left.\hat{\sigma}_{\tau_{21}}^{2}\right)$ e da covariância destes com os efeitos aditivos $\left[\hat{\operatorname{Cov}}_{\left(\Lambda_{1} \tau_{2}\right)}\right.$ e $\left.\hat{\operatorname{Cov}}_{\left(\Lambda_{2} \tau_{21}\right)}\right]$, podem ser analisadas com base em suas expressões para um loco com dois alelos desenvolvida por SOUZA JR. (1993): 


$$
\begin{aligned}
& \sigma_{\tau_{12}}^{2}=8 p q(p-r)^{2} d^{2} \text { e } \sigma_{\tau_{21}}^{2}=8 r s(p-r)^{2} d^{2} \\
& \operatorname{Cov}\left(A_{1} \pi_{2}\right)=2 p q(p-r) \alpha_{1} d \text { e } \operatorname{Cov}\left(A_{2} \tau_{21}\right)=2 r s(r-p) \alpha_{2} d \\
& \text { sendo } \alpha_{1}=\mathrm{a}+(\mathrm{q}-\mathrm{p}) \mathrm{d} \text { e } \alpha_{2}=\mathrm{a}+(\mathrm{s}-\mathrm{r}) \mathrm{d} \\
& \text { onde: } \alpha_{1} \text { e } \alpha_{2} \text { são os efeitos médios de uma substituição }
\end{aligned}
$$
gênica nas populações 1 e 2 , respectivamente; $\mathbf{p}$ e $\mathbf{q}, \mathbf{r}$ e $\mathbf{s}$ são as frequências dos alelos favoráveis e desfavoráveis das populações 1 e 2 , respectivamente; a é a metade da diferença dos valores genotípicos dos homozigotos, e d é o valor genotípico do heterozigoto.

As expressões de $\sigma_{\tau_{12}}^{2}$ e $\sigma_{\tau_{21}}^{2}$ mostram que estes parâmetros estão diretamente relacionados com a heterose. Os quatro parâmetros são relacionados à divergência genética $(p-r)$ das populações base utilizadas, e ao nível de dominância (d) dos caracteres.

As estimativas de $\sigma_{\tau_{12}}^{2}$ obtidas para a população BR-106 apresentaram erros relativamente altos. As estimativas de $\sigma_{\tau_{21}}^{2}$ apresentaram erros associados relativamente baixos para a população BR-105, e indicam que a diferença entre as frequências dos alelos favoráveis nos locos com dominância (p-r) deve ser diferente de zero e, portanto, existe diversidade nestes locos. Segundo SOUZA JR. (1993), estes parâmetros devem ser importantes para caracteres com alto grau de dominância como PE e de pouca ou nenhuma importância para aqueles com baixo grau de dominância. Para a população BR-106 os efeitos de dominância (d) devem ser pequenos nos locos onde existe divergência genética, fazendo com que as magnitudes dessas variâncias fossem pequenas em relação às dos erros obtidos com este delineamento. Na população BR-105 estes efeitos de dominância nos locos 
divergentes devem ser grandes para alcançar tais estimativas de $\hat{\sigma}_{\tau_{21}}^{2}$ (Tabelas 18 e 19 e Figuras 1 e 2).

De acordo com seus significados genéticos mostrados nas expressões acima, espera-se que $\hat{\operatorname{Cov}}_{\left(\mathrm{A}_{1} \pi_{2}\right)}$ e $\hat{\operatorname{Cov}}\left(\mathrm{A}_{2 \tau 21)}\right.$ tenham sinais opostos quando as populações são divergentes $(p \neq x)$. Entretanto, todas as estimativas com exceção de CE e NGF para a população BR-106 foram negativas. Os erros associados às estimativas negativas da população BR-106 foram relativamente altos, de forma que os respectivos parâmetros podem ser nulos ou até positivos. Já os erros associados à $\hat{\operatorname{Cov}}_{\left(\mathrm{A}_{2} \tau_{21}\right)}$ foram bem menores em relação aos valores estimados, indicando que este parâmetro tem sinal negativo para todos os caracteres da população BR-105. Para um loco dar a sua contribuição para a covariância entre efeitos aditivos com seus desvios intra por interpopulacionais é necessário também uma divergência genética entre as duas populações neste dado loco aliado a um efeito de dominância. Este componente, como o anterior, também mostrou que, para a população BR-105, a dominância (d) esteve presente nos locos com divergência genética de forma significativa, enquanto para BR-106 este mesmo nível de divergência genética não foi importante na média dos locos envolvidos (Tabelas 18 e 19 e Figuras 1 e 2).

Como ainda não estão disponíveis estimativas para estes parâmetros na literatura, eles foram calculados com os dados de SOUZA JR. (1983) obtidos também com progênies de meios irmãos intra e interpopulacionais das populações ESALQ-PB1 e BR-105, permitindo comparações. Paralelamente pode-se comparar algumas relações importantes entre parâmetros com os valores obtidos com a ajuda de avaliações numéricas 
feitas por SOUZA JR. (1993), que são apenas expectativas teóricas, mas que podem servir como referência para comparações deste tipo.

Pelos dados de SOUZA JR. (1983), os valores calculados de $\hat{\sigma}_{\tau_{12}}^{2}, \hat{\sigma}_{\tau_{21}}^{2}, \hat{\operatorname{Cov}}_{\left(\mathrm{A}_{1} \tau_{12}\right)}$ e $\hat{\operatorname{Cov}}_{\left(\mathrm{A}_{2} \tau_{21}\right)}$ para $\operatorname{PE}$ foram 37,$57 ; 47,03 ; 24,16$ e $-19,38(\mathrm{~g} / \text { planta })^{2}$, respectivamente. Estes valores equivalem a $54,11,59$ e $22 \%$ dos valores absolutos obtidos aqui, lembrando que as estimativas das covariâncias foram negativas. Portanto, os módulos das estimativas obtidas para as populações 1 (BR-106 e ESALQ-PB1) estiveram mais distantes que aquelas obtidas para as populações 2 (BR-105 nos dois casos).

Estas mesmas estimativas calculadas $\left(\hat{\sigma}_{\tau_{12}^{2}}^{2}, \hat{\sigma}_{\tau_{21}}^{2},{\hat{\operatorname{Cov}}\left(\Lambda_{1} \tau_{12}\right)}_{\mathrm{e}}\right.$ $\hat{\operatorname{Cov}}_{\left(\mathrm{A} 2 \tau_{21}\right)}$ de SOUZA JR., 1983$)$ para o caráter AP foram -32,04;55,68;18,60 e $-17,62(\mathrm{~cm} / \text { planta })^{2}$, respectivamente, e para AE foram 10,$54 ;-5,12 ; 2,15$ e $0,16(\mathrm{~cm} / \text { planta })^{2}$, respectivamente. Para AP, $\hat{\sigma}_{\tau_{21}^{2}}^{2}$ e $\hat{\operatorname{Cov}}_{\left(\mathrm{A} 2 \tau_{21}\right)}$ apresentaram o mesmo sinal e menores magnitudes, enquanto $\hat{\sigma}_{\tau_{12}^{2}}^{2}$ e ${\hat{\operatorname{Cov}}\left(\Lambda_{1} \pi_{2}\right)}_{\text {apresentaram }}$ maiores magnitudes e sinais contrários aos observados neste trabalho $(18,57$; 164,$24 ;-8,90$ e $-44,67$; respectivamente). Para AE,$\hat{\sigma}_{\tau_{12}^{2}}^{2}$ apresentou maior magnitude e sinal contrário; enquanto $\hat{\operatorname{Cov}}_{\left(\Lambda_{1} \pi_{2}\right)}, \quad \hat{\sigma}_{\tau_{21}^{2}}^{2}$ e $\hat{\operatorname{Cov}}_{\left(\Lambda_{2} \tau_{21}\right)}$ apresentaram menores magnitudes e sinais contrários em relação aos daqui $(-1,48 ; 110,37 ;-5,93$ e $-32,06$; respectivamente)

As estimativas das covariâncias intra por interpopulacionais $\left[\hat{\operatorname{Cov}}_{\left(A_{1} A_{2}\right)}\right.$ e $\left.\hat{\operatorname{Cov}}_{\left(A_{2} A_{1}\right)}\right]$ são muito importantes pois estão diretamente envolvidas nas respostas indiretas esperadas para SRR nas populações per se e para SRI no híbrido interpopulacional (Tabela 5). Sabe-se que: 


$$
\begin{aligned}
& \operatorname{Cov}_{\left(\Lambda_{1} A_{2}\right)}=\sigma_{\mathrm{A}_{11}}^{2}+2 \operatorname{Cov}\left(\Lambda_{1} \pi_{2}\right) \\
& \operatorname{Cov}\left(\mathrm{A}_{2} \mathrm{~A}_{1}\right)=\sigma_{\mathrm{A}_{22}}^{2}+2 \operatorname{Cov}\left(\Lambda_{2} \pi_{2} 1\right)
\end{aligned}
$$

Desta forma, quando $\operatorname{Cov}\left(A_{1} \pi_{2}\right)$ for positivo e $\operatorname{Cov}_{\left(A_{2} \tau_{2}\right)}$ for negativo, espera-se as seguintes relações: $\operatorname{Cov}\left(\mathrm{A}_{1} \mathrm{~A}_{2}\right)<\sigma_{\mathrm{A}_{11}}^{2}$ e $\operatorname{Cov}_{\left(\Lambda_{2} \mathrm{~A}_{1}\right)}>\sigma_{\mathrm{A}_{22}}^{2}$, observando-se $\mathrm{o}$ inverso quando apresentarem sinais contrários. Todas as estimativas de $\operatorname{Cov}\left(\Lambda_{1} \pi_{2}\right)$ e $\operatorname{Cov}\left(\Lambda_{2} \tau_{2}\right)$ foram negativas, com exceção de CE e NGF para a população BR-106, fazendo com que as covariâncias aditivas intra $x$ inter fossem sempre menores que as variâncias aditivas intrapopulacionais, ou seja: $\operatorname{Cov}_{\left(\mathrm{A}_{1} \Lambda_{2}\right)}<\sigma_{\mathrm{A} 11}^{2}$ e $\operatorname{Cov}\left(\Lambda_{2} \mathrm{~A}_{\mathrm{I}}\right)<\sigma_{\mathrm{A}_{22}}^{2}$.

Os valores teóricos esperados (SOUZA JR.,1993) para PE $(\mathrm{d} / \mathrm{a} \cong 1,0)$ para a relação $\sigma_{\text {Al1 }}^{2} / \sigma_{\tau_{12}}^{2}$ em populações divergentes (com frequências dos alelos favoráveis das populações de 0,4 e 0,6$)$ é de 2,14; e para $\operatorname{AP}$ e $\operatorname{AE}(d / a \cong 0,5)$ é de 8,93 . Esta mesma situação quanto ao grau de dominância dos caracteres e de divergência entre as populações será mantida nos parágrafos seguintes. Os valores observados para $\mathrm{PE}(5,4)$ e para AP $(5,89)$ estiveram próximos aos esperados, enquanto para $\mathrm{AE}(-50,0)$ o sinal foi inverso e a magnitude foi acima da esperada. Os valores desta relação para PE $(6,28)$ e AE $(8,67)$, utilizando os dados de SOUZA JR. (1983), foram próximos aos esperados, mas para AP $(-6,96)$ o sinal aparece trocado.

Pela avaliação numérica (SOUZA JR.,1993) a relação $\sigma_{\mathrm{A} 22}^{2} / \sigma_{\tau_{21}}^{2}$ se aproximaria de 5,0 para PE e de 16,50 para AP e AE. Foram obtidos aqui 1,$02 ; 1,13$ e 1,15 para $\mathrm{PE}$, AP e $\mathrm{AE}$, respectivamente. Para 
SOUZA JR. (1983) foi calculado 3,$85 ; 4,67$ e $-12,81$; respectivamente. As estimativas concordaram com os valores esperados pelo menos em sinal, com exceção de AE neste último caso.

A expectativa para $\sigma_{\mathrm{A}_{11}}^{2} / \operatorname{Cov}_{\left(\mathrm{A}_{1} \pi 2\right)}$ seria de 10,0 para $\mathrm{PE}$ e de 13,89 para AP e AE. Comparando-se com os valores obtidos aqui $(-9,15$; $-12,28$ e -12,49) e com os calculados para SOUZA JR. (1983): 9,78; 12,0; e 42,50 para $\mathrm{PE}, \mathrm{AP}$ e $\mathrm{AE}$, respectivamente, observa-se que todos os valores no primeiro caso apresentaram sinais trocados enquanto no segundo coincidiram em sinal, e em magnitude com exceção de AE.

O valor esperado (SOUZA JR., 1993) para $\sigma_{\mathrm{A}_{22}^{2}}^{2} / \operatorname{Cov}\left(\mathrm{A}_{2} \tau_{21}\right)$ seria de $-6,25$ para PE e -11,79 para AP e AE. Em comparação com os valores obtidos neste trabalho: $-5,0 ;-4,16$ e $-3,98$ e em SOUZA JR (1983): $-9,34 ;-14,75$ e 437,94 ; respectivamente, observa-se que apenas para $\mathrm{AE}$ neste último caso não houve concordância no sinal da estimativa.

Para a relação $\sigma_{\tau_{12}}^{2} / \operatorname{Cov}_{\left(A_{1} \tau_{12}\right)}$ a expectativa seria de 4,67 para PE e 1,56 para AP e AE. Observou-se -1,69; -2,09 e 0,25 enquanto para SOUZA JR. (1983) obteve-se 1,56;-1,72 e 4,90, respectivamente. Os sinais não coincidiram em PE e AP no primeiro caso e em AP no segundo. Para $\sigma_{\tau_{21}}^{2} / \operatorname{Cov}\left(\mathrm{A}_{2} \tau_{21}\right)$ a expectativa teórica é de $-1,25$ para PE e $-0,71$ para AP e $\mathrm{AE}$, e observou-se $-4,91 ;-3,68$ e $-3,44$ neste trabalho, enquanto para SOUZA JR. (1983) obteve-se $-2,43 ;-3,16$ e $-32,0$ para PE, AP e AE, respectivamente. Neste caso, todos os valores coincidiram em sinal com os esperados. A magnitude observada no segundo trabalho é que ficou mais distante do valor esperado. 
Para a relação $\operatorname{Cov}\left(\mathrm{A}_{1} \pi_{2}\right) / \operatorname{Cov}\left(\mathrm{A}_{2} \tau_{21}\right)$ as expectativas seriam $-2,67$ para $\mathrm{PE}$ e $-1,56$ para AP e AE. Observou-se aqui 0,$46 ; 0,20$ e 0,18 e em SOUZA JR. (1983) -1,25; -1,06 e 13,44 para PE, AP e AE, respectivamente. Houve discordância no sinal para os três caracteres no primeiro caso, e para AE neste último.

Estimativas de variância e covariância normalmente apresentam erros elevados, principalmente quando alguns componentes $\left(\sigma_{\tau_{12}}^{2}\right.$ e $\operatorname{Cov}\left(A_{1} T_{2}\right)$ ) são parte de outro $\left(\hat{\sigma}_{A_{12}^{2}}^{2}\right)$, e isto torna dificil a obtenção de boas estimativas para estes parâmetros. A discordância no sinal de algumas das relações descritas acima (principalmente quando envolveu a população BR-106) ocorreram basicamente em virtude de algumas estimativas negativas de $\sigma_{\tau_{12}}^{2}$ e principalmente $\operatorname{Cov}\left(A_{1} \pi_{2}\right)$, as quais em geral apresentaram erros elevados. Talvez outro delineamento seja mais eficiente para estimar estes parâmetros, apesar das estimativas obtidas para a população 2 terem apresentado erros relativamente pequenos, aproximando-se das expectativas teóricas.

Dos caracteres restantes, $r, D E$, NF e NE apresentaram comportamento similar a $\mathrm{PE}$, com exceção de $\sigma_{\tau_{12}}^{2} / \operatorname{Cov}\left(\mathrm{A}_{1} \pi_{2}\right)$ para $\mathbf{r}$, enquanto CE e NGF apresentaram valores próximos aos esperados teoricamente com exceção de $\sigma_{\mathrm{A} 11}^{2} / \sigma_{\tau_{12}}^{2}$ e $\sigma_{\tau_{21}}^{2} / \operatorname{Cov}\left(\mathrm{A}_{2} \tau_{21}\right)$ que apresentaram sinais trocados. Observa-se que para este conjunto de relações, o par de caracteres DE e NF e o par CE e NGF foram similares, indicando que as 
avaliações sobre DE e CE serviram de referência para o comportamento de NF e NGF, respectivamente (Figuras 1 e 2).

As estimativas das interações dos parâmetros estudados com ambientes não apresentaram um bom nivel de precisão, principalmente para a população BR-105, como já era esperado de acordo com as análises da variância, onde não houve significância da interação progênies com ambientes para a maioria dos casos. Erros relativamente baixos em relação às estimativas foram observados para $\hat{\sigma}_{\mathrm{aA}_{11}^{2}}^{2}\left(\mathrm{CE}\right.$ e NF); $\hat{\sigma}_{\mathrm{aA} 12}^{2}(\mathrm{PE}, \mathbf{r}, \mathrm{CE}$ e $\mathrm{NGF}) ; \hat{\sigma}_{\mathrm{a} \pi 22}^{2}(\mathrm{AE}, \mathrm{CE}, \mathrm{NF}$ e $\mathrm{NGF})$ e $\hat{\operatorname{Cov}\left(\mathrm{aA}_{1} \tau_{12}\right)}(\mathrm{CE}$ e NF) para BR-106 e apenas para $\hat{\sigma}_{\text {a } 221}^{2}(\mathrm{r})$ para BR-105.

\subsection{Variabilidade fenotípica e herdabilidade.}

As variâncias fenotípicas ao nível de médias de progênies e ao nível de plantas das populações intra e interpopulacionais apresentaram magnitudes relativamente próximas para todos os caracteres (Tabelas 23 e 24). O mesmo ocorreu com as variâncias do resíduo experimental entre parcelas e para as variâncias fenotípicas dentro de progênies de meios irmãos intra e interpopulacionais das duas populações (Tabelas 25 e 26).

As estimativas dos coeficientes de herdabilidade ao nivel de plantas de cada população foram maiores para a população BR-105. Estes valores de herdabilidade são importantes pois são utilizados no esquema de seleção massal, que é aplicado por ocasião da escolha das plantas que darão 
origem às progênies. Os valores de herdabilidade para AP $(35,10$ para BR-106 e 53,61 para BR-105) e para $\mathrm{AE}(37,88$ para BR-106 e 59,73 para BR-105) demonstraram que para BR-105 a seleção massal deve apresentar boas respostas. Para os demais caracteres, valores altos de herdabilidade também foram observados para CE, DE e NF nas duas populações, com valores um pouco mais baixos para $\mathbf{r}$ e NGF (Tabelas 23 e 24).

As estimativas de herdabilidade à nível de médias de parcelas, têm maior importância para $\mathrm{PE}$, que será o principal objetivo da seleção e que, justamente por ter menor herdabilidade em relação aos outros caracteres normalmente considerados nos programas (como AP, AE e r), precisa de progênies e repetições para ser melhor avaliado. As herdabilidades obtidas ao nível de médias de progênies intra e interpopulacionais para PE para a população BR-106 (56,96\% e 47,53\%; respectivamente) e para BR-105 (69,65\% e 65,67\%; respectivamente), revelam que em BR-105 a seleção deve ser mais eficiente, pois liberou maior variabilidade aditiva que BR-106. Para todos os outros caracteres, com exceção de NE, observaram-se maiores valores de herdabilidade, o que já era esperado. Pela comparação dos pares de caracteres CE com NGF e DE com NF observa-se que suas magnitudes foram similares tanto ao nível intra como interpopulacional para as duas populações (Tabelas 23 e 24) 


\subsection{Respostas esperadas à seleção.}

O valor do diferencial de seleção estandardizado utilizado no cálculo das respostas esperadas aos vários esquemas de seleção foi de 1,40 que equivale à seleção de $20 \%$ da população. A seleção foi truncada, ou seja, cada caráter foi considerado individualmente na seleção, o que não corresponde à realidade, onde são considerados vários caracteres na seleção dos melhores genótipos. Também vale lembrar que as avaliações foram feitas em dois anos e dois locais e com duas repetições por ano e por local, o que reduz consideravelmente a variância fenotípica. Desta forma, as variâncias fenotípicas ao nível de médias de parcelas (intra e interpopulacionais) foram constituídas de:

$$
\sigma_{\overline{\mathrm{F}}}^{2}=\sigma_{\mathrm{p}}^{2}+\frac{\sigma_{\mathrm{p} \mathrm{a}}^{2}}{\mathrm{I}}+\frac{\sigma_{\mathrm{e}}^{2}}{\mathrm{IJ}}+\frac{\sigma_{\mathrm{d}}^{2}}{\mathrm{IJK}}
$$

Sendo que I foi o número de ambientes (combinação de dois anos e dois locais), $\mathbf{J}$ o número de repetições e $\mathbf{k}$ o número de plantas dentro da parcela. Isto não é feito normalmente nos programas de seleção recorrente. As avaliações são feitas em apenas um ano e em dois ou três locais no máximo. Muitas vezes, o número de plantas por parcela é reduzido para se ter mais locais de avaliação. Para a seleção massal, foi utilizada a variância fenotípica ao nível de plantas, que não estavam disponíveis para PE e NE.

Estes motivos fizeram com que os valores obtidos para as respostas à seleção fossem relativamente altos. Através destes valores pode-se comparar os diversos esquemas de seleção (Tabelas 27 e 28). É importante relembrar que os métodos de seleção recorrente modificados, 
designados SRM(a) e SRM(b), referem-se aos esquemas de seleção onde as populações BR-105 e BR-106 (menor e maior média, respectivamente) foram as testadoras. Desta forma, em SRM(a) a população BR-105 foi testadora dela mesma, o que caracteriza um método intrapopulacional, e também de BR-106, caracterizando um método interpopulacional.

A resposta por ciclo de seleção massal, sem levar em consideração o tempo necessário para completar cada ciclo, apresentou menores expectativas de resposta em relação aos outros métodos para quase todos os casos.

Comparando-se as respostas esperadas obtidas para PE observa-se que: os métodos de seleção recorrente intrapopulacional (SRI) e de seleção recorrente modificada (a) [SRM(a)] foram similares $(10,1$ e 10,2\%, respectivamente) e inferiores aos métodos de seleção recorrente recíproca (SRR) e seleção recorrente modificada (b) [SRM(b)] (13,9 e 13,8\%, respectivamente), no melhoramento do híbrido interpopulacional (H.I.); os métodos SRR e SRM(a) foram similares $(11,4 \%)$ e inferiores a SRI e SRM(b) $(13,8 \%)$ no melhoramento da população BR-106; SRR e SRM(b) foram similares $(9,6 \%)$ e inferiores a SRI e $\operatorname{SRM(a)~(18\% )~para~BR-105;~SRI~e~}$ $\operatorname{SRM}(a)(-77,4$ e $-57 \%$, respectivamente) foram inferiores a $\operatorname{SRM}(\mathrm{b})(44,9 \%)$ e SRR $(65,2 \%)$ para a heterose. Nas comparações SRM(b) e SRR levam muita vantagem em relação aos outros dois tipos para H.I. e para a heterose e SRM(b) ainda foi melhor para BR-106. Desta forma, o método SRM(b) foi a melhor opção, já que foi igual à SRR para H.I. e para BR-105, e melhor que SRR para BR-106, o que o fez perder para SRR na heterose, o que era esperado já que a heterose é medida em relação à média dos parentais. 
Entretanto, a resposta na heterose por $\operatorname{SRM(b)}$ pode ser considerada alta (Tabela 27 e Figura 3).

As respostas para PE (g/planta/ciclo) calculadas para os dados de SOUZA JR. (1983), para as populações ESALQ-PB1 e BR-105 foram as seguintes: pelo esquema SRR obteve-se 12,25 (9,9\%) em H.I.; 12,73 (20,8\%) para ESALQ-PBI; $7,49(6,6 \%)$ para BR-105; e 2,14 (26,3\%) na heterose. Pelo método SRI estes valores foram $10,57(8,6 \%) ; 11,76(10,0 \%) ; 8,87$ $(7,9 \%)$ e $0,25(3,1 \%)$, respectivamente. Para $\operatorname{SRM(a)~foram~} 11,77(9,5 \%)$; $12,73(10,8 \%) ; 8,87(7,9 \%)$ e 0,97 (11,9\%), respectivamente. Para SRM(b) foram de $11,05(8,9 \%) ; 11,76(10,0 \%) ; 7,49(6,6 \%)$ e $1,42 \quad(17,5 \%)$, respectivamente. Pela comparação dessas respostas esperadas, obtêm-se as seguintes relações entre os métodos: $\operatorname{SRI}<\operatorname{SRM}(b)<\operatorname{SRM}(a)<\operatorname{SRR}$ para o híbrido interpopulacional (H.I.); $\quad \mathrm{SRI}=\mathrm{SRM}(\mathrm{b})<\mathrm{SRR}=\operatorname{SRM}(\mathrm{a})$ para ESALQ-PB $1 ; \quad \operatorname{SRR}=\mathrm{SRM}(\mathrm{b})<\mathrm{SRI}=\mathrm{SRM}(\mathrm{a}) \quad$ para $\quad \mathrm{BR}-105 ; \quad$ e $\operatorname{SRI}<\operatorname{SRM}(\mathrm{a})<\operatorname{SRM}(\mathrm{b})<\mathrm{SRR}$ na heterose. Portanto, para estas populações o método SRM(a) (utilizando BR-105 como testadora para as duas populações) foi o que apresentou os melhores resultados para o melhoramento, cujo objetivo é produzir híbridos de linhagens. Neste experimento, a população ESALQ-PBl além de maior média, também apresentou variância aditiva interpopulacional maior que a intrapopulacional $\left(\hat{\sigma}_{\mathrm{A}_{12}^{2}}^{2}>\hat{\sigma}_{\mathrm{A}_{11}^{2}}\right)$ e a covariância $\left(\operatorname{Cov}_{\left(\Lambda_{1} \tau_{12}\right)}\right)$ foi positiva, o que levou a estes resultados.

Conforme já mencionado, a classificação das populações BR-106 e BR-105 como populações 1 e 2 baseou-se nas médias per se, sendo 
que em BR-106 predominou a relação $\hat{\sigma}_{\mathrm{A}_{12}^{2}}^{2}<\hat{\sigma}_{\mathrm{A}_{11}^{2}}$ (exceção de CE e NE) e a covariância $\hat{\operatorname{Cov}}_{\left(\mathrm{A}_{1} \tau_{12}\right)}$ foi negativa (exceção de $\mathrm{CE}$ e $\mathrm{NGF}$ ), enquanto para BR-105 predominou a relação $\hat{\sigma}_{\mathrm{A}_{21}^{2}}^{2}>\hat{\sigma}_{\mathrm{A}_{22}^{2}}^{2}$ (exceção de $\mathrm{AP}, \mathrm{AE}, \mathrm{CE}$ e NE) e a covariância $\operatorname{Cov}_{\left(\mathrm{A}_{2} \tau_{2}\right)}$ foi negativa para todos os caracteres, de forma que em termos de variâncias, o método SRM(b) estudado aqui é equivalente ao SRM(a) aplicado sobre os dados de SOUZA JR. (1983).

As respostas observadas para os caracteres AP, AE e r, foram similares às apresentadas para PE. Estes caracteres normalmente são considerados nos programas de melhoramento, embora com objetivos bem diferentes em relação à PE (Tabela 27).

Alguns componentes da produção como número de fileiras (NF) e número de sementes por fileira (NGF) são de dificil mensuração e dificilmente são avaliados. Entretanto, o diâmetro de espiga (DE) e o comprimento de espiga (CE) são facilmente avaliados e podem estar bem relacionados com NF e NGF, respectivamente. Observou-se que o par DE e NF, e o par CE e NGF apresentaram variações bem correlacionadas nas respostas para o híbrido interpopulacional, nas populações per se, e na heterose, quando considera-se todos os métodos testados. Estas correlações foram detectadas anteriormente em várias oportunidades, indicando que DE e CE são bons parâmetros de referência para os outros componentes de produção (NF e NGF, respectivamente), (Tabela 28).

$\mathrm{O}$ caráter $\mathrm{NE}$ foi a exceção quanto às respostas apresentadas pelos vários métodos, com as seguintes relações: $\mathrm{SRM}(\mathrm{b})<\mathrm{SRI}<\mathrm{SRR}<\mathrm{SRM}$ (a) 
para H.I.; $\quad \mathrm{SRR}=\mathrm{SRM}(\mathrm{a})<\mathrm{SRI}=\mathrm{SRM}(\mathrm{b}) \quad$ para $\quad \mathrm{BR}-106 ; \quad \mathrm{SRR}=\mathrm{SRM}(\mathrm{b})$ $<$ SRI $=$ SRM(a) para BR-105; e $\mathrm{SRI}<\mathrm{SRM}($ a $)<\mathrm{SRM}($ b) $<$ SRR para a heterose. Neste caso, o método SRM(a) seria superior para o híbrido interpopulacional e para a população com menor média (BR-105), o que o torna mais interessante para o melhoramento (Tabela 28).

Embora o método SRM(b) tenha sido superior aos demais neste estudo para a maioria dos caracteres, ele não atendeu de forma plena a um dos objetivos básicos do melhoramento do milho visando a produção de híbridos de linhagens, pois esperava-se que as respostas sobre a população menos desenvolvida por SRM(b) fosse superior ao esquema SRR. O motivo principal deste resultado, foi a estimativa de $\hat{\operatorname{Cov}}_{\left(\Lambda_{1}, \tau_{12}\right)}$ que foi predominantemente negativa, fazendo diminuir a resposta esperada na população designada como população 1 (Tabela 6). O mesmo não aconteceu com as populações ESALQ-PBl x BR-105 (SOUZA JR.,1983), onde o esquema equivalente $[\operatorname{SRM}(\mathrm{a})]$ obteve resposta próxima no híbrido interpopulacional, igual em ESALQ-PBl e superior em BR-105 em relação à SRR.

O método modificado aplicado neste trabalho e sobre os dados de SOUZA JR. (1983) foi superior aos demais métodos. O importante para se obter os melhores resultados é definir de forma correta qual população será utilizada como testadora. Esta definição, como já foi concluído, não deve se basear apenas nos valores médios populacionais como fora sugerido por SOUZA JR. (1993), mas sobre as magnitudes dos componentes de variância intra e interpopulacionais que podem ser obtidas em experimentos como este, ou até com delineamentos mais apropriados. 


\section{CONCLUSÕES}

Para as condições em que foi realizado o trabalho, pode-se concluir:

a) As populações BR-105 e BR-106 apresentaram boas performances para os caracteres estudados, assim como o seu híbrido interpopulacional que apresentou um valor alto de heterose, mas ainda abaixo dos valores observados sob outras condições, indicando a presença de divergência genética entre as populações. Assim, estas populações apresentam bom potencial genético para se constituirem em fontes de híbridos de linhagens.

b) As estimativas dos componentes de variância genética aditiva para peso de espigas obtidas ao nivel intra e interpopulacional comprovam o potencial dessas populações para o melhoramento. As estimativas dos novos componentes $\sigma_{\tau}^{2}$ e $\operatorname{Cov}(\mathrm{A} \tau)$ para as duas populações confirmam que estes efeitos estão interferindo em muitos casos, de forma negativa, nas respostas diretas e indiretas à seleção recorrente reciproca (SRR) e na resposta indireta à seleção recorrente intrapopulacional (SRl). 
c) Para os demais caracteres, as estimativas mostraram que as duas populações possuem variabilidade genética aditiva ao nível intra- e interpopulacional. Para a população BR-106, na maioria dos casos, os valores obtidos da $\operatorname{Cov}\left(\mathrm{A}_{1} \tau_{12}\right)$ foram negativos e de baixa magnitude enquanto os valores de $\sigma_{\tau 12}^{2}$ apresentaram sinal negativo em alguns casos, mas todos com magnitudes pequenas quando comparados aos mesmos componentes estimados para BR-105. Para a população BR-105, todos os valores obtidos da $\operatorname{Cov}\left(\mathrm{A}_{2} \tau 21\right)$ foram negativos $\mathrm{e}$ com magnitudes relativamente altas e para $\sigma_{T 21}^{2}$ foram positivos e com magnitudes também altas. No caso destes caracteres, como aconteceu para peso de espigas, todas as estimativas do progresso que apresentem no numerador de suas expressões o componente $\operatorname{Cov}(\mathrm{A} \tau)$ estão sendo prejudicadas por este efeito. Os erros associados à $\sigma_{\tau_{12}}^{2}$ e $\operatorname{Cov}\left(\mathrm{A}_{1} \tau_{12}\right)$ foram relativamente altos para todos os caracteres, inclusive para o peso de espigas.

d) O esquema de seleção recorrente modificado (SRM) foi considerado mais eficiente que a seleção recorrente recíproca (SRR) e a seleção recorrente intrapopulacional (SRI) para atender de forma ampla às necessidades de um programa de produção de híbridos de linhagens.

e) Os progressos esperados calculados para os caracteres avaliados mostraram que a seleção recorrente modificada [SRM, equivalente ao SRM(b)] foi a melhor opção para o melhoramento de populações visando desenvolver híbridos de linhagens. Entretanto, o método não foi totalmente satisfatório, uma vez que as respostas esperadas para a população BR-105 ainda são relativamente baixas. Apenas o caráter prolificidade apresentou 
um comportamento bem diferente dos demais, indicando o esquema SRM(a) como o mais eficiente.

f) Para os caracteres relacionados à produção, o comprimento de espiga (CE) e o diâmetro de espigas (DE) estiveram bem relacionados com o número de grãos por fileira na espiga (NGF) e o número de fileiras na espiga (NF), respectivamente. Desta forma, $\mathrm{CE}$ e $\mathrm{DE}$, que são de fácil avaliação, podem ser utilizados como referências dos comportamentos de NGF e NF, respectivamente.

g) A escolha da população testadora no esquema SRM feita com base apenas nas médias intrapopulacionais pode não ser correta. Seria mais apropriado, quando possivel, considerar também as magnitudes relativas das variâncias aditivas intra- e interpopulacionais de cada população.

h) Os delineamentos genéticos e estatísticos não atingiram plenamente os objetivos do trabalho, pois os novos componentes $\sigma_{\tau}^{2}$ e $\operatorname{Cov}(A \tau)$ só foram estimados eficientemente (com erros associados relativamente baixos) para a população BR-105. Contudo, foram raros os problemas de estimabilidade, tais como estimativas negativas de variâncias com erros associados relativamente pequenos ou valores de correlação genética maiores que a unidade, podendo estar relacionados com problemas na amostragem. 


\section{REFERÊNCIAS BIBLIOGRÁFICAS}

COMSTOCK, R.E.; ROBINSON H.F.; HARVEY, P.H. A breeding procedure designed to make maximum use of both general and specific combining ability. Agronomy Journal, Madison, 41: 360-7, 1949.

COORS, J.G. \& MARDONES, M.C. Twelve cycles of mass selection for prolificacy in maize. I. Direct and correlated responses. Crop Science, Madison, 29:262-6, 1989

COWEN, N.M. Testcross selection theory. Theoretical and Applied Genetics, Berlin, 73: 371-8, 1987

DARRAH, L.L.; EBERHART, S.A.; PENNY, L.H. Six years of maize selection in "Kitale Synthetic II", "Ecuador 573", and "Kitale Composite A" using methods of the comprehensive breeding systems. Euphytica, Wageningen, 27:191-204, 1978.

DEVEY, D.E. \& RUSSELL, W.A. Evaluation of recurrent selection for stalk quality in a maize cultivar and effects of other agronomic traits. Iowa State Jounal Research, 58:207-19, 1983.

DHILLON, B.S. \& KHEHRA, A.S. Modified S1 recurrent selection in maize improvement. Crop Science, Madison, 29: 226-8, 1989. 
DUDLEY, J.W. Seventy-six generations of selection for oil and protein percentage in maize. In INTERNATIONAL CONFERENCE OF QuAntitative Genetics, Ames, 1976. Proceedings. Ames, Iowa State University Press, 1977. p.459-73.

DUDLEY, J.W. \& LAMBERT, R.J. Ninety generations of selection for oil and protein in maize. Maydica, Bergamo, 37:81-7, 1992.

EBERHART, S.A.; DEBELA, S.; HALLAUER, A.R. Reciprocal recurrent selection in BSSS and BSCB1 maize populations and half-sib selection in BSSS. Crop Science, Madison, 13:451-6, 1973.

EYHERABIDE, G.H. \& HALlAUER, A.R. Reciprocal full-sib recurrent selection in maize: I. Direct and indirect responses. Crop Science, Madison, 31:952-9, 1991 a.

EYHERABIDE, G.H. \& HALLAUER, A.R. Reciprocal full-sib recurrent selection in maize: II. Contributions of additive, dominance, and genetic drift effects. Crop Science, Madison, 31:1442-8, 1991 b.

FALCONER, D.S. Introduction to quantitative genetics. New York, Ronald Press, 1960. 365p.

GARDNER, C.O. Quantitative genetic studies and population improvment in maize and sorghum. In INTERNATIONAL CONFERENCE OF QuAntitative Genetics, Ames, 1976. Proceedings. Ames, Iowa State University Press, 1977. p.16-21. 
GARDNER, C.O. Population improvement in maize. In: WALDEN, D.B., ed. Maize breeding and genetics. New York, John Wiley and Sons, 1978. p.207-28.

GEVERS, H.O. Three cycles of reciprocal recurrent selection in maize under two systems of plant selection. Agroplante, 7:107-8, 1975.

GHINI, R. \& MIRANDA FILHO, J.B. Herdabilidade da altura da planta e da espiga no segundo ciclo de seleção da população ESALQ-PBl de milho. Relatório Científico do Departamento de Genética, Piracicaba, 13: 130-8, 1979 .

HALlAUER, A.R. Reciprocal full-sib selection in maize. Crop Science, Madison, 24: 755-9, 1984.

HALlAUER, A.R. \& EBERHART, S.A. Reciprocal full-sib selection. Crop Science, Madison, 10: 315-6, 1970.

HALlAUER, A.R.; RUSSEll, W.A.; LAMKEY, K.R. Corn breeding. In: SPRAGUE, G.F. \& DUDLEY, J.W., ed. Corn and corn improvement. Madison, ASA, 1988. p.463-565.

HAMMOND, J.J. \& GARDNER, C.O. Modification of the variety cross diallel model for evaluating cycles of selection. Crop Science, Madison, 14:6-8, 1974.

HELMS, T.C.; HALLAUER, A.R.; SMITH, O.S. Genetic drift and selection evaluated from recurrent selection programs in maize. Crop Science, Madison, 29:602-7, 1989. 
HORNER, E.S. Effects of selection for S2 progeny versus testcross performance in corn. In: ANNUAL CORN AND SORGHUM INDUSTRY RESEARCH CONFERENCE, 1985. Proceedings. 1985. p. $142-50$.

HORNER, E.S.; MAGLOIRE, E.; MORERA, J.A. Comparisons of selection for S2 progeny vs testcross performance for population improvement in maize. Crop Science, Madison, 29: 868-74, 1989.

HORNER, E.S.; LUNDY, H.W.; LUTRICK, M.C.; CHAPMAN, W.H. Comparisons of three methods of recurrent selection in maize. Crop Science, Madison, 13:485-9, 1973.

HULL, H.F. Recurrent selection and specific combining ability in corn. Journal of the American Society of Agronomy, Washington, 37: 134-45, 1945.

JENKINS, M.T. The segregation of genes affecting yield of grain in maize. Journal of the American Society of Agronomy, Washington, 32:55-63, 1940.

KEERATINIJAKAL, V. \& LAMKEY, K.R. Genetic effects associated with reciprocal recurrent selection in BSSS and BSCB1 maize populations. Crop Science, Madison, 33:78-82, 1993 a.

KEERATINIJAKAL, V. \& LAMKEY, K.R. Responses to reciprocal recurrent selection in BSSS and BSCBl maize populations. Crop Science, Madison, 33:73-7, 1993b. 
KEMPTHORNE, O. An introduction to genetical statistics. New York, John Wiley, 1966. 545p.

LAMKEY, K.R. Fifty years of recurrent selection in Iowa Stiff Stalk Synthetic maize population. Maydica, Bergamo, 37:19-28, 1992.

LIMA, M. \& PATERNiANi, E. Seleção entre e dentro de famílias de meios irmãos na população de milho (Zea mays L.) ESALQ-VD-2. Relatório Científico do Departamento de Genética, Piracicaba, 11:82-3, 1977.

LIVINI, C.; PIROVANO, L.; BRANDOLINI, A.; LORENZONI, C.; MOTTO, M. Evaluation of three cycles of recurrent selection for yield in an opaque-2 variety of maize. Maydica, Bergamo, 37:89-93, 1992.

MARTIN, J.M. \& HALLAUER, A.R. Seven cycles of reciprocal recurrent selection in BSSS and BSCB1 maize populations. Crop Science, Madison, 20: 599-603, 1980.

MARTINS, C.S. Potencial genético de linhagens e híbridos de duas populações de milho (Zea mays L.) braquítico, Piracicaba, 1986. 135p. (Mestrado - Escola Superior de Agricultura "Luiz de Queiroz" / USP).

MATHER, K. \& JINKS, J.L. Biometrical genetics. 3.ed. London, Chapman and Hall, 1982. 396p.

MIRANDA, L.T.; MIRANDA, L.E.C.; POMMER, C.V.; SAWASAKI, E. Oito ciclos de seleção entre e dentro de famílias de meios irmãos no milho IAC-1. Bragantia, Campinas, 36:187-96, 1977. 
MIRANDA FILHO, J.B. \& PATERNIANI, E. Intra and interpopulation genetic parameter estimates and implications in selection. Revista Brasileira de Genética, Ribeirão Preto, 6:15-27, 1983.

MOLL, R.H. \& HANSON, W.D. Comparisons of effects of intrapopulation vs. interpopulation selection in maize. Crop Science, Madison, 24: 1047-52, 1984.

MOLL, R.H. \& STUBER, C.W. Comparisons of response to alternative selection procedures initiated with two population of maize (Zea mays L.) Crop Science, Madison, 11:706-11, 1971 .

MOLL, R.H.; COCKERHAM, C.C.; STUBER, C.W.; WILLIAMS, W.P. Selection responses, genetic-environmental interactions, and heterosis with recurrent selection for yield in maize. Crop Science, Madison, 18:599-603, 1978 .

MULAMBA, N.N.; HALlAUER, A.R.; SMITH, O.S. Recurrent selection for grain yield in a maize population. Crop Science, Madison, 23:536-40, 1983.

NASPOLINI FILHO, V.; GAMA, E.E.G.; VIANNA, R.T.; MÔRO, J.R. General and specific combining ability for yield in a diallel cross among 18 maize populations (Zea mays L.). Revista Brasileira de Genética, Ribeirão Preto, 4: 571-7, 1981.

OBILANA, A.T.; HALlAUER, A.R.; SMITH, O.S. Estimated genetic variability in a maize interpopulation. Journal of Heredity, Washington, 70: $127-32,1979$. 
PANDEY,S.; DIALlO, A.O.; ISLAM, T.M.T.; DEUTSCH, J. Progress from selection in eight tropical maize populations using international testing. Crop Science, Madison, 26:879-84, 1986.

PATERNIANi, E. Avaliação do método de seleção entre e dentro de famílias de meios irmãos no melhoramento do milho (Zea mays L.). Piracicaba, 1968. 92p. (Cátedra - Escola Superior de Agricultura "Luiz de Queiroz"/USP).

PATERNIANI, E. Selection among and within half-sib families in a brazilian population of maize (Zea mays L.). Crop Science, Madison, 7:212-6, 1967.

PATERNIANI, E. Seleção massal com controle biparental para prolificidade em milho. Relatório Científico do Departamento de Genética / ESALQ, Piracicaba, 14:69-76, 1980.

PATERNIANI, E. Seleção recorrente recíproca com plantas prolíficas. Relatório Científico do Departamento de Genética / ESALQ, Piracicaba, 5:129-32, 1971 .

PATERNIANI, E. \& VENCOVSKY, R. Reciprocal recurrent selection in maize (Zea mays L.) based on testcross of half-sib families. Maydica, Bergamo, 22:141-52, 1977

PATERNIANI, E. \& VENCOVSKY, R. Reciprocal recurrent selection on half-sib progenies and prolific plants in maize (Zea mays L.). Maydica, Bergamo, 23: 209-19, 1978. 
PENNY, L.H. \& EBERHART, S.A. Twenty years of reciprocal recurrent selection with two synthetic varieties of maize (Zea mays L.). Crop Science, Madison, 11:900-3, 1971.

POMMER, C.V. \& GERALDI, I.O. Selection among and within half-sib families in OPAQUE-2 maize populations. Revista Brasileira de Genética, Ribeirão Preto, 6:461-72, 1983.

RAMALHO, M.A.P. Efíciência relativa de alguns processos de seleção intrapopulacional no milho baseados em famílias não endógamas. Piracicaba, 1977. 122p. (Doutorado - Escola Superior de Agricultura "Luiz de Queiroz" / USP).

RUSSELL, W.A. \& EBERHART, S.A. Hybrid performance of maize lines from reciprocal recurrent and testcross selection programs. Crop Science, Madison, 15: 1-4, 1975.

RUSSELL, W.A.; BLACKBURN, D.J.; LAMKEY, K.R. Evaluation of a modified reciprocal recurrent selection procedure for maize improvement. Maydica, Bergamo, 37:61-7, 1992.

SALAZAR, A.M. \& HALlAUER, A.R. Divergent mass selection for ear length in maize. Revista Brasileira de Genética, Ribeirão Preto, 9:281-94, 1986.

SANTOS, M.X. \& NASPOLINI FILHO, V. Estimativas de parâmetros genéticos em três ciclos de seleção entre e dentro de famílias de meios irmãos no milho (Zea mays L.) Dentado Composto Nordeste. Revista Brasileira de Genética, Ribeirão Preto, 9:307-19, 1986a. 
SANTOS, M.X. \& NASPOLINI FILHO, V. Estimativas de parâmetros genéticos para peso de espigas na população de milho "Flint Composto Nordeste". Pesquisa Agropecuária Brasileira, Brasília, 21:739-46, 1986b.

SEGOVIA, R.T. Seis ciclos de seleção entre e dentro de famílias de meios irmãos no milho (Zea mays L.) Centralmex. Piracicaba, 1976. 98p. (Doutorado - Escola Superior de Agricultura "Luiz de Queiroz" / USP).

SHULL, G.H. A pure line method of corn breeding. American Breeders' Association Report, 5:51-9, 1909.

SINGH, M.; KHEHRA, A.S.; DHILLON, B.S. Direct and correlated response to recurrent full-sib selection for prolificacy in maize. Crop Science, Madison, 26:275-8, 1986.

SMITH, O.S. Application of a modified diallel analysis to evaluate recurrent selection for grain yield in maize. Crop Science, Madison, 19:819-22, 1979a.

SMITH, O.S. A model for evaluating progress from recurrent selection. Crop Science, Madison, 19:223-6, 1979b.

SMITH, O.S. Evaluation of recurrent selection in BSSS, BSCB 1, and BS13 maize populations. Crop Science, Madison, 23:35-40,1983. 
SOUZA JÚNIOR, C.L. Variabilidade genética em milho (Zea mays L.) e relações com a seleção recorrente intra e interpopulacional. Piracicaba, 1983. 151p. (Doutorado - Escola Superior de Agricultura "Luiz de Queiroz" / USP).

SOUZA JÚNIOR, C.L. Reciprocal recurrent selection with half-sib progenies obtained alternately from non-inbred (So) and inbred (S1) plants in maize (Zea mays L.) Maydica, Bergamo, 32: 19-31, 1987.

SOUZA JÚNIOR, C.L. Componentes de variância genética e suas implicações no melhoramento vegetal. Piracicaba, FEALQ, 1989. $134 \mathrm{p}$.

SOUZA JÚNIOR, C.L. Interpopulation genetic variances and hybrid breeding programs. Revista Brasileira de Genética, Ribeirão Preto, 15: 643-56, 1992.

SOUZA JÚNIOR, C.L. Comparisons of intra-, interpopulation, and modified recurrent selection methods. Revista Brasileira de Genética, Ribeirão Preto, 16: 91-105, 1993.

SOUZA JÚNIOR, C.L. \& MIRANDA FILHO, J.B. Alterações na heterose via seleção intra e interpopulacional. Pesquisa Agropecuária Brasileira, Brasília, 20:1197-201, 1985.

SOUZA JÚNIOR., C.L. \& MIRANDA FILHO, J.B. Avaliação do potencial genético das populações de milho (Zea mays L.) ESALQ PB-4 e ESALQ PB-5 para o melhoramento interpopulacional. In: CONGRESSO NACIONAL DE MILHO E SORGO, 17. Anais, 1988. 
SOUZA JÚNIOR, C.L. \& MIRANDA FILHO, J.B. Genetic variability in two maize (Zea mays L.) populations and its relationship with intra and interpopulation recurrent selection. Revista Brasileira de Genética, Ribeirão Preto, 12:271-85, 1989.

SOUZA JÚNIOR, C.L.; SANTOS, M.X.; MAGNAVACA, R.; GAMA, E.E.G. Estimativas de parâmetros genéticos na interpopulação de milho BR-105 x BR-106 e suas implicações no melhoramento. Pesquisa Agropecuária Brasileira, Brasília, 28: 473-9, 1993.

STEEL, R.G.D. \& TORRIE, J.H. Principles and procedures of statistics. New York, Mc Graw-Hill, 1960. 481 p.

STROMBERG, L.D. \& COMPTON, W.A. Ten cycles of full-sib selection in maize. Crop Science, Madison, 29:1170-72, 1989.

STUBER, C.W. Characterization and estimation of genetic parameters in the interpopulation formed by crossing two population of maize. Raleigh, 1965. 105p. (Ph. D. - Thesis, North Carolina State University).

STUBER, C.W. \& COCKERHAM, C.C. Gene effects and variances in hybrid populations. Genetics, Princeton, 54: 1279-86, 1966.

TANNER, A.H. Comparison of half-sib and S1 recurrent selection in "Krug Yellow Dent". Ames, 1984. (Ph.D. - Iowa State University).

TANNER, A.H. \& SMITH, O.S. Comparison of half-sib and S1 recurrent selection in Krug Yellow Dent maize populations. Crop Science, Madison, 27: 509-13, 1987. 
VENCOVSKY, R. \& BARRIGA, P. Genética biométrica no fitomelhoramento. Ribeirão Preto, Sociedade Brasileira de Genética, 1992. 496p.

VENCOVSKY, R.; MIRANDA FILHO, J.B.; SOUZA JÚNIOR, C.L. Quantitative genetics and corn breeding in Brazil. In: INTERNATIONAL CONFERENCE ON QUANTITATIVE GENETICS, 2., Raleigh, 1987. Proceedings, Sinauer Associates, Sunderland, 1988. p. 465-77. 
FIGURAS 

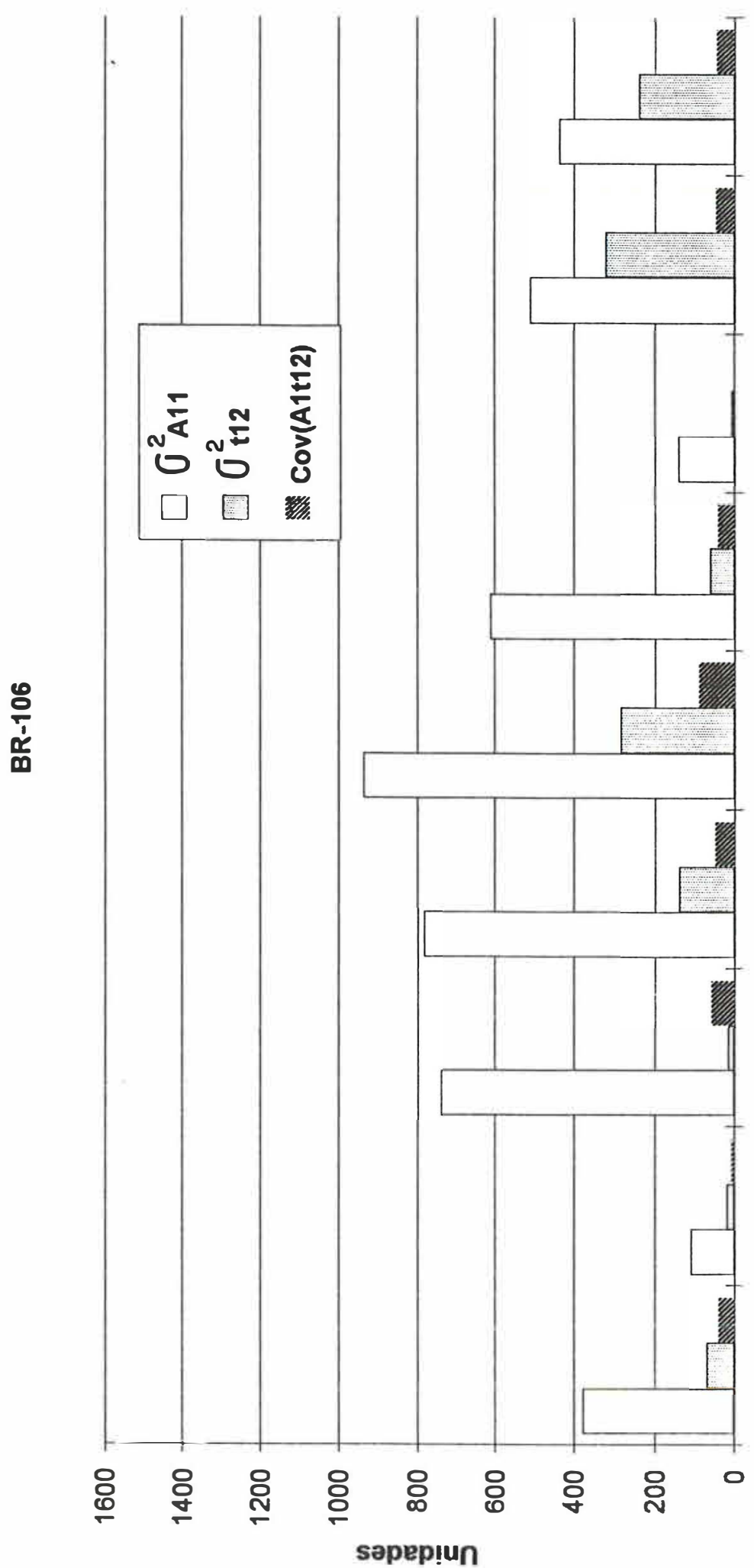

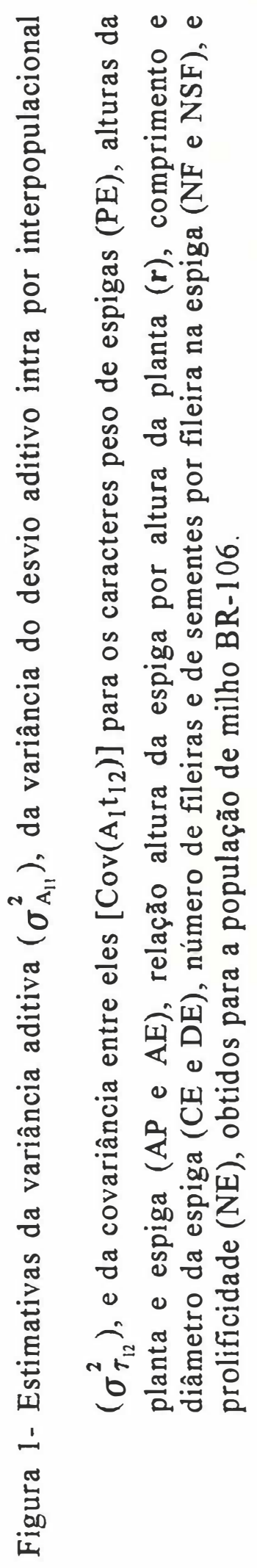



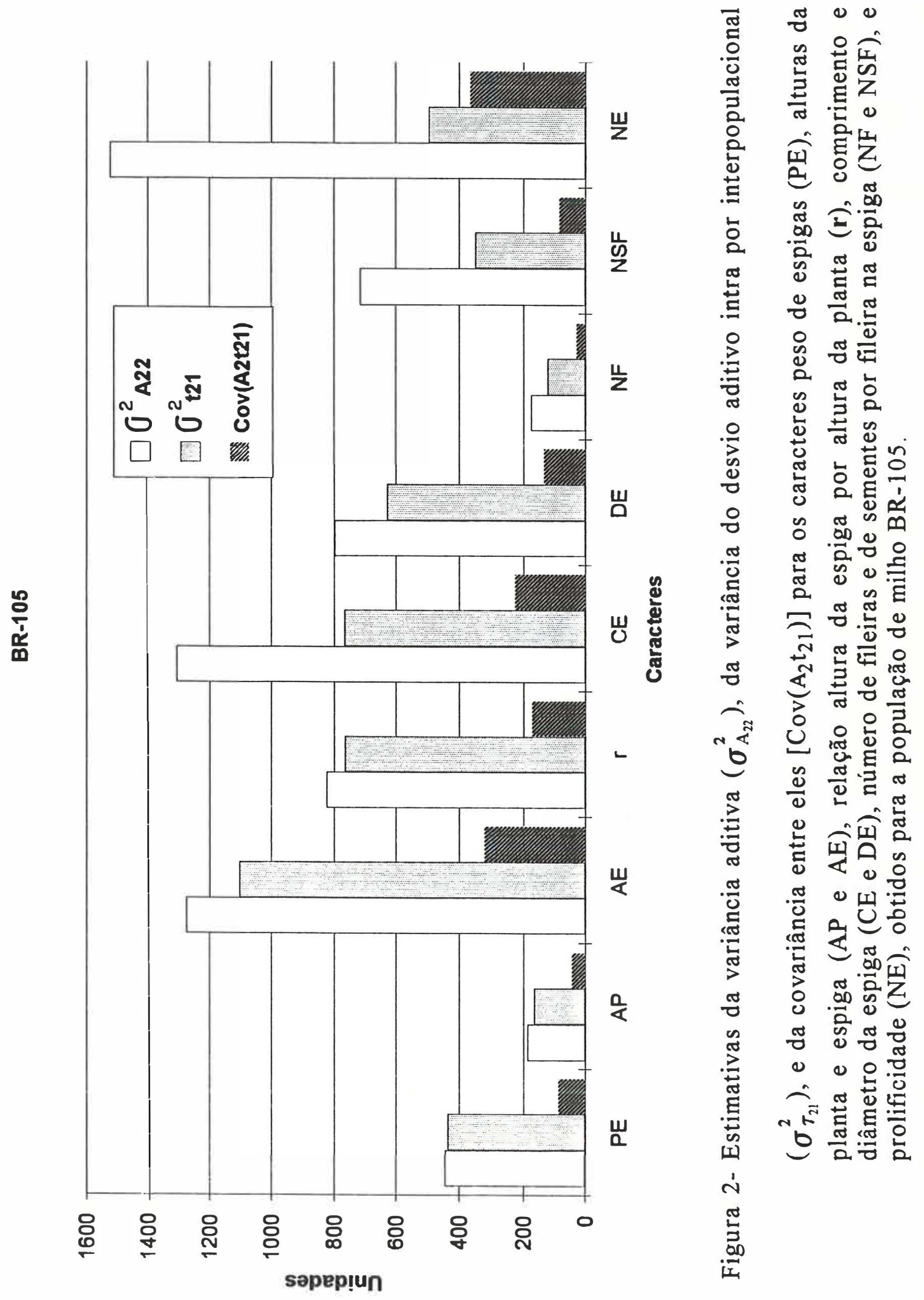

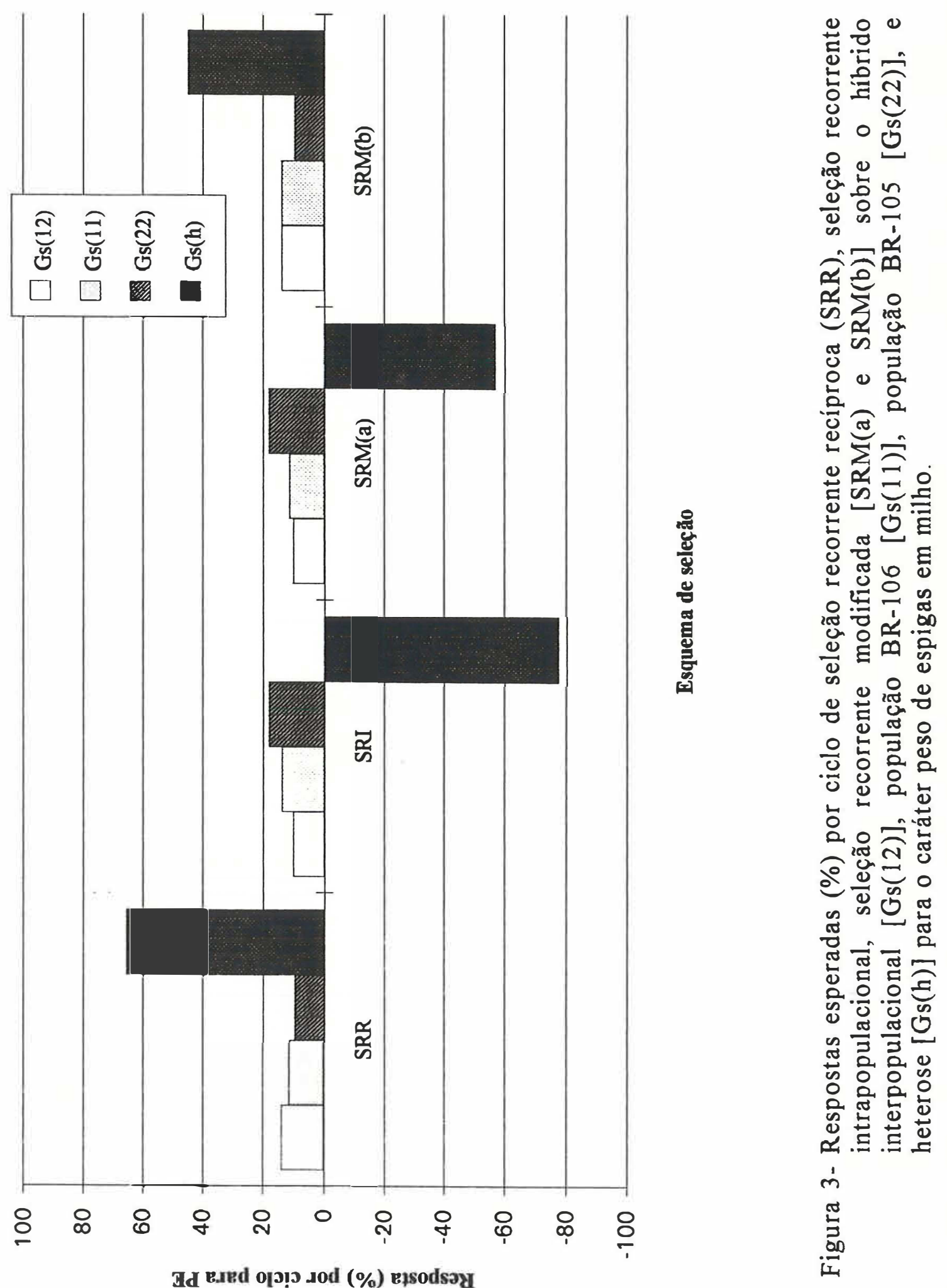
TABELAS 


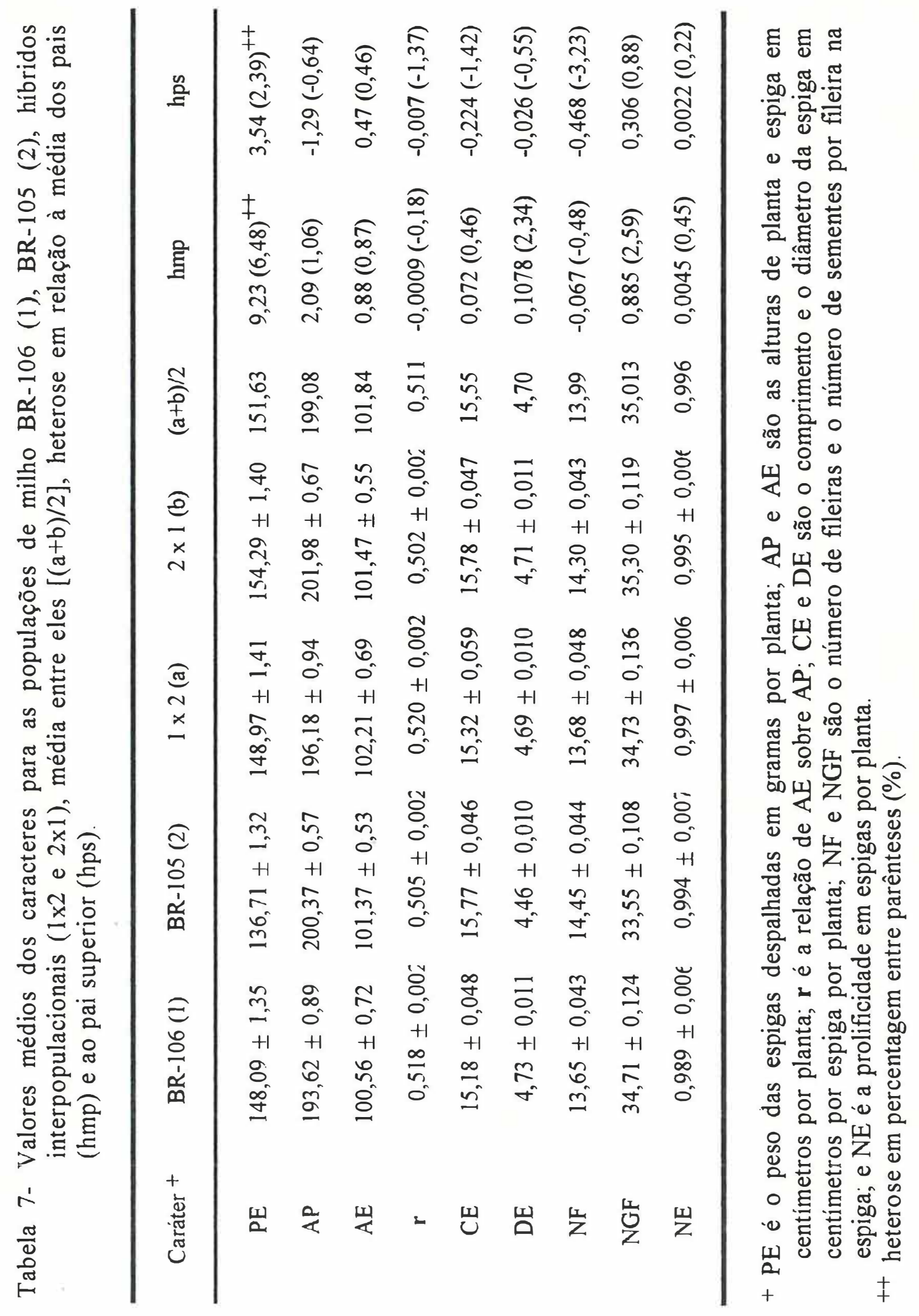




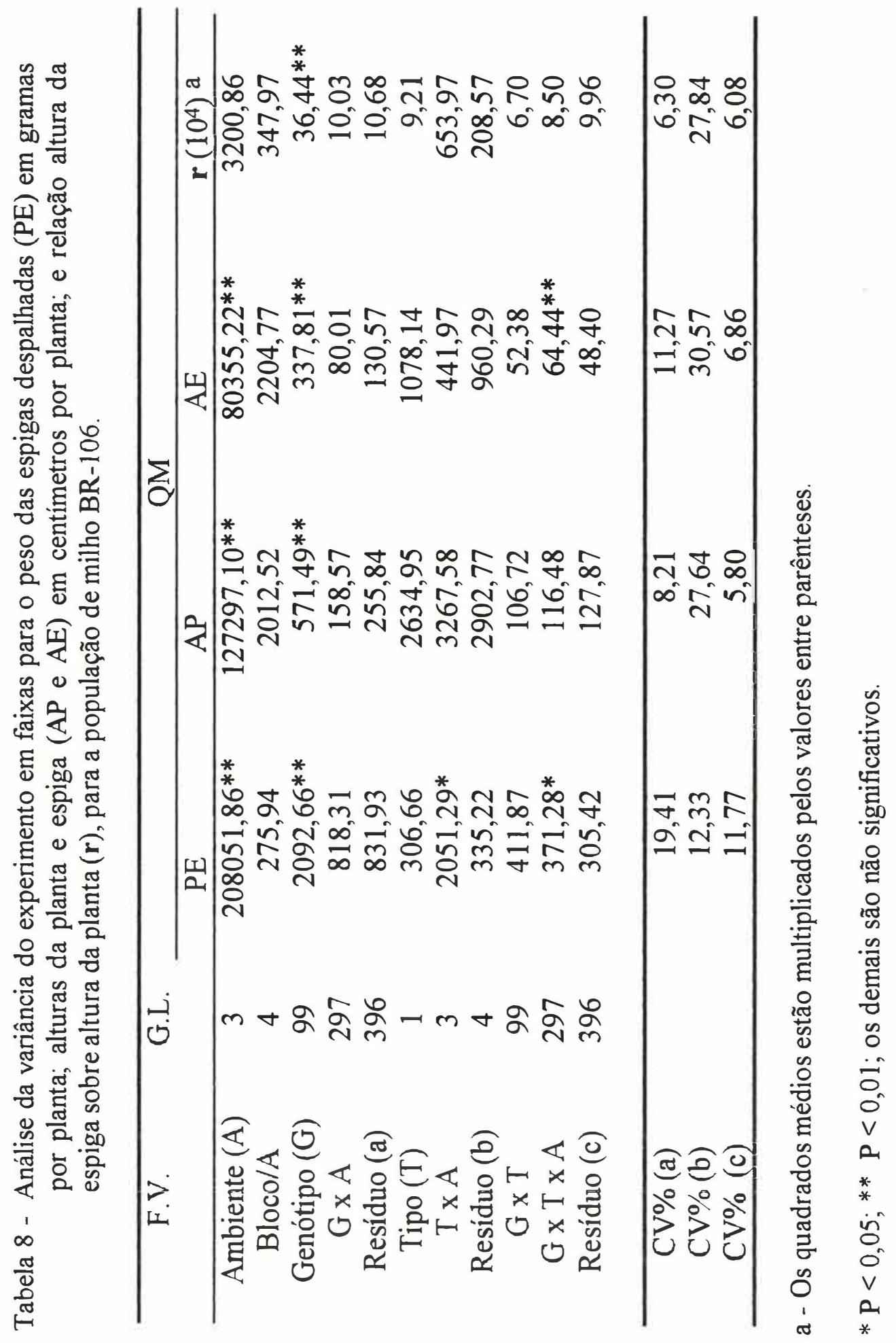




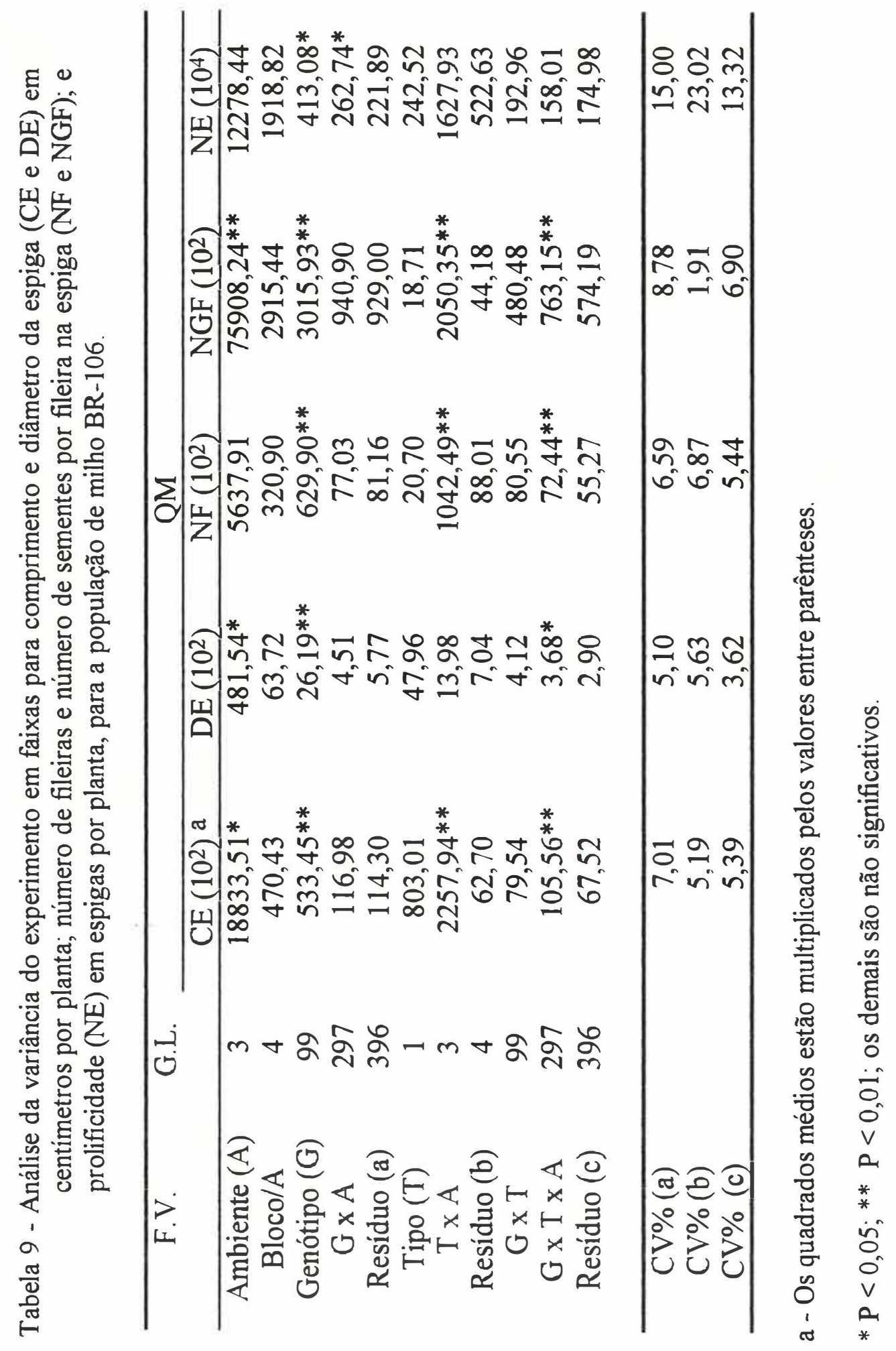




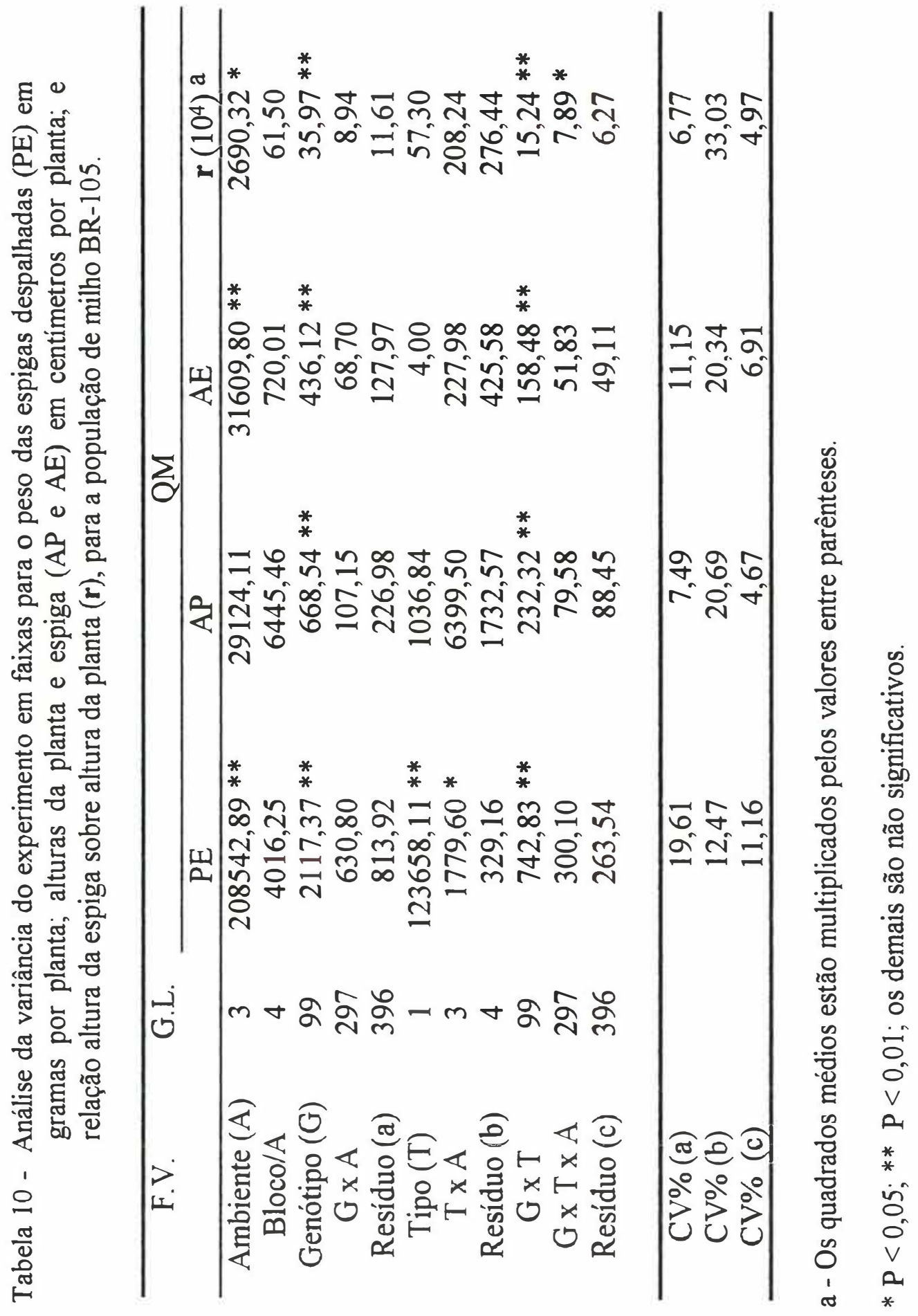




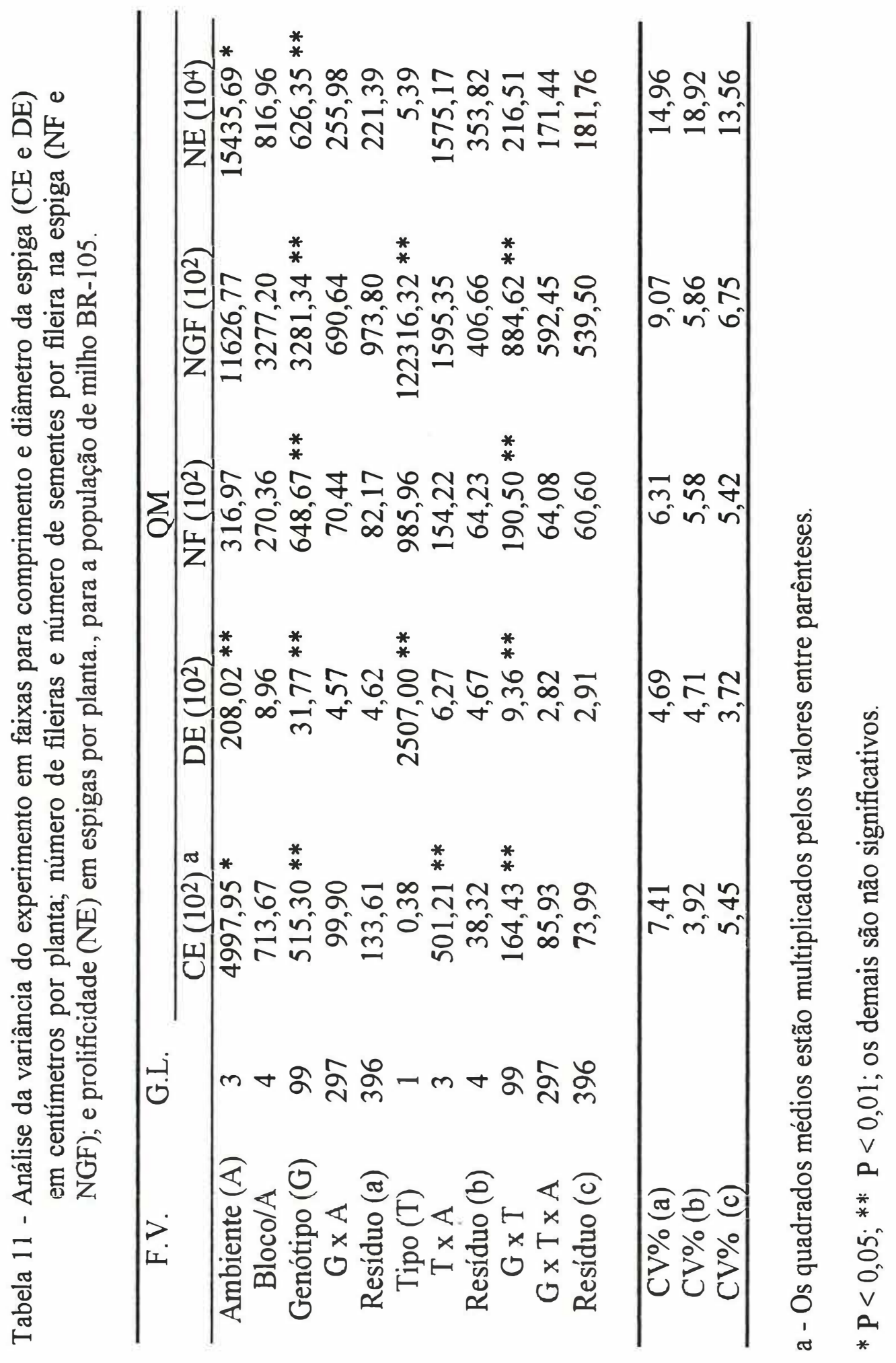


Tabela 12 - Quadrados e produtos médios obtidos para peso de espigas (PE), altura da planta e da espiga (AP e AE), e relação altura da espiga sobre altura da planta (r) das análises de variância e covariância feitas com progênies intra (11) e interpopulacionais (12), para a população de milho BR-106.

\begin{tabular}{|c|c|c|c|c|}
\hline F.C. & G.L. & QM11 & QM12 & PM12 \\
\hline \multicolumn{5}{|c|}{ PE (gramas/planta) } \\
\hline Ambiente (A) & 3 & $96302,67 * *$ & $113800,47^{* *}$ & 103000,28 \\
\hline Blocos/A & 4 & 202,28 & 408,87 & $-29,64$ \\
\hline Progênie (P) & 99 & $1320,56^{* *}$ & $1183,96^{* *}$ & 815,23 \\
\hline $\mathrm{P} \times \mathrm{A}$ & 297 & 568,39 & $621,18^{* *}$ & 227,39 \\
\hline Resíduo médio & 324 & 479,89 & 435,56 & 166,64 \\
\hline CV\% & & 14,79 & 14,01 & \\
\hline \multicolumn{5}{|c|}{$\mathrm{AP}$ (centímetros/planta) } \\
\hline Ambiente (A) & 3 & $61821,16^{* *}$ & $68743,51^{* *}$ & 62014,75 \\
\hline Blocos/A & 4 & 2588,00 & 2327,29 & $-445,12$ \\
\hline Progênie (P) & 99 & $344,06 * *$ & $334,14^{* *}$ & 207,27 \\
\hline $\mathrm{P} \times \mathrm{A}$ & 297 & 125,43 & 149,61 & 24,25 \\
\hline Resíduo médio & 324 & 122,25 & 129,16 & 35,02 \\
\hline $\mathrm{CV} \%$ & & 5,71 & 5,79 & \\
\hline \multicolumn{5}{|c|}{$\mathrm{AE}$ (centímetros/planta) } \\
\hline Ambiente (A) & 3 & $41522,37^{* *}$ & $39274,81^{* *}$ & 39956,62 \\
\hline Blocos/A & 4 & 2435,03 & 730,02 & 622,24 \\
\hline Progênie (P) & 99 & $221,08^{* *}$ & $169,10^{* *}$ & 134,70 \\
\hline $\mathrm{P} \times \mathrm{A}$ & 297 & 73,00 & $71,43 *$ & 10,35 \\
\hline Resíduo médio & 324 & 66,55 & 57,72 & 17,34 \\
\hline $\mathrm{CV} \%$ & & 8,11 & 7,43 & \\
\hline \multicolumn{5}{|c|}{$\mathbf{r}\left[10^{4}\right]^{\mathrm{a}}$} \\
\hline Ambiente (A) & 3 & 2386,02 & $1468,80^{* *}$ & 1273,44 \\
\hline Blocos/A & 4 & 515,63 & 40,89 & 69,70 \\
\hline Progênie (P) & 99 & $25,67^{* *}$ & $17,46^{* *}$ & 14,48 \\
\hline $\mathrm{P} \times \mathrm{A}$ & 297 & 9,99 & $8,53^{* *}$ & 0,78 \\
\hline Resíduo médio & 324 & 8,36 & 6,46 & 0,63 \\
\hline $\mathrm{CV} \%$ & & 5,59 & 4,89 & \\
\hline
\end{tabular}

a. Os quadrados e produtos médios estão multiplicados pelos valores entre colchetes.

${ }^{*} \mathrm{P}<0,05 ;{ }^{* *} \mathrm{P}<0,01$; os demais são não significativos. 
Tabela 13 - Quadrados e produtos médios obtidos para comprimento e diâmetro da espiga (CE e $\mathrm{DE}$ ), número de fileiras na espiga (NF), número de sementes por fileira na espiga (NGF), e prolificidade (NE) das análises de variância e covariância feitas com progênies intra- (11) e interpopulacionais (12), para a população de milho BR-106.

\begin{tabular}{|c|c|c|c|c|}
\hline F.C. & GL & QM11 & QM12 & PM12 \\
\hline \multicolumn{5}{|c|}{$\mathrm{CE}$ (centímetros/planta) $\left[10^{2}\right]^{\mathrm{a}}$} \\
\hline Ambiente (A) & 3 & $4601,85^{* *}$ & $16489,59^{* *}$ & 8287,78 \\
\hline Blocos/A & 4 & 276,29 & 256,84 & 203,86 \\
\hline Progênie (P) & 99 & $296,81^{* *}$ & $316,17^{* *}$ & 229,15 \\
\hline $\mathrm{P} \times \mathrm{A}$ & 297 & $109,41^{* *}$ & $113,12^{*}$ & 5,24 \\
\hline Resíduo médio & 324 & 74,95 & 88,56 & 18,12 \\
\hline $\mathrm{CV} \%$ & & 5,70 & 6,14 & \\
\hline \multicolumn{5}{|c|}{ DE (centímetros/planta) $\left[10^{2}\right]$} \\
\hline Ambiente (A) & 3 & 272,18 & $223,33^{* *}$ & 233,77 \\
\hline Blocos/A & 4 & 56,01 & 14,74 & 28,33 \\
\hline Progênie (P) & 99 & $16,10 * *$ & $14,20^{* *}$ & 11,00 \\
\hline $\mathrm{P} \times \mathrm{A}$ & 297 & 3,91 & 4,28 & 0,55 \\
\hline Resíduo médio & 324 & 3,49 & 3,57 & 0,63 \\
\hline $\mathrm{CV} \%$ & & 3,95 & 4,03 & \\
\hline \multicolumn{5}{|c|}{ NF (fileiras/espiga) $\left[10^{2}\right]$} \\
\hline Ambiente (A) & 3 & 1004,59 & $5675,80^{* *}$ & 2297,71 \\
\hline Blocos/A & 4 & 370,09 & 38,82 & 116,44 \\
\hline Progênie $(P)$ & 99 & $357,73^{* *}$ & $352,70^{* *}$ & 275,13 \\
\hline$P \times A$ & 297 & $76,13 *$ & 73,34 & 1,78 \\
\hline Resíduo médio & 324 & 58,46 & 66,32 & 6,23 \\
\hline $\mathrm{CV} \%$ & & 5,60 & 5,96 & \\
\hline \multicolumn{5}{|c|}{ NGF (sementes/fileira/espiga) $\left[10^{2}\right]$} \\
\hline Ambiente (A) & 3 & $29447,87^{* *}$ & $48510,71^{* *}$ & 36928,94 \\
\hline Blocos/A & 4 & 1472,64 & 1486,96 & 1435,63 \\
\hline Progênie (P) & 99 & $1793,07^{* *}$ & $1703,32^{* *}$ & 1311,27 \\
\hline $\mathrm{P} \times \mathrm{A}$ & 297 & $774,26^{*}$ & $929,78^{*}$ & 96,60 \\
\hline Resíduo médio & 324 & 639,59 & 712,92 & 101,43 \\
\hline CV\% & & 7,29 & 7,69 & \\
\hline \multicolumn{5}{|c|}{ NE (espigas/planta) $\left[10^{4}\right]$} \\
\hline Ambiente (A) & 3 & 8739,27 & $5167,09^{* *}$ & 5325,25 \\
\hline Blocos/A & 4 & 2164,90 & 276,55 & 698,09 \\
\hline Progênie (P) & 99 & $284,49^{*}$ & $321,54^{*}$ & 115,61 \\
\hline $\mathrm{P} \times \mathrm{A}$ & 297 & 197,46 & $223,29^{*}$ & 47,00 \\
\hline Resíduo médio & 324 & 187,69 & 184,95 & 22,52 \\
\hline $\mathrm{CV} \%$ & & 13,85 & 13,64 & \\
\hline
\end{tabular}

a. Os quadrados e produtos médios estão multiplicados pelos valores entre colchetes

${ }^{*} \mathrm{P}<0,05 ;{ }^{* *} \mathrm{P}<0,01$; os demais são não significativos. 
Tabela 14 - Quadrados e produtos médios obtidos para peso de espigas (PE), altura da planta e da espiga (AP e AE), e relação altura da espiga sobre altura da planta (r) das análises de variância e covariância feitas com progênies intra- (22) e interpopulacionais (21), para a população de milho BR105.

\begin{tabular}{|c|c|c|c|c|}
\hline F.C. & GL & QM22 & QM21 & PM21 \\
\hline \multicolumn{5}{|c|}{ PE (gramas/planta) } \\
\hline Ambiente (A) & 3 & $105820,93 * *$ & $104501,55^{* *}$ & 103381,64 \\
\hline Blocos/A & 4 & 1930,65 & 2414,75 & 1843,54 \\
\hline Progênie (P) & 99 & $1270,12^{* *}$ & $1590,07 * *$ & 697,09 \\
\hline $\mathrm{P} \times \mathrm{A}$ & 297 & 385,50 & 545,39 & 166,11 \\
\hline Resíduo médio & 324 & 379,23 & 473,29 & 149,42 \\
\hline $\mathrm{CV} \%$ & & 14,24 & 14,10 & \\
\hline \multicolumn{5}{|c|}{ AP (centímetros/planta) } \\
\hline Ambiente (A) & 3 & $9022,69^{*}$ & 26500,90 & 11362,30 \\
\hline Blocos/A & 4 & 1350,52 & 6827,50 & 2356,44 \\
\hline Progênie (P) & 99 & $477,61^{* *}$ & $423,24 * *$ & 205,89 \\
\hline $\mathrm{P} \times \mathrm{A}$ & 297 & 106,12 & 80,60 & 13,07 \\
\hline Resíduo médio & 324 & 108,69 & 99,40 & 23,78 \\
\hline $\mathrm{CV} \%$ & & 5,20 & 4,93 & \\
\hline \multicolumn{5}{|c|}{$\mathrm{AE}$ (centímetros/planta) } \\
\hline Ambiente (A) & 3 & $14162,65 * *$ & $17675,12^{* *}$ & 15690,91 \\
\hline Blocos/A & 4 & 654,99 & 490,59 & 147,21 \\
\hline Progênie (P) & 99 & $313,74 * *$ & $280,85^{* *}$ & 136,15 \\
\hline$P \times A$ & 297 & 58,84 & 61,68 & 9,48 \\
\hline Resíduo médio & 324 & 63,56 & 61,89 & 17,13 \\
\hline CV\% & & 7,86 & 7,75 & \\
\hline \multicolumn{5}{|c|}{$\mathbf{r}\left[10^{4}\right]^{\mathrm{a}}$} \\
\hline Ambiente (A) & 3 & $1576,01^{*}$ & $1322,54^{*}$ & 1241,03 \\
\hline Blocos/A & 4 & 130,62 & 207,31 & $-107,46$ \\
\hline Progênie (P) & 99 & $24,54 * *$ & $26,66 * *$ & 9,87 \\
\hline $\mathrm{P} \times \mathrm{A}$ & 297 & 8,06 & $8,76^{*}$ & 0,34 \\
\hline Resíduo médio & 324 & 8,03 & 7,11 & 1,85 \\
\hline CV\% & & 5,61 & 5,32 & \\
\hline
\end{tabular}

a. Os quadrados e produtos médios estão multiplicados pelos valores entre colchetes.

${ }^{*} \mathrm{P}<0,05 ;{ }^{* *} \mathrm{P}<0,01 ;$ os demais são não significativos. 
Tabela 15 - Quadrados e produtos médios obtidos para comprimento e diâmetro da espiga (CE e DE), número de fileiras na espiga (NF), número de sementes por fileira na espiga (NGF), e prolificidade (NE) das análises de variância e covariância feitas com progênies intra- (22) e interpopulacionais (21), para a população de milho BR-105.

\begin{tabular}{|c|c|c|c|c|}
\hline F.C. & GL & QM22 & QM21 & PM21 \\
\hline \multicolumn{5}{|c|}{$\mathrm{CE}$ (centímetros/planta) $\left[10^{2}\right]^{\mathrm{a}}$} \\
\hline Ambiente (A) & 3 & $2406,64^{*}$ & $3092,52^{*}$ & 2248,36 \\
\hline Blocos/A & 4 & 367,12 & 384,86 & 337,67 \\
\hline Progênie $(\mathrm{P})$ & 99 & $350,77^{* *}$ & $328,96^{* *}$ & 177,53 \\
\hline $\mathrm{P} \times \mathrm{A}$ & 297 & 89,51 & 96,31 & 7,27 \\
\hline Resíduo médio & 324 & 95,75 & 96,11 & 24,08 \\
\hline $\mathrm{CV} \%$ & & 6,20 & 6,21 & \\
\hline \multicolumn{5}{|c|}{ DE (centímetros/planta) $\left[10^{2}\right]$} \\
\hline Ambiente (A) & 3 & $92,07 * *$ & $122,21^{* *}$ & 100,87 \\
\hline Blocos/A & 4 & 7,44 & 6,18 & 2,14 \\
\hline Progênie (P) & 99 & $19,71^{* *}$ & $21,41^{* *}$ & 11,60 \\
\hline $\mathrm{P} \times \mathrm{A}$ & 297 & 3,74 & 3,64 & 1,03 \\
\hline Resíduo médio & 324 & 3,72 & 3,26 & 0,34 \\
\hline CV\% & & 4,33 & 3,83 & \\
\hline \multicolumn{5}{|c|}{ NF (fileiras/espiga) $\left[10^{2}\right]$} \\
\hline Ambiente (A) & 3 & 48,34 & 422,85 & 81,37 \\
\hline Blocos/A & 4 & 233,10 & 101,48 & 103,06 \\
\hline Progênie (P) & 99 & $423,18^{* *}$ & $415,99 * *$ & 234,92 \\
\hline $\mathrm{P} \times \mathrm{A}$ & 297 & 73,41 & 61,10 & 3,31 \\
\hline Resíduo médio & 324 & 70,14 & 68,24 & 8,13 \\
\hline CV\% & & 5,79 & 5,78 & \\
\hline \multicolumn{5}{|c|}{ NGF (sementes/fileira/espiga) $\left[10^{2}\right]$} \\
\hline Ambiente (A) & 3 & 5189,12 & $8032,99^{* *}$ & 5015,70 \\
\hline Blocos/A & 4 & 2908,66 & 775,20 & 1435,26 \\
\hline Progênie (P) & 99 & $1984,48 * *$ & $2181,46^{* *}$ & 1144,94 \\
\hline $\mathrm{P} \times \mathrm{A}$ & 297 & 553,79 & 729,28 & 51,10 \\
\hline Resíduo médio & 324 & 662,03 & 725,85 & 183,33 \\
\hline CV\% & & 7,67 & 7,63 & \\
\hline \multicolumn{5}{|c|}{ NE (espigas/planta) $\left[10^{4}\right]$} \\
\hline Ambiente (A) & 3 & $12173,83^{*}$ & $4837,03^{* *}$ & 6930,26 \\
\hline Blocos/A & 4 & 1101,80 & 68,97 & 231,57 \\
\hline Progênie (P) & 99 & $531,18^{* *}$ & $311,67^{* *}$ & 191,78 \\
\hline $\mathrm{P} \times \mathrm{A}$ & 297 & 226,86 & 200,54 & 33,69 \\
\hline Resíduo médio & 324 & 223,15 & 169,97 & 12,74 \\
\hline $\mathrm{CV} \%$ & & 15,03 & 13,10 & \\
\hline
\end{tabular}

a. Os quadrados e produtos médios estão multiplicados pelos valores entre colchetes ${ }^{*} \mathrm{P}<0,05 ;{ }^{* *} \mathrm{P}<0,01$; os demais são não significativos. 


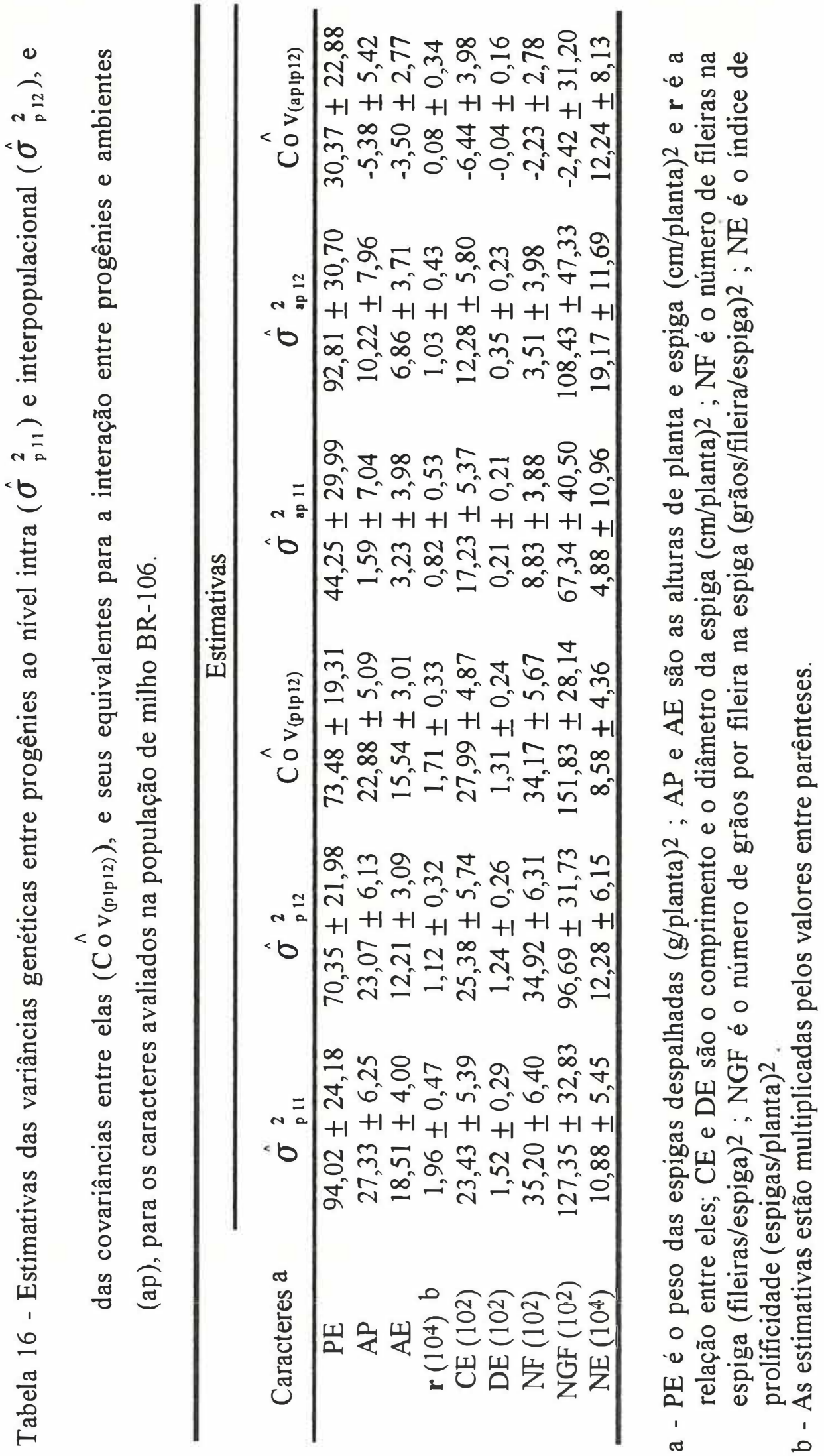




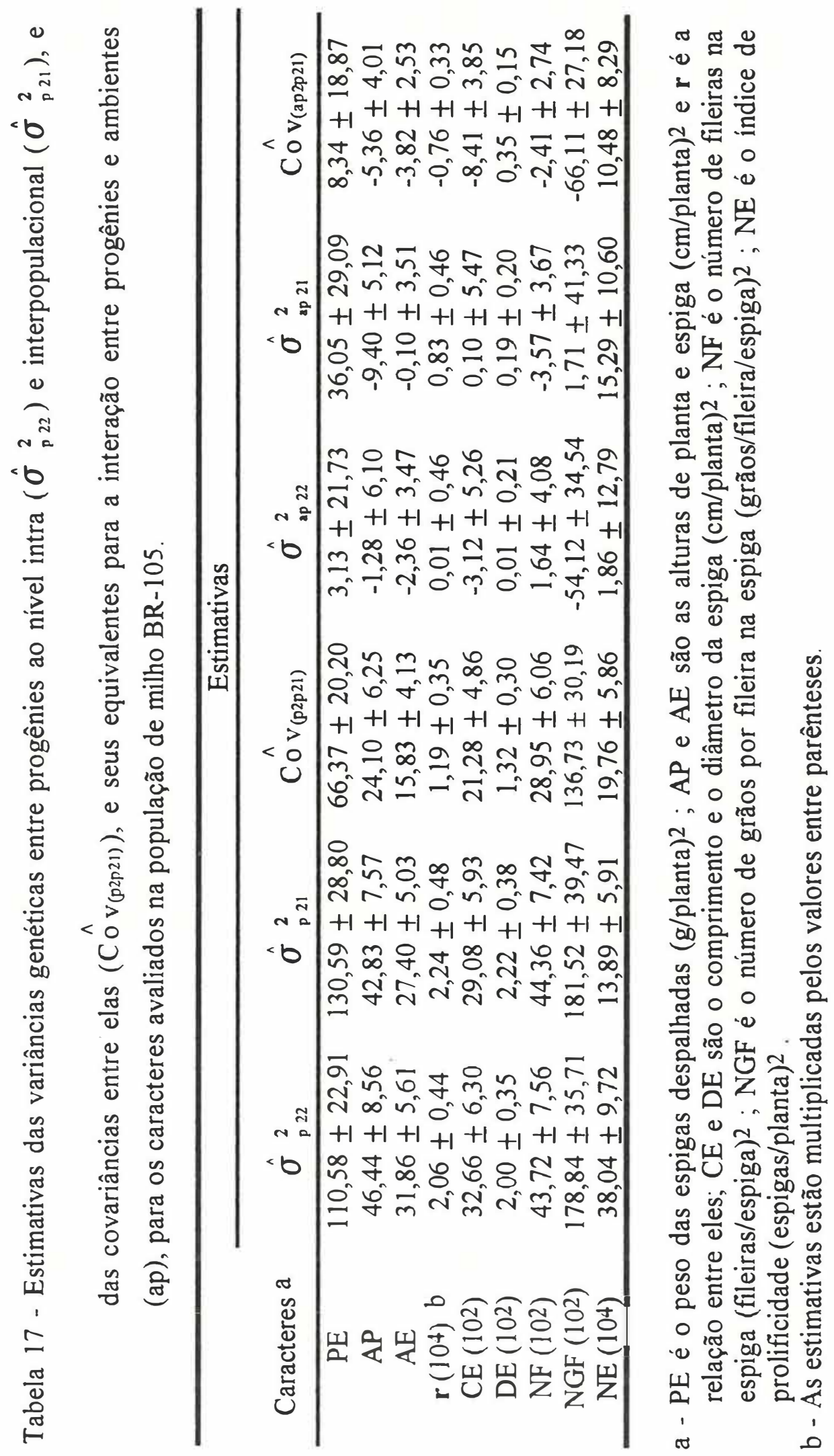




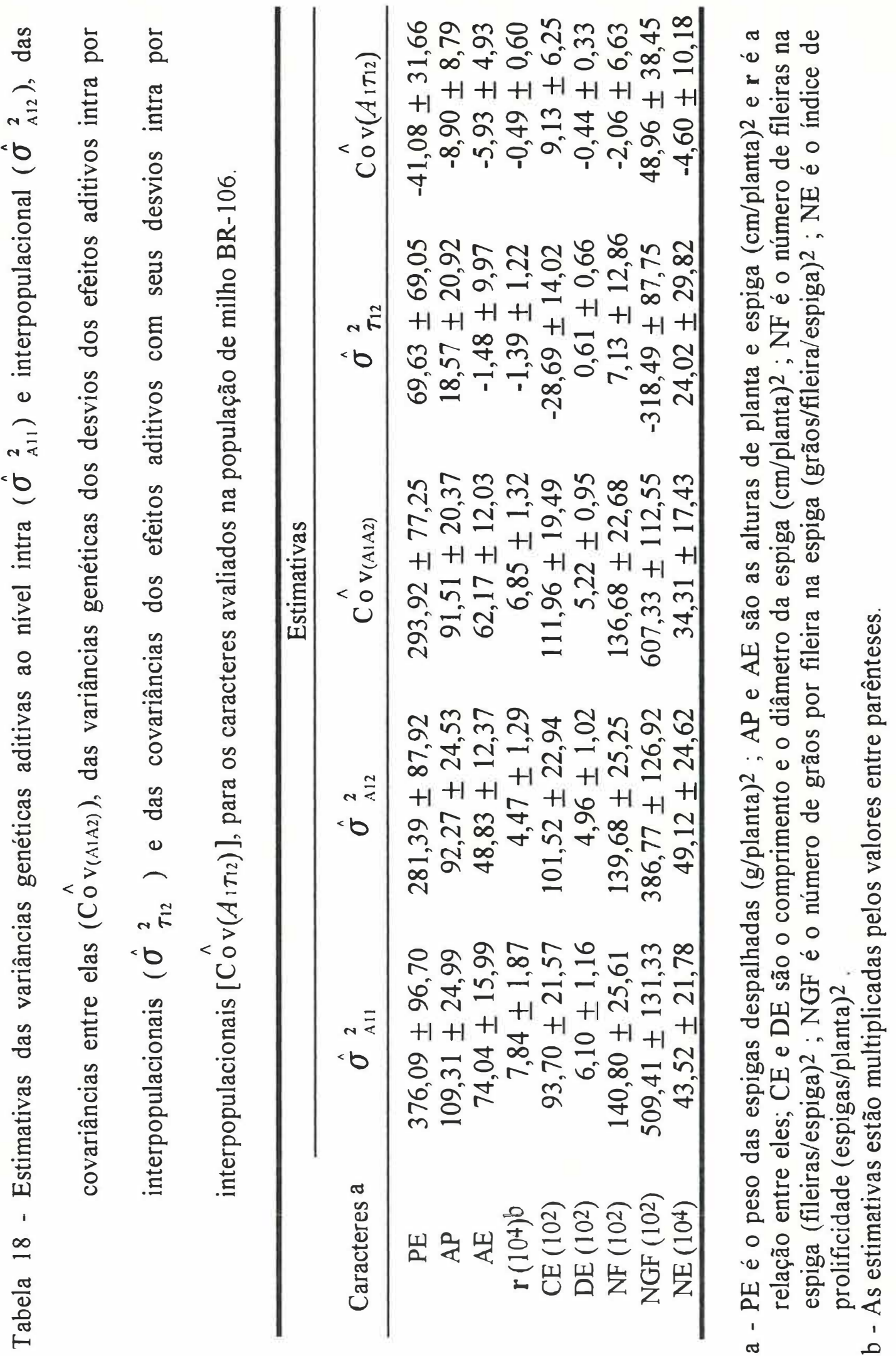


祃 总

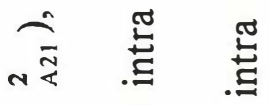

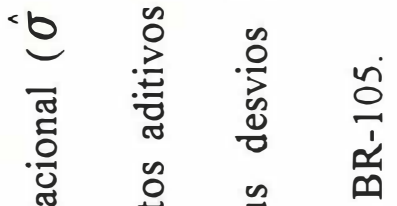

言竞离离

总

$\because$ क o

$\approx$ 告

<रे क्ष

0 :

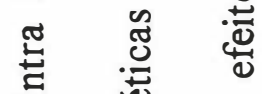

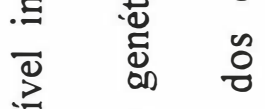

त्र

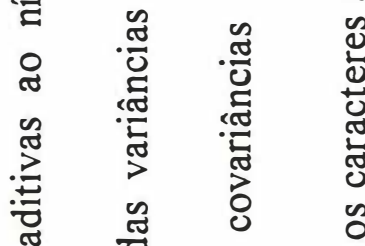

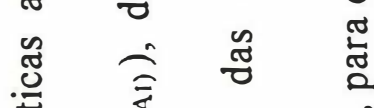

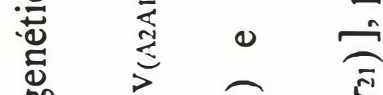

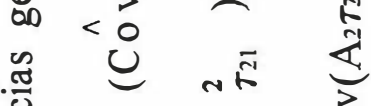

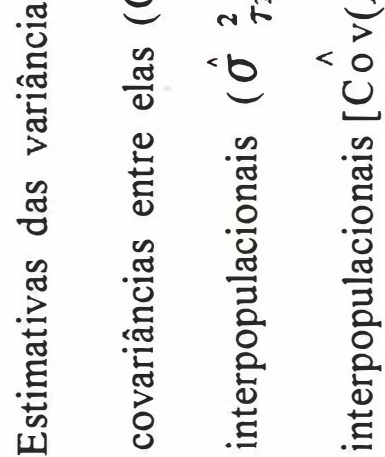

9

迹

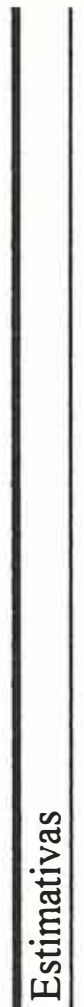

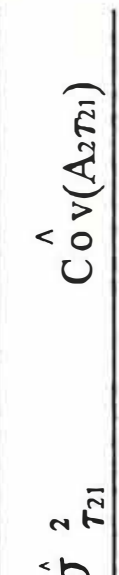

ẫ

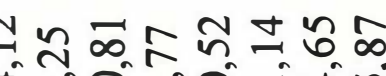

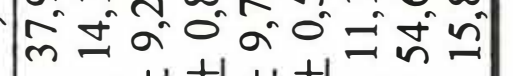

$+\mathrm{H}+1+\mathrm{H}+\mathrm{H}+\mathrm{H}+\mathrm{H}+\mathrm{H}$

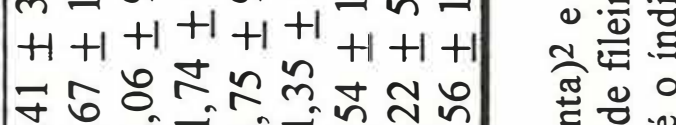

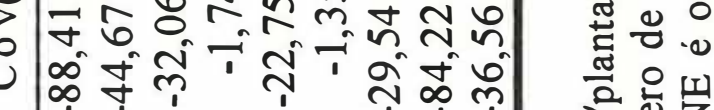

穴

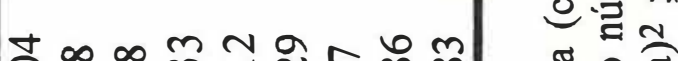

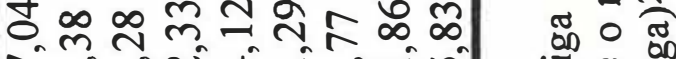

ஸिं

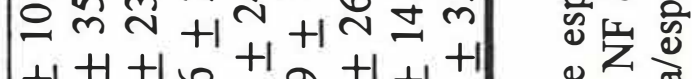

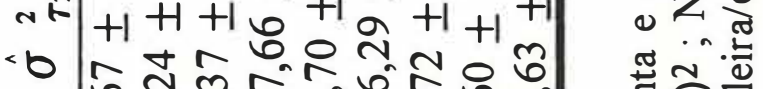

6.

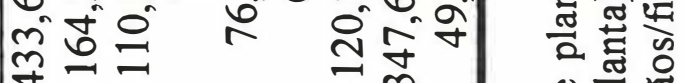

当

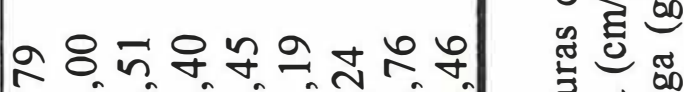

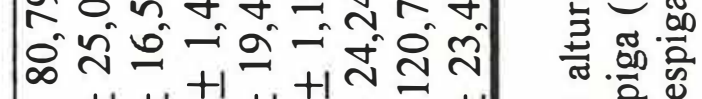

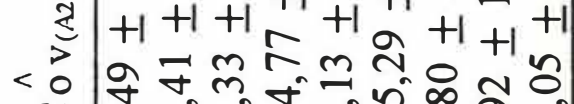

$u$

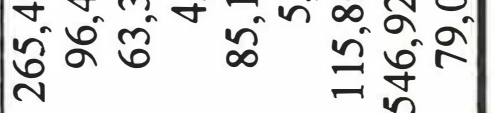

유ำ

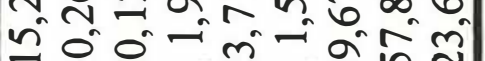

a $\bar{x}$

$=m+1 \hat{N}+1$ in

政

$<0$

$\forall \sim \infty \Omega^{2}+\infty+1+1$

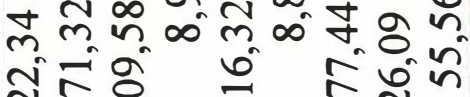

กี으으유

ชั่

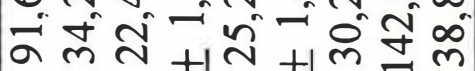

$4 \div$

$+1+1+1++1 \infty+1+1+1$

$<0$

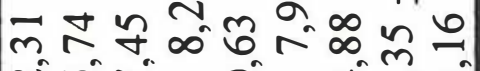

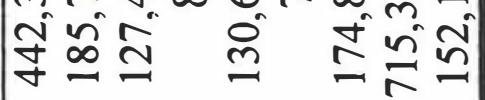

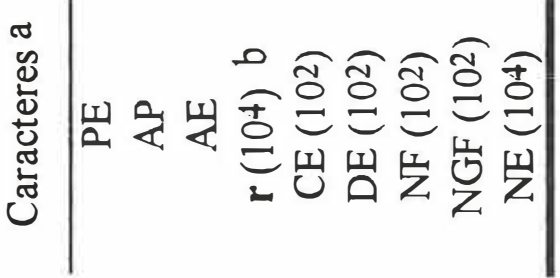

तै के ब

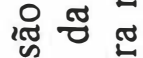

베은 흔

《志芯

结造

< 0 \%

인

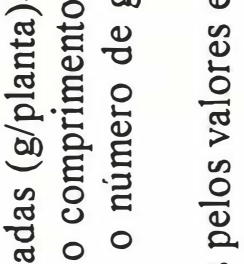

至 0 . त

空出

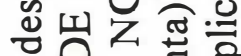

is 0 证

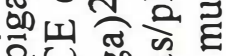

\% . .

क के के

तु के क्ष

$\circ 0$.

离离总.

․ㅠ

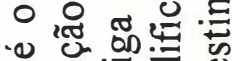

-

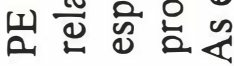




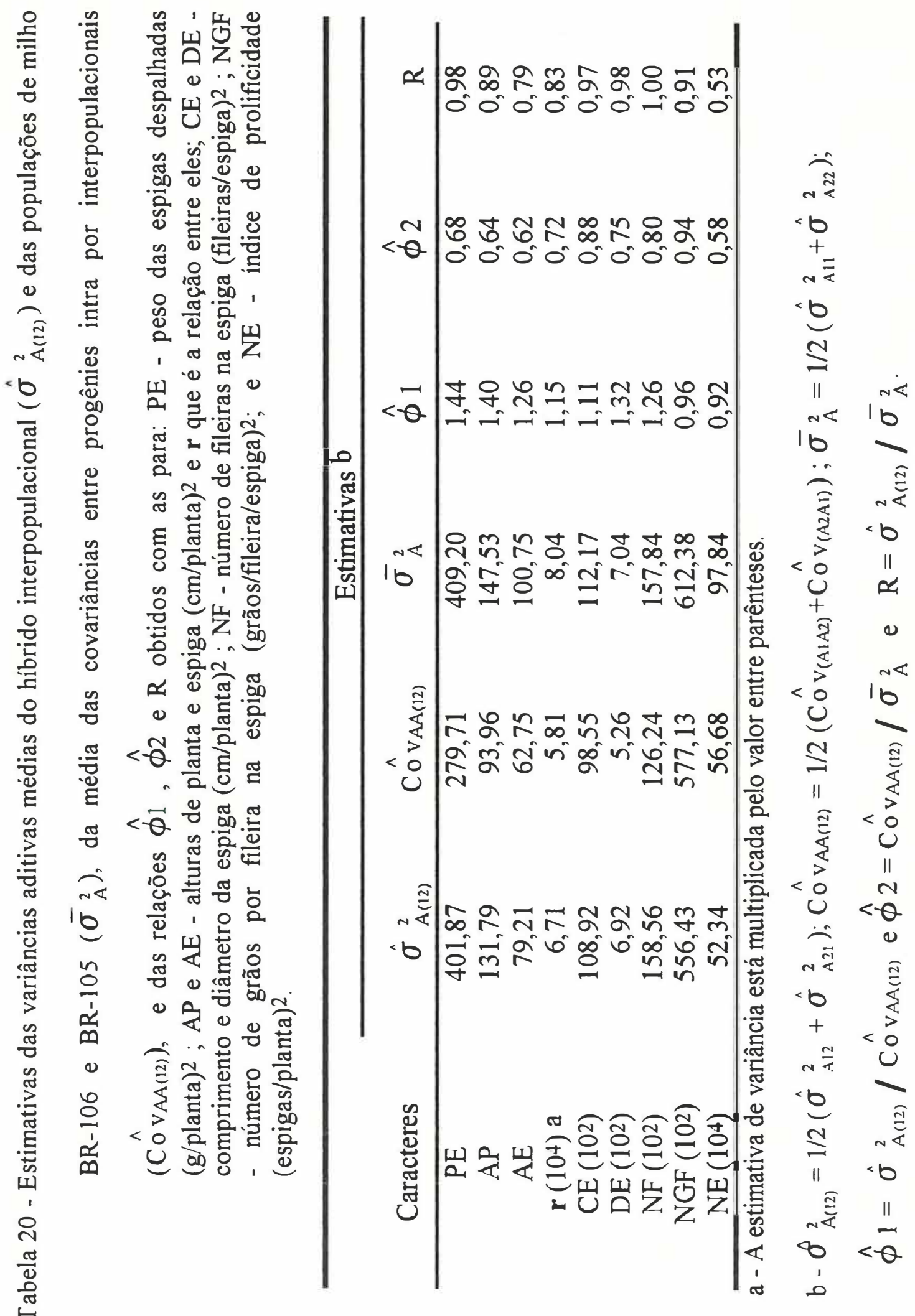




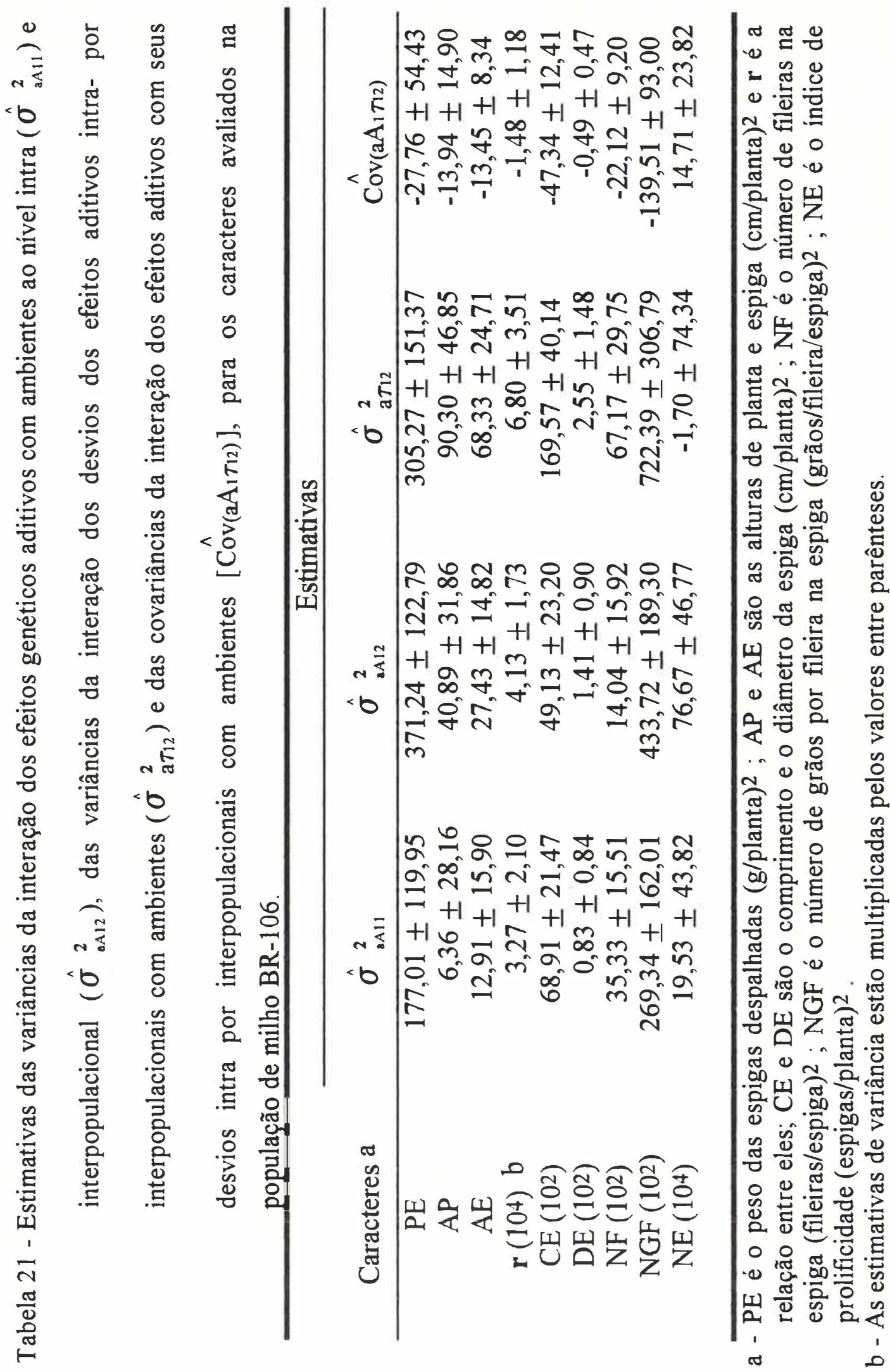




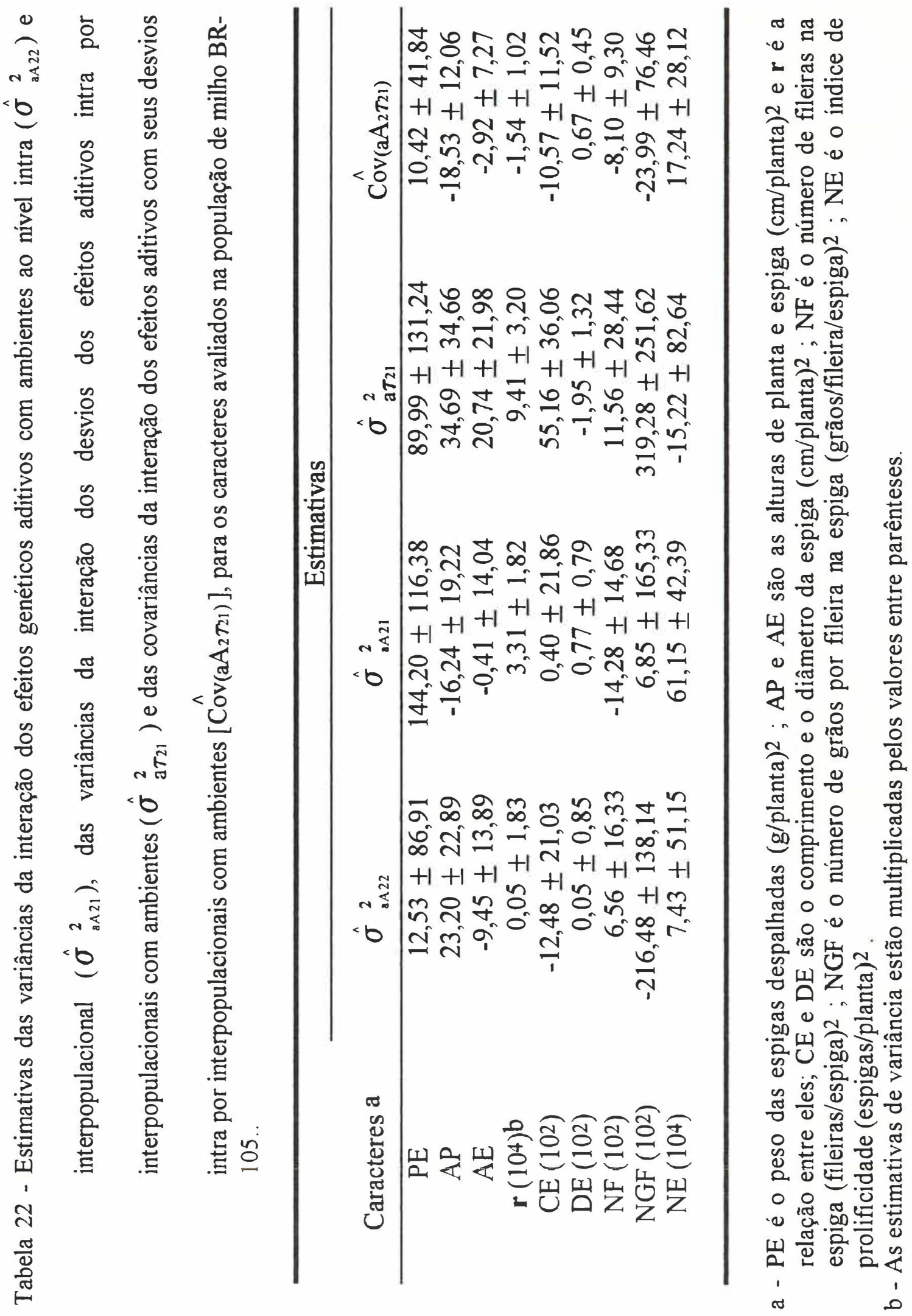




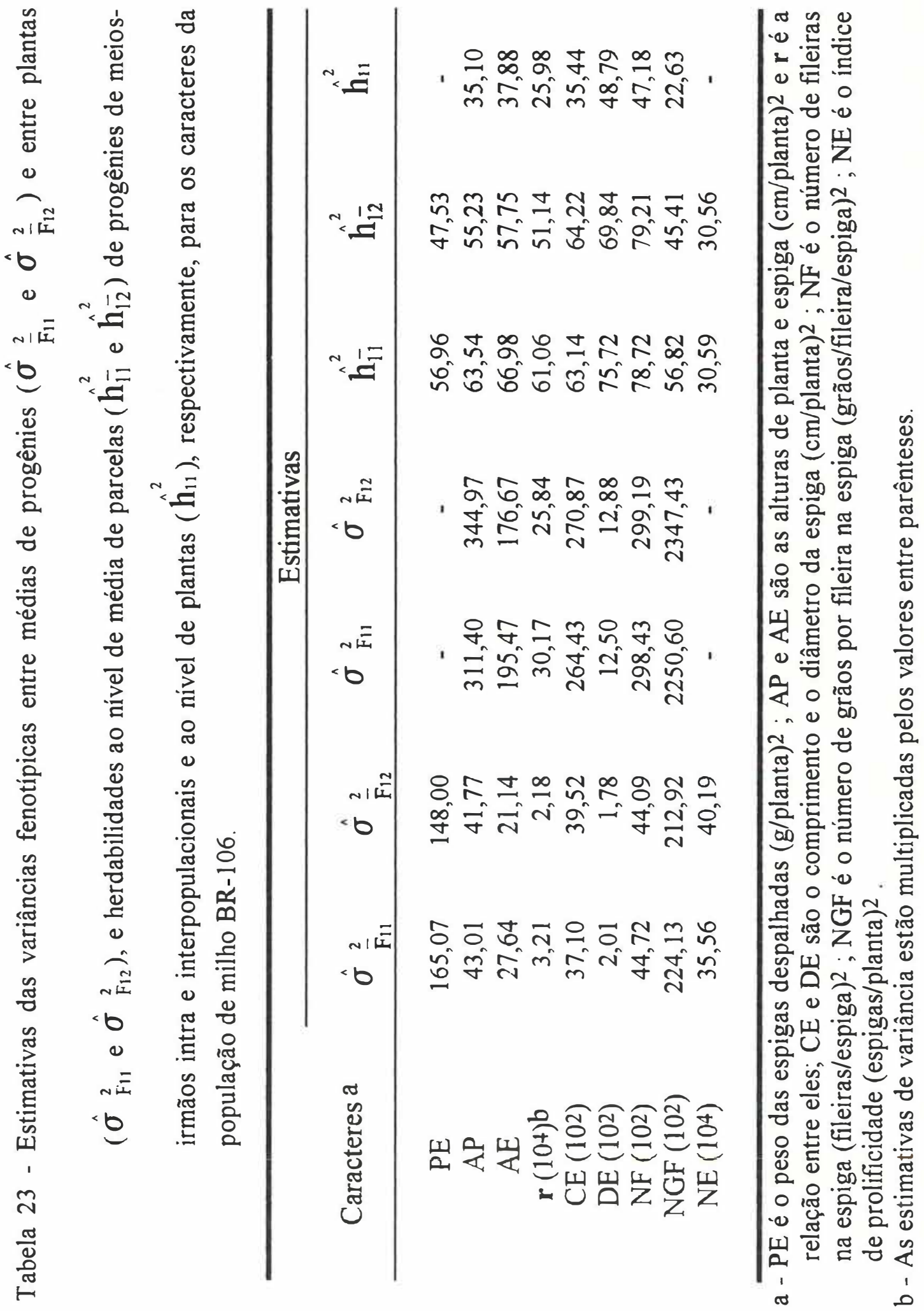




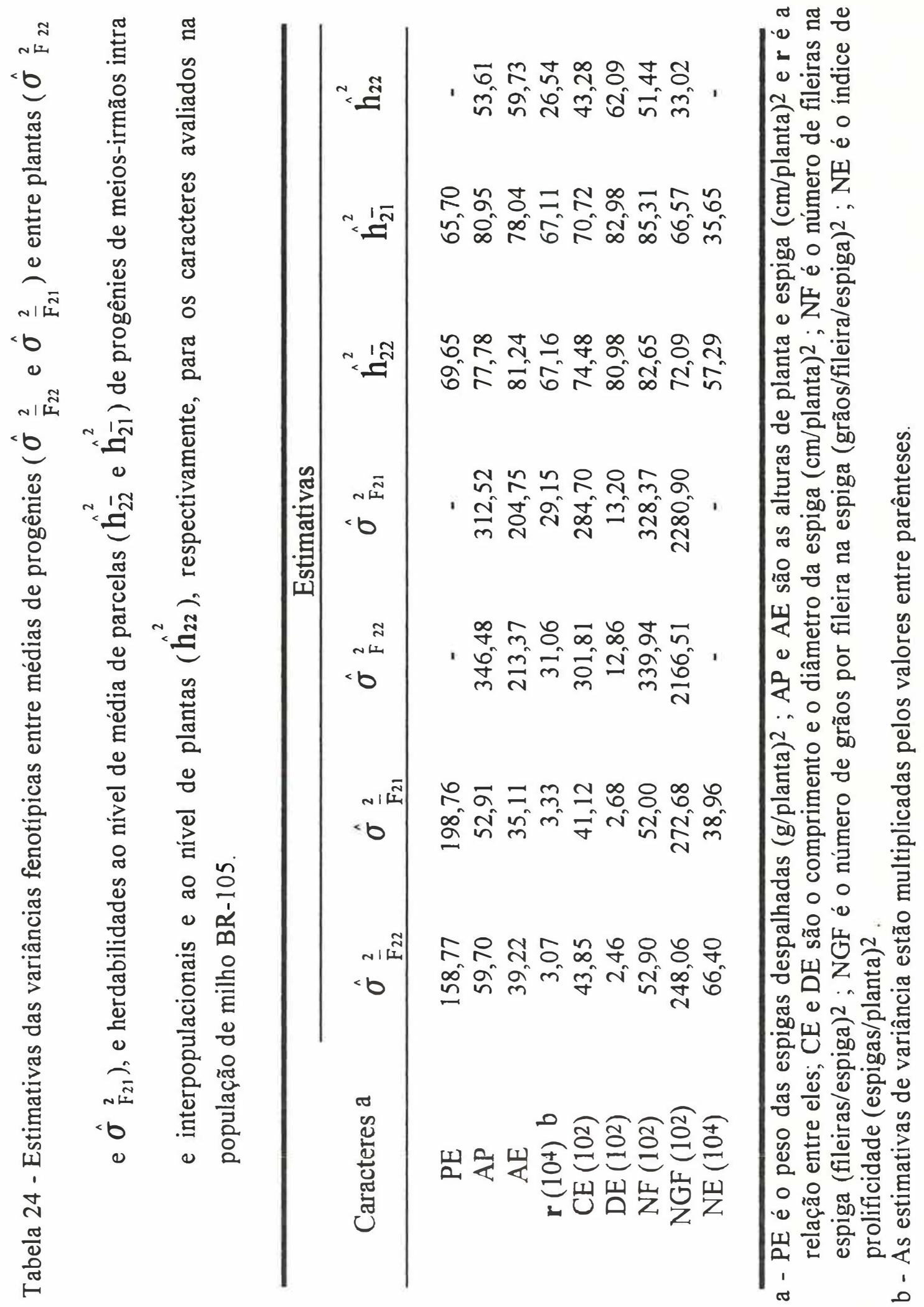




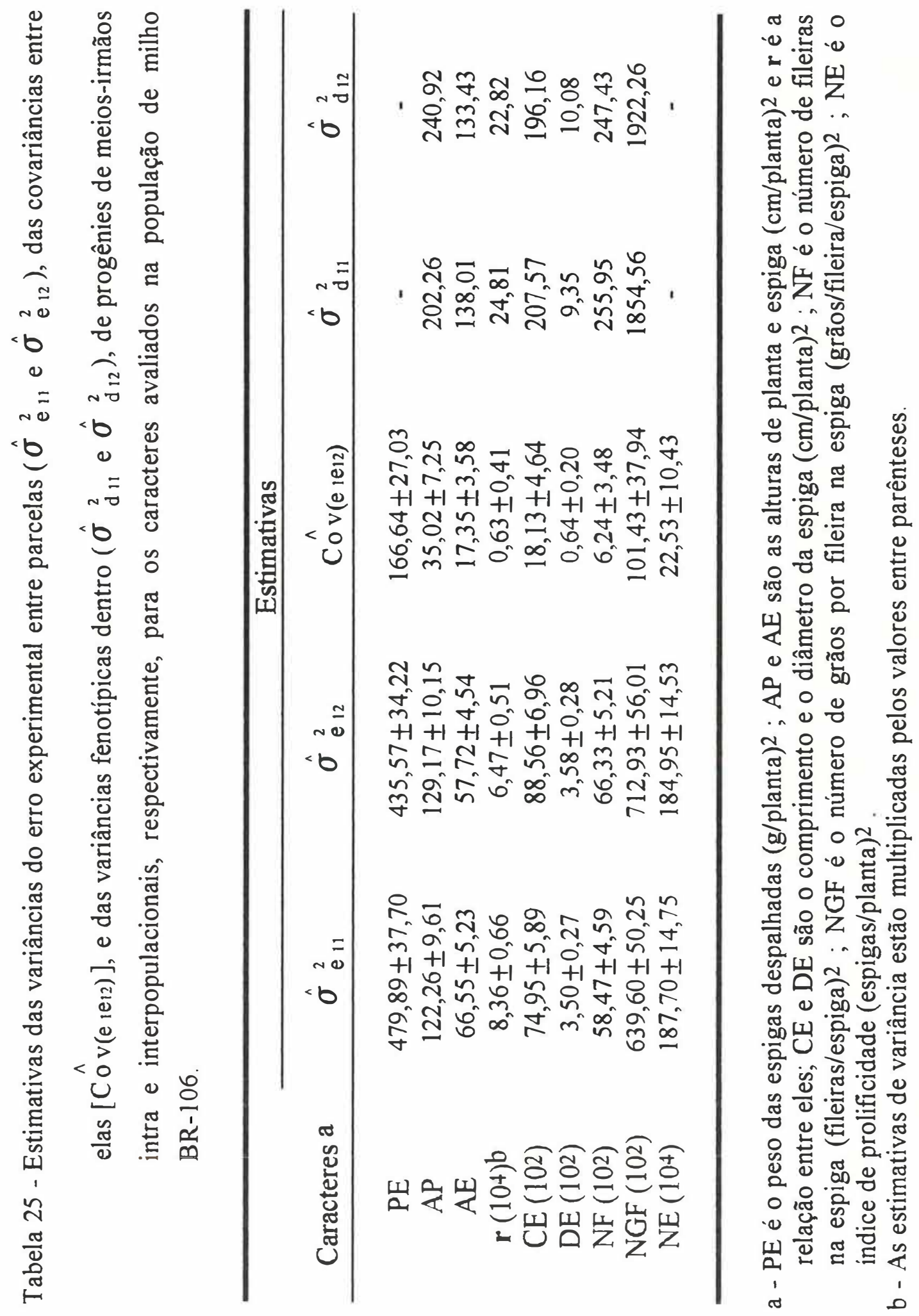




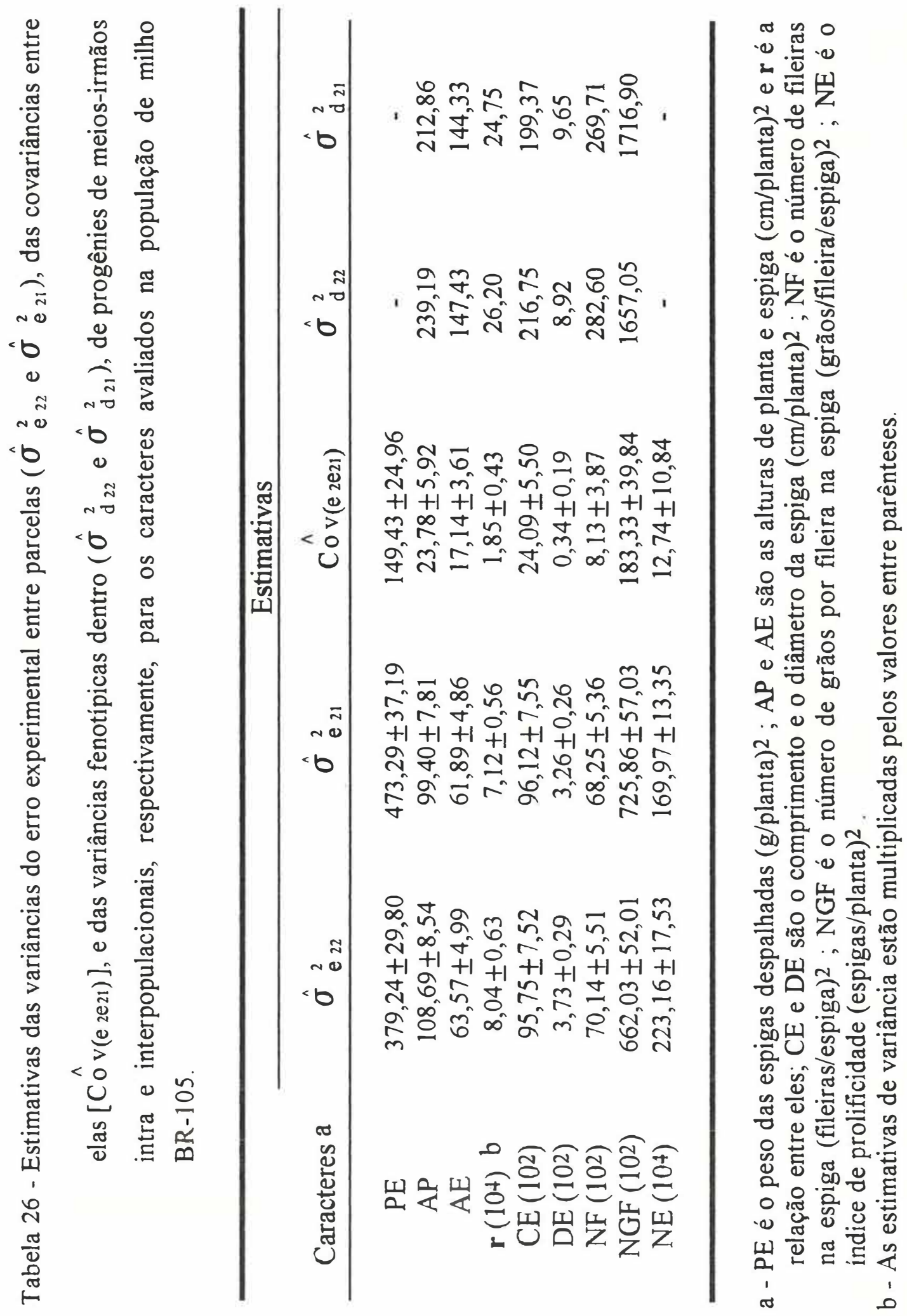


Tabela 27 - Respostas esperadas por ciclo de seleção sobre o peso de espigas despalhadas (PE), altura da planta e da espiga e da relação entre elas (AP, AE e r), segundo o esquema de seleção: SRR - Seleção Recorrente Recíproca; SRI - Seleção Recorrente Intrapopulacional; SRM - Seleção Recorrente Modificada e SM - Seleção Massal.

\begin{tabular}{|c|c|c|c|c|c|}
\hline \multirow{2}{*}{$\begin{array}{l}\text { Resposta }^{\mathrm{a}} \\
\text { à seleção }\end{array}$} & \multicolumn{5}{|c|}{ Esquema de Seleção } \\
\hline & SRR & SRI & $\operatorname{SRM}(a) b$ & $\operatorname{SRM}(b) b$ & SM \\
\hline \multicolumn{6}{|c|}{ PE (gramas/planta) } \\
\hline & c & & & & \\
\hline Gs(12) & $21,05(13,9)$ & $15,38(10,1)$ & $15,47(10,2)$ & $20,97(13,8)$ & - \\
\hline Gs(11) & $16,91(11,4)$ & $20,49(13,8)$ & $16,91(11,4)$ & $20,49(13,8)$ & - \\
\hline Gs(22) & $13,18(9,60)$ & $24,57(18,0)$ & $24,57(18,0)$ & $13,18(9,60)$ & - \\
\hline $\mathrm{Gs}(\mathrm{h})$ & $6,01(65,2)$ & $-7,15(-77,4)$ & $-5,26(-57,0)$ & $4,14(44,9)$ & - \\
\hline \multicolumn{6}{|c|}{ AP (centímetros/planta) } \\
\hline Gs(12) & $13,23(6,6)$ & $9,25(4,6)$ & $9,36(4,7)$ & $13,13(6,6)$ & 7,26 \\
\hline Gs(11) & $9,91(5,1)$ & $11,66(6,0)$ & $9,91(5,1)$ & $11,66(6,0)$ & 8,67 \\
\hline Gs(22) & $9,28(4,6)$ & $16,82(8,4)$ & $16,82(8,4)$ & $9,28(4,6)$ & 13,97 \\
\hline $\mathrm{Gs}(\mathrm{h})$ & $3,64(172,2)$ & $-4,99(-239,1)$ & $-4,00(-191,8)$ & $2,66(127,2)$ & $-4,07$ \\
\hline \multicolumn{6}{|c|}{$\mathrm{AE}$ (centímetros/planta) } \\
\hline $\mathrm{Gs}(12)$ & $10,19(10,0)$ & $7,67(7,5)$ & $7,25(7,1)$ & $10,61(10,4)$ & 6,14 \\
\hline Gs $(11)$ & $9,46(9,4)$ & $9,85(9,8)$ & $9,46(9,4)$ & $9,85(9,8)$ & 7,41 \\
\hline $\mathrm{Gs}(22)$ & $7,47(7,4)$ & $14,24(14,0)$ & $14,24(14,0)$ & $7,47(7,4)$ & 12,21 \\
\hline Gs(h) & $1,72(196,9)$ & $-4,37(-501,9)$ & $-4,59(-527,6)$ & $1,94(222,6)$ & $-3,66$ \\
\hline \multicolumn{6}{|c|}{$\mathbf{r}$} \\
\hline $\mathrm{Gs}(12)$ & $0,028(5,4)$ & $0,023(4,5)$ & $0,020(3,9)$ & $0,031(6,0)$ & 0,015 \\
\hline Gs(11) & $0,032(6,3)$ & $0,031(5,9)$ & $0,032(6,3)$ & $0,031(5,9)$ & 0,020 \\
\hline Gs(22) & $0,018(3,6)$ & $0,033(6,5)$ & $0,033(6,5)$ & $0,018(3,6)$ & 0,021 \\
\hline Gs(h) & $0,002(257,0)$ & $-0,009(-983,9)$ & $-0,013(-1391,6)$ & $0,006(673,6)$ & $-0,006$ \\
\hline
\end{tabular}

a - Gs(12), Gs(11), Gs(22), e Gs(h) referem-se às respostas no híbrido interpopulacional, nas populações de milho BR-106 e BR-105, e na heterose, respectivamente.

b - BR-105 e BR-106 (menor e maior média para PE) como testadoras das duas populações em SRM(a) e SRM(b), respectivamente.

c - Ganhos em percentagem entre parênteses (\%). 
Tabela 28 - Respostas esperadas por ciclo sobre comprimento e diâmetro da espiga (CE e DE), número de fileiras e de sementes por fileira na espiga (NF e NGF) e prolificidade (NE), segundo o esquema de seleção: SRR Seleção Recorrente Recíproca; SRI - Seleção Recorrente Intrapopulacional; SRM - Seleção Recorrente Modificada e SM - Selecão Massal

\begin{tabular}{|c|c|c|c|c|c|}
\hline \multirow{2}{*}{$\begin{array}{l}\text { Resposta a } \\
\text { à seleção }\end{array}$} & \multicolumn{5}{|c|}{ Esquema de Seleção } \\
\hline & SRR & SRI & $\operatorname{SRM}(a) b$ & $\operatorname{SRM}(b) b$ & SM \\
\hline \multicolumn{6}{|c|}{$\mathrm{CE}$ (centímetros/espiga) } \\
\hline $\begin{array}{l}\mathrm{Gs}(12) \\
\mathrm{Gs}(11) \\
\mathrm{Gs}(22) \\
\mathrm{Gs}(\mathrm{h})\end{array}$ & $\begin{array}{r}\mathrm{c} \\
1,20(7,7) \\
1,25(8,2) \\
0,93(5,9) \\
0,11(154,3)\end{array}$ & $\begin{array}{c}1,09(7,0) \\
1,08(7,1) \\
1,38(8,8) \\
-0,14(-187,3) \\
\end{array}$ & $\begin{array}{c}1,02(6,5) \\
1,25(8,2) \\
1,38(8,8) \\
-0,30(-412,1) \\
\end{array}$ & $\begin{array}{c}1,29(8,2) \\
1,08(7,1) \\
0,93(5,9) \\
0,28(380,1)\end{array}$ & $\begin{array}{l}- \\
- \\
- \\
-\end{array}$ \\
\hline \multicolumn{6}{|c|}{$\mathrm{DE}$ (centímetros/espiga) } \\
\hline $\begin{array}{c}\text { Gs(12) } \\
\text { Gs(11) } \\
\text { Gs(22) } \\
\text { Gs(h) }\end{array}$ & $\begin{array}{c}0,32(6,8) \\
0,27(5,8) \\
0,23(5,1) \\
0,07(64,4)\end{array}$ & $\begin{array}{r}0,25(5,2) \\
0,30(6,4) \\
0,36(8,0) \\
-0,08(-75,5) \\
\end{array}$ & $\begin{array}{r}0,25(5,3) \\
0,27(5,8) \\
0,36(8,0) \\
-0,07(-62,2)\end{array}$ & $\begin{array}{c}0,32(6,8) \\
0,30(6,4) \\
0,23(5,1) \\
0,06(51,1)\end{array}$ & $\begin{array}{r}0,21 \\
0,24 \\
0,31 \\
-0,07 \\
\end{array}$ \\
\hline \multicolumn{6}{|c|}{ NF (fileiras/espiga) } \\
\hline $\begin{array}{c}\text { Gs(12) } \\
\text { Gs(11) } \\
\text { Gs(22) } \\
\text { Gs(h) }\end{array}$ & $\begin{array}{c}1,60(11,4) \\
1,44(10,6) \\
1,12(7,8) \\
0,31(468,1)\end{array}$ & $\begin{array}{c}1,27(9,1) \\
1,47(10,8) \\
1,68(11,6) \\
-0,31(-455,0)\end{array}$ & $\begin{array}{c}1,29(9,2) \\
1,44(10,6) \\
1,68(11,6) \\
-0,27(-399,2)\end{array}$ & $\begin{array}{c}1,58(11,3) \\
1,47(10,8) \\
1,12(7,8) \\
0,28(413,4)\end{array}$ & $\begin{array}{r}0,99 \\
1,14 \\
1,33 \\
-0,24 \\
\end{array}$ \\
\hline \multicolumn{6}{|c|}{ NGF (sementes/fileira/espiga) } \\
\hline $\begin{array}{c}\text { Gs(12) } \\
\text { Gs(11) } \\
\text { Gs(22) } \\
\text { Gs(h) }\end{array}$ & $\begin{array}{r}2,47(7,0) \\
2,91(8,4) \\
2,32(6,9) \\
-0,15(-16,9) \\
\end{array}$ & $\begin{array}{r}2,64(7,5) \\
2,38(6,9) \\
3,18(9,5) \\
-0,15(-16,4) \\
\end{array}$ & $\begin{array}{c}2,14(6,1) \\
2,91(8,4) \\
3,18(9,5) \\
-0,90(-102,0) \\
\end{array}$ & $\begin{array}{c}2,96(8,4) \\
2,38(6,9) \\
2,32(6,9) \\
0,61(68,8) \\
\end{array}$ & $\begin{array}{r}1,72 \\
1,50 \\
2,15 \\
-0,11 \\
\end{array}$ \\
\hline \multicolumn{6}{|c|}{$\mathrm{NE}$ (espigas/planta) } \\
\hline $\begin{array}{c}\text { Gs(12) } \\
\text { Gs(11) } \\
\text { Gs(22) } \\
\text { Gs(h) }\end{array}$ & $\begin{array}{c}0,058(5,8) \\
0,038(3,8) \\
0,089(8,9) \\
-0,005(-109,9)\end{array}$ & $\begin{array}{c}0,054(5,4) \\
0,051(5,2) \\
0,131(13,1) \\
-0,037(-817,2)\end{array}$ & $\begin{array}{c}0,061(6,1) \\
0,038(3,8) \\
0,131(13,1) \\
-0,023(-515,9) \\
\end{array}$ & $\begin{array}{c}0,051(5,1) \\
0,051(5,2) \\
0,089(8,9) \\
-0,019(-413,0) \\
\end{array}$ & $\begin{array}{l}- \\
- \\
- \\
-\end{array}$ \\
\hline
\end{tabular}

a - Gs(12), Gs(11), Gs(22), e Gs(h) referem-se às respostas no híbrido interpopulacional, nas populações de milho BR-106 e BR-105, e na heterose, respectivamente.

b - BR-105 e BR-106 (menor e maior média para PE) como testadoras das duas populações em SRM(a) e SRM(b), respectivamente.

$c$ - Ganhos em percentagem entre parênteses (\%). 
Apêndice 1 - Esquema da construção da matriz de pesos (V) segundo MATHER \& JINKS (1982).

Supondo uma matriz Y de observações com dois quadrados médios (Q1 e Q2) relacionados por um produto médio (P12), e ainda um outro quadrado médio $(\mathrm{Q} 3)$ independente do demais, sendo que a covariância deste com os demais vale zero. A matriz $\mathrm{V}$ é construida da seguinte forma:

Y

$\mid$

\begin{tabular}{l|l} 
Q1 \\
Q2 \\
P12 \\
Q3
\end{tabular}

$2(\mathrm{Q} 1)^{2} / \mathrm{N} \quad 2(\mathrm{P} 12)^{2} / \mathrm{N}$

2 Q1P12/N

$2 \mathrm{Q} 2 \mathrm{P} 21 / \mathrm{N}$

0

$2(\mathrm{P} 12)^{2} / \mathrm{N} \quad 2(\mathrm{Q} 2)^{2} / \mathrm{N}$

$2 \mathrm{Q} 2 \mathrm{P} 21 / \mathrm{N}$

$\left[(\mathrm{P} 12)^{2}+\mathrm{Q} 1 \mathrm{Q} 2\right] / \mathrm{N}$

0

0

0

0

$2(\mathrm{Q} 3)^{2 / N^{\prime}}$

Onde N é o número de graus de liberdade relacionados a Q1, Q2 e P12 e N'é o número de graus de liberdade de Q3. 